\title{
IONO-COVALENT CHARACTER OF THE METAL-OXYGEN BONDS IN OXIDES: A COMPARISON OF EXPERIMENTAL AND THEORETICAL DATA
}

\author{
M. LENGLET \\ Université de Rouen, LASTSM, IUT, 76821 Mont Saint Aignan Cedex, France
}

(Received 27 January 2003; In final form 21 March 2003)

\begin{abstract}
The aim of this paper is to review the actual data on the chemical bond in binary and mixed oxides. The electronegativity $\left(\chi_{M}\right)$ and the acidity $P a$ scales are the most significant semi-empirical concepts for predicting the trend of bonding character in iono-covalent oxides. A satisfactory correlation between the data issued from the acidity scale and the calculated ionic charges has been established.

The most recent studies show that the hybrid methods such as the B3LYP method lead to more reliable results for the description of structural, energetic and electronic properties of binary oxides than those from standard methods.
\end{abstract}

\section{INTRODUCTION}

Oxide materials are interesting from both a theoretical and technological point of view, especially since they can have important electrical, electronic, magnetic, optical and catalytic properties. The ionic-covalent character of the metal-to-oxygen bonding in metal oxides influences the physical and chemical properties of the technologically important materials.

While the nature of the cohesive forces in fully covalent or fully ionic compounds is well established, there was until recently a lack of conceptual basis to describe it in mixed ionocovalent materials. The understanding of how the competition between ionic and covalent processes fixes the anion-cation electronic-sharing, the characteristics of the energy bands and the cohesive energy is incomplete, both from the experimental and theoretical points of view. Iono-covalent materials may be charge transfer or Mott insulators, semiconductors, metals or even superconductors.

This paper aims at a comparison of theoretical and experimental data relative to the cation-anion bonding in mixed iono-covalent materials. The paper is organized as follows: in Section 2, we analyze the semi-empirical concepts, i.e. electronegativity, acid-base properties and scales of ionicity. In Section 3, we present the results of the experimental determination of ionic charges by means of neutron diffraction, X-ray diffraction, lattice 
dynamical calculations and ligand-field spectroscopy. Section 4 summarizes the actual theoretical techniques for electronic structure determination and Section 5 is devoted to a discussion about the validity of semi-empirical concepts and theoretical models.

\section{SEMI-EMPIRICAL CONCEPTS}

\subsection{Electronegativity: Scales for Strengths of Lewis Acids}

Although chemical bonding is a subject which is often dealt with in terms of quantum theory, there is much to be gained by using an approach based on semi-empirical parameters which relate to individual atoms or ions. The best known of these approaches, among chemists and physicists, is that based upon electronegativity, and this has become increasingly popular in the field of solid state chemistry. Electronegativity was devised by Pauling in 1932 [1] for providing a measure of the unequal sharing of electrons in a chemical bond. The concept was aimed at partial ionicity in covalent compounds. The original concept of atomic electronegativity (one datum per element) has moved towards a more general one taking into account the oxidation states and orbital hybridization (several data per element). Over the years, various other methods have been proposed for evaluating the electronegativity values of the elements as alternatives to Pauling's thermochemical scale [2-7]. The physical meaning of electronegativity is ambiguous. As discussed by Mullay [8], the various scales correspond to different concepts and consequently to different units: Pauling [1], (energy $)^{1 / 2}$; Mulliken [2], energy; Allred and Rochow [5] and Zhang [6], force; Gordy [3], energy per electron; Sanderson [4] and Portier [7], dimensionless.

Zhang proposed an electronegativity scale for cations in specific valence states [6]. This author defined the electronegativity of the element in valence states as "the electrostatic force exerted by the effective nuclear charges on the valence electrons":

$$
\chi_{z}=0.241 \frac{n^{*}\left(I_{z} / R\right)^{1 / 2}}{r^{2}}+0.775
$$

where $r$ is the covalent radius, $I_{z}$ is the ionization potential, $R$ is the Rydberg constant and $n^{*}$ is the effective principal quantum number.

Portier et al. [7] show that a simple relation exists between electronegativities, oxidation states and ionic radii of cations. An empirical law $\chi=0.274 z-0.15 z r_{i}-0.01 r_{i}+\alpha$ is proposed, where $z$ is the oxidation number, $r_{i}$ is the ionic radius and $\alpha$ is a term dependant on the atomic number. It allows the calculation of electronegativity values for cations in all their electronic and crystallographic situations of oxidation state, spin state and coordination. Good agreement is obtained with Zhang's electronegativity scale. However, despite this coherence, significant differences exist, particularly for the transition elements. For example, in the case of iron:

\begin{tabular}{lllllll}
\hline & & & \multicolumn{2}{c}{$\mathrm{Fe}^{3+}$} & Ref. \\
\hline$\chi_{z}$ & \multicolumn{2}{c}{1.438} & \multicolumn{1}{c}{1.687} & {$[6]$} \\
$C N$ & 4 & 6 & 4 & 6 & \\
$\chi$ & 1.533 & 1.486 & 1.777 & 1.705 & {$[7]$} \\
\hline
\end{tabular}


In Portier's electronegativity scale, the following evolution is observed:

- the electronegativity of cations formed by ionization of an element increases with the oxidation number (for a given coordination number),

- the electronegativity increases as the ionic radius diminishes (for a given oxidation state)

- the electronegativity varies with the spin state: it is higher for low spin cations than for high spin cations.

According to the Lewis concept, an acid is an electrophile which accepts an electron pair and a base is a nucleophile that acts as an electron pair donor. Lewis acid-base interactions play an important role in understanding chemical bonds, reactions and equilibrium; yet, this concept is often inadequate for solid state chemistry. Indeed, in a redox reaction, single-electron transfers are also commonly involved. A more general concept has been proposed by Usanovitch [9];

- an acid is a species which combines with anions or is an electron acceptor,

- a base is one that combines with cations or is an electron donor.

Pearson, in his theory of Hard and Soft Acids and Bases (HSAB) [10], proposed a classification of acids and bases on their strengths and introduced the notion of covalence and its effects on the acid properties of an ion. He classified ions as hard, soft, or borderline acids or bases and specified that a hard acid (A) will react with a hard base (B) and a soft acid with a soft base to give stable combinations according to the reaction:

$$
\begin{aligned}
& \mathrm{A}(\text { hard })+\mathrm{B}(\text { hard }) \stackrel{K}{\leftrightarrows} \mathrm{AB} \\
& \log K=S_{\mathrm{A}} S_{\mathrm{B}}+\sigma_{\mathrm{A}} \sigma_{\mathrm{B}}
\end{aligned}
$$

where $K$ represents the equilibrium constant and $S_{i}$ the acid/base strength; $\sigma_{i}$ is a covalency term.

In an oxide, the cation will be the acid, as it can accept a partial negative charge. Essentially, soft acids and bases are those of high polarizability. Although the HSAB principle has been useful in a variety of contexts [11], this system of classification is still only qualitative. The explanation given by Klopman [12] emphasized that soft acids and bases were largely covalently bound and hard acids and bases were ionically bound.

Zhang [13] has proposed a numerical scale for the acid strengths of cations. The advantage of such a scale is the predictive power for thermochemical and physical properties that obviously depend on the nature of the chemical bond established between the acid cation and the basic anion. In the case of inorganic compounds, this bond is called iono-covalent, meaning that this bond involves simultaneously electrostatic forces (ionic part) and covalent forces resulting from the combination of atomic orbitals of cations and anions. To express this duality, for a given cation, Zhang took into account its polarizing power for the ionic part and its electronegativity for the covalent part and defined a parameter $Z$ called the acid strength of the concerned cation as:

$$
Z=\frac{Z}{r^{2}}-7.7 \chi+8
$$

$Z$ : charge, $r$ : ionic radius and $\chi$ : electronegativity [6]. Zhang proposed the following classification:

$$
0< \begin{cases}Z>0.66 & \text { large electrostatic acids } \\ Z<0.66 & \text { border acids } \\ Z<0 & \text { large covalent acids }\end{cases}
$$

The $Z$ value gives a quantitative order of relative Pearson hardness or softness for the various Lewis acids and agrees fairly well with the previous classifications [10, 12, 14, 15]. 
Recently, Portier [16] presented a new parameter, the ionic-covalent parameter (ICP), derived from the HSAB principle of Pearson and from the quantitative evaluation of acidic strengths of Lewis acids proposed by Zhang [13]:

$$
I C P=\log (P)-1.38 \chi+2.07 .
$$

$P$ : polarizing power of the cation ( $P=Z / r^{2}, r$ : Shannon ionic radius); $\chi$ : electronegativity [7].

The ICP of cations such as the Zhang's parameter takes into account the ionic forces (polarizing power) and the covalent forces (electronegativity). Correlations between ICP and various thermodynamic (bond energy, formation enthalpy, fusion temperature) and electronic properties have been emphasized.

With density functional theory as a starting point, two new concepts of potential importance have been introduced for any chemical system: its electronic chemical potential, $\mu$ and its absolute hardness $\eta[18,19]$. Operational and approximate definitions are:

$$
-\mu=\frac{(I+A)}{2}=\chi \quad \eta=\frac{(I-A)}{2}
$$

where $I$ is the ionization potential and $A$ is the electron affinity.

Since $(I+A) / 2$ is the Mulliken electronegativity for atoms, the value for any system, $\chi$, is called the absolute electronegativity.

According to Klopman's theorem, the frontier orbital energies defined in HSAB theory are given by:

$$
-\varepsilon_{\mathrm{HOMO}}=I \quad-\varepsilon_{\mathrm{LUMO}}=A .
$$

Consequently, hard molecules have a large HOMO-LUMO gap and soft molecules have a small HOMO-LUMO gap [20]. Pearson [17] used these definitions to calculate experimental values for a large number of cations, atoms, radicals and molecules.

The graphs $Z / \chi_{M}, I C P / \chi_{M}$ and $\log \eta / \log \chi$ (Figs. 1(a)-(c)) show the distribution of the cations according to their valence (and usual coordination in the case of Portier's data) in the areas "ionic-covalent" and "hard-soft" acid. The $Z$ [13] and $\eta$ [17] parameters give a quantitative order of relative Pearson hardness and softness for the various Lewis acids and agree fairly well with the first Pearson classification [10].

In addition to the expected effects on ionic charge and size, the influence of $d$ electrons is very clear. That the $d$ sub shell is very important in promoting soft behavior has been emphasized by Ahrland [15]. The role of $d$ electrons in chemical bonding is usually attributed to $\pi$-back-bonding and/or polarization in the field of ligands. However ligand field stabilization is also important, and it is interesting to point out that this is also a polarizability effect. Localizing the $d$ electrons in certain favored orbitals is a special kind of polarization.

Some cases where the three classifications are not reliable are listed hereafter:

\begin{tabular}{lccc}
\hline & \multicolumn{3}{c}{ Classification according to } \\
\cline { 2 - 4 } Cations & Zhang [13] & Pearson [17] & Portier [16] \\
\hline $\mathrm{K}^{+}$ & $\mathrm{H}$ & $\mathrm{H}$ & $\mathrm{S}$ \\
$\mathrm{Rb}^{+}, \mathrm{Cs}^{+}$ & $\mathrm{H}$ & $\mathrm{H}$ or B & $\mathrm{S}$ \\
$\mathrm{Fe}^{3+}$ & $\mathrm{H}$ & $\mathrm{H}$ & $\mathrm{B}$ or S \\
$\mathrm{Cr}^{3+}$ & $\mathrm{B}$ & $\mathrm{B}$ & $\mathrm{H}$ \\
$\mathrm{V}^{5+}, \mathrm{Nb}^{5+}, \mathrm{Ta}^{5+}$ & $\mathrm{H}$ & & $\mathrm{S}$ \\
$\mathrm{Cr}^{6+}, \mathrm{Mo}^{6+}, \mathrm{W}^{6+}$ & $\mathrm{H}$ & & $\mathrm{S}$ \\
\hline
\end{tabular}

Note: H: hard; S: soft; B: borderline. 


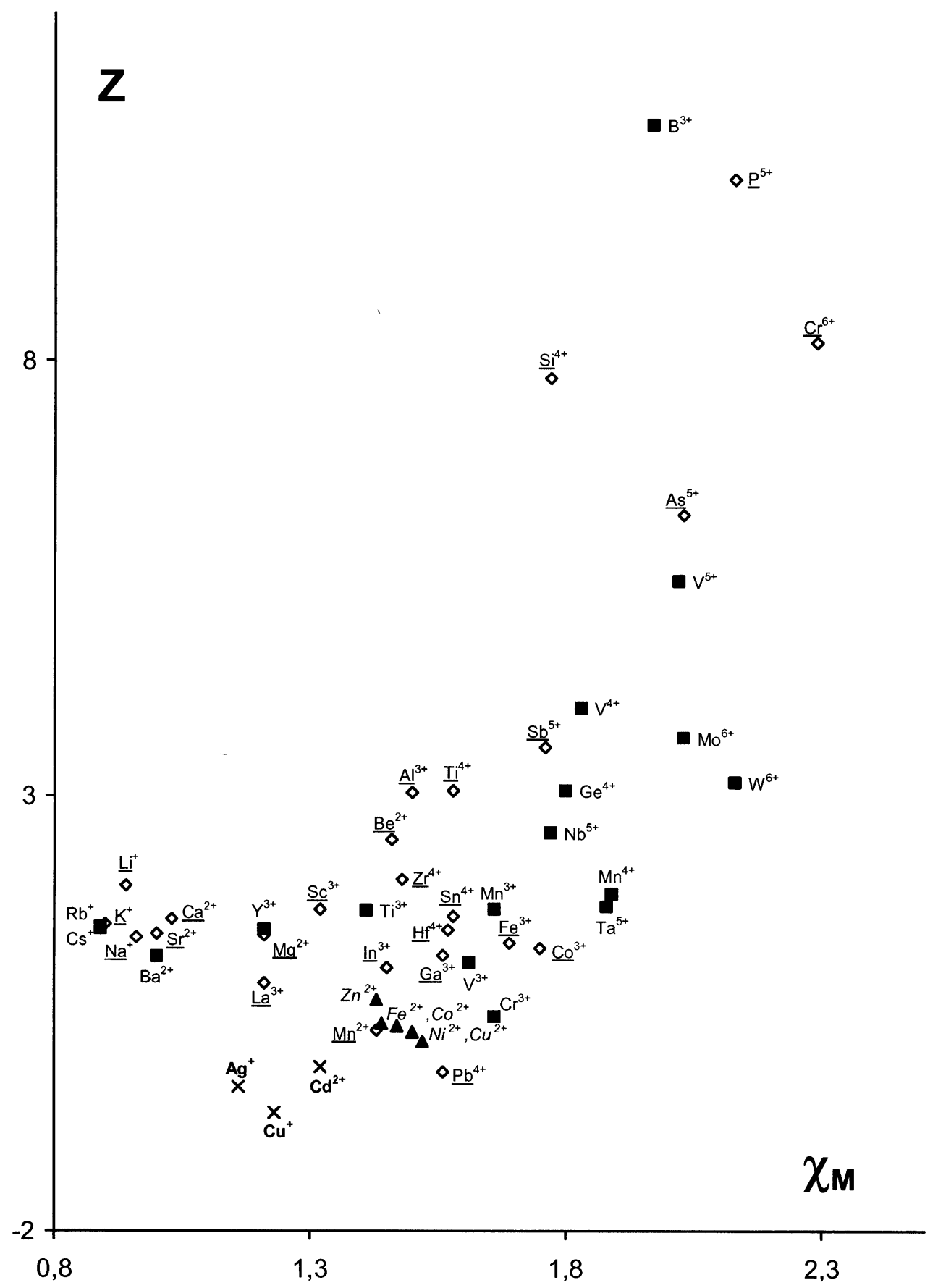

FIGURE 1(a) Electronegativities of elements in valence states and various scales for strengths of Lewis acids, Ref. [13]: $\diamond \mathrm{Mn}^{+}: \mathrm{H}$ (hard); $\boldsymbol{\Delta}: \mathrm{B}$ (borderline); $\times$ : S (soft); $\mathbf{\square}$ : unspecified (Pearson's classification).

\subsection{Acid-Base Properties of Oxides}

Many oxides, on the basis of their chemical behavior can be classified as basic, e.g. $\mathrm{CaO}$ and $\mathrm{MgO}$, or acidic, e.g. $\mathrm{P}_{2} \mathrm{O}_{5}$ or $\mathrm{SiO}_{2}$. Furthermore, their acid/base chemistry is not restricted 


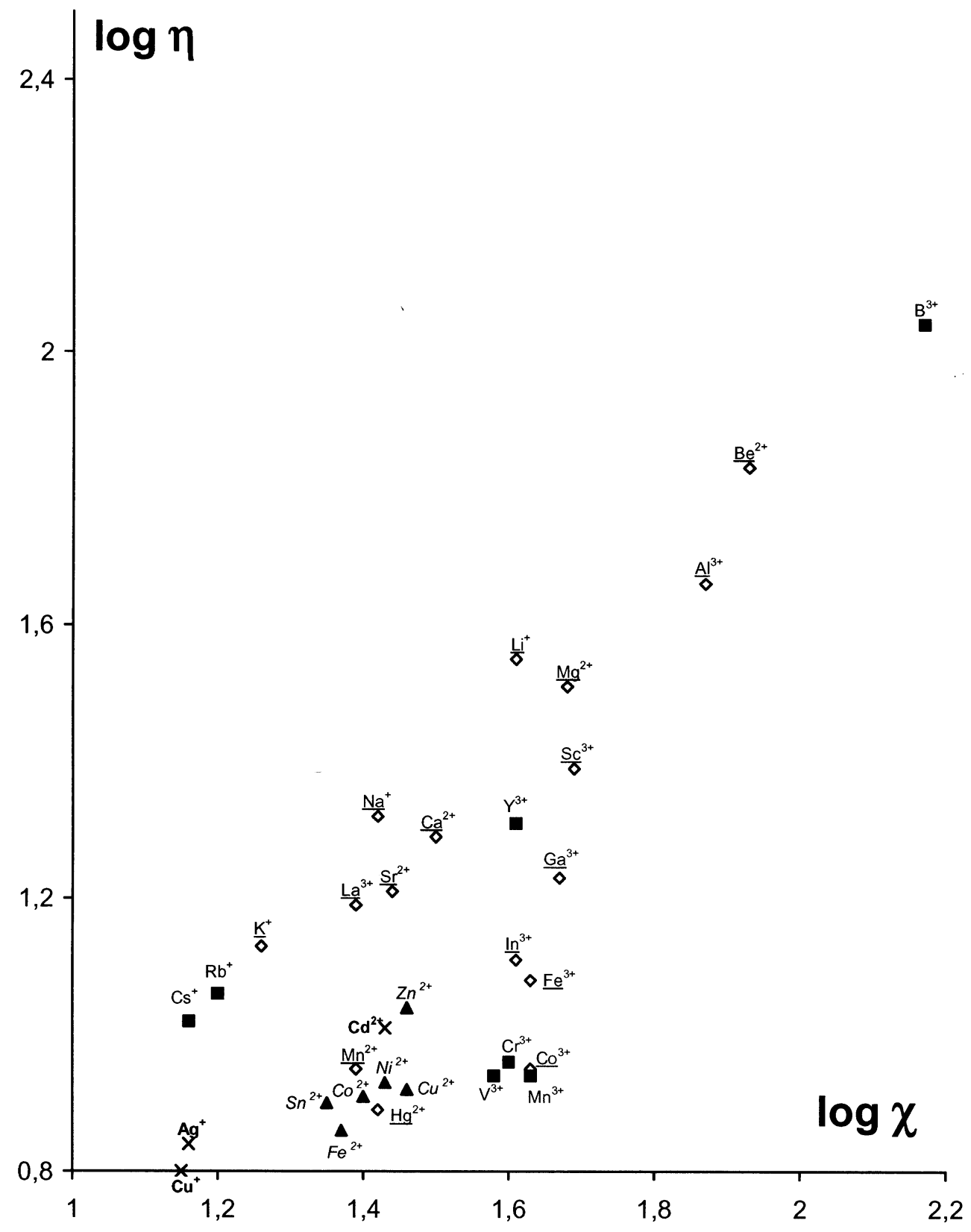

FIGURE 1(b) Electronegativities of elements in valence states and various scales for strengths of Lewis acids, Ref. [16]: $\diamond \mathrm{Mn}^{+}: \mathrm{H}$ (hard); $\boldsymbol{\Delta}: \mathrm{B}$ (borderline); $\times$ : S (soft); $\mathbf{\square}$ : unspecified (Pearson's classification).

to aqueous conditions, since reactions of the type $2 \mathrm{CaO}+\mathrm{SiO}_{2} \rightarrow \mathrm{Ca}_{2} \mathrm{SiO}_{4}$ occur in the liquid (molten) state, or even between intimately mixed solids at elevated temperature. Acid/base interaction is a formation of a coordinate bond, $\mathrm{B} \rightarrow \mathrm{A}$, and the strength of the base (or of the acid) can be thought of in terms of the extent of electron donation in the coordinate bond. The oxide(-II) base has an electron donor power which is governed by the various cations, e.g. $\mathrm{Ca}^{2+}$ or $\mathrm{Si}^{4+}$ which polarize it. Thus, it is expected that the magnitude of the electron donor power of the oxide(-II) species will depend on its state of polarization. 

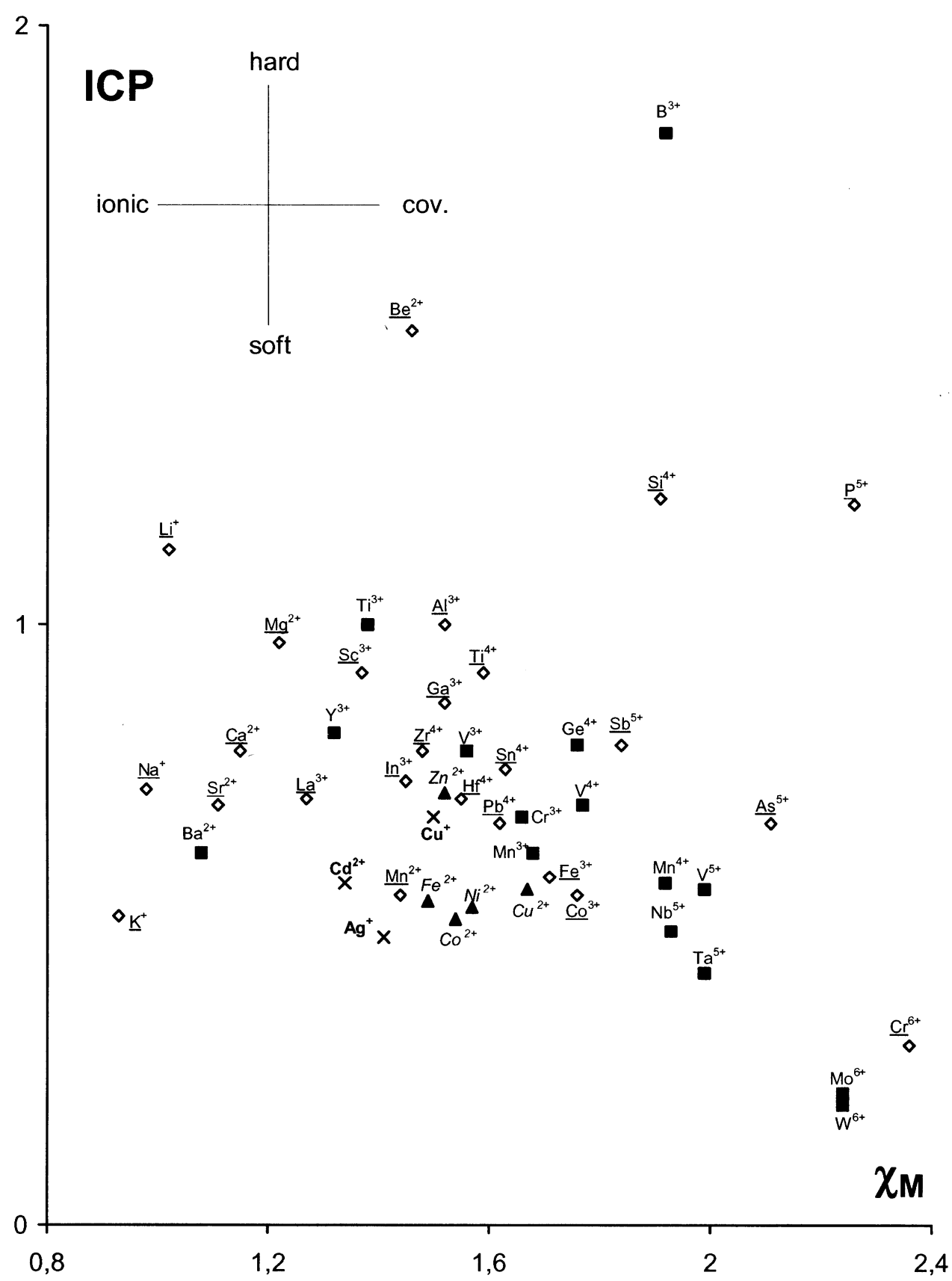

FIGURE 1(c) Electronegativities of elements in valence states and various scales for strengths of Lewis acids, Ref. [17]: $\diamond \mathrm{Mn}^{+}: \mathrm{H}$ (hard); $\boldsymbol{\Delta}:$ B (borderline); $\times$ : S (soft); $\mathbf{\square}:$ unspecified (Pearson's classification).

Most ions have a more or less fixed value for their electronic polarizability $\alpha$, but for the oxide(-II) species, $\alpha_{\mathrm{O}^{2-}}$ has a wide range of values.

The reason for this is that the unpolarized $\mathrm{O}^{2-}$ ion has an electron charge cloud which can be regarded as very "floppy" and this gives great scope for its tightening by the cations present in the compound. The effect of this tightening (indicated by the values of $\alpha_{\mathrm{O}^{2-}}$ ) on 
the electron donor power or rather the basicity can be seen in the following progression from the basic $\mathrm{BaO}$ to the oxide $\mathrm{P}_{2} \mathrm{O}_{5}$ :

\begin{tabular}{llllllll}
\hline & \multicolumn{7}{c}{ Oxide, $M_{x} O_{y}$} \\
\cline { 2 - 7 } & $\mathrm{BaO}$ & $\mathrm{SrO}$ & $\mathrm{CaO}$ & $\mathrm{MgO}$ & $\mathrm{SiO}_{2}$ & $\mathrm{P}_{2} \mathrm{O}_{5}$ & Ref. \\
\hline$\alpha_{M^{y+}}$ & 1.60 & 0.86 & 0.47 & 0.094 & 0.033 & Negl. & {$[21]$} \\
$n_{0}$ & 1.98 & 1.81 & 1.838 & 1.736 & 1.544 & 1.599 & \\
$\alpha_{\mathrm{O}^{2-}}(n)^{*}$ & 3.652 & 2.918 & 2.505 & 1.699 & 1.401 & 1.33 \\
$\alpha_{\mathrm{O}^{2-}}\left(E_{g}\right)^{\dagger}$ & 3.83 & 3.382 & 2.334 & 1.675 & 1.454 & & \\
\hline
\end{tabular}

Note: Electronic polarizabilities, $\alpha$, in $\AA^{3}$.

${ }^{*} \alpha_{\mathrm{O}^{2-}}(n)=(1 / y)\left(\alpha_{m}-x \alpha_{M^{y+}}\right) ; \alpha_{m}$, molar polarizabilities are obtained from the Clausius-Mossoti equation:

$$
\alpha_{m}=\frac{3 V_{m}}{4 \pi N} \cdot \frac{n_{0}^{2}-1}{n_{0}^{2}+2}
$$

${ }^{\dagger} \alpha_{\mathrm{O}^{2-}}\left(E_{g}\right)$ are obtained from the relation established by Duffy [22]: $R_{m}=V_{m}\left(1-\sqrt{E_{g} / 20}\right)\left(E_{g}\right.$ : energy gap)

\subsubsection{Optical Basicity, $\Lambda$}

Optical basicity expresses the basicity of a glass (or other oxidic medium) in terms of the electron density carried by the oxygen's, i.e. their ability to donate negative charge [23-25]. Originally, optical basicity was obtained from spectroscopic shifts (in the ultra-violet region) of ions such as $\mathrm{Ti}^{+}$and $\mathrm{Pb}^{2+}$ dissolved as probes sensing the electron donor power of the oxygen [23]. The accumulation of optical basicity data revealed in time that it was possible to calculate $\Lambda$ for an oxidic system from its composition [25]. The method has been used very successfully in extraction metallurgy in predicting the refining power of slag's and also in glass science.

The great advantages of optical basicity compared to all the other concepts used in aciditybasicity is that $\Lambda$ is a global parameter (relative to a phase) and that it permits a quantitative classification of the phases and calculations for mixed oxides.

When spectroscopic experiments could not be used, as in the case of transition metal ions which absorb intensely in the UV region, other methods were investigated to obtain $\Lambda$ values. One of these consists of calculations based on the electronic polarizability of oxygen $\left(\alpha_{\mathrm{O}^{2-}}\right)$ $v s$. the basicity of the material. This method has been used for obtaining optical basicities of transition metal oxides by Duffy [26,27].

This author has specified that the additivity of the electronic polarizabilities is normally only valid for the ionic compounds and observed a linear correlation between $1 / \alpha_{\mathrm{O}^{2-}}$ and $\Lambda$ for a given structural family:

$$
\Lambda=1.67\left(1-\frac{1}{\alpha_{\mathrm{O}^{2-}}}\right) .
$$

More recently, Dimitrov and Sakka [21] have applied the correlation $1 / \alpha_{\mathrm{O}^{2-}}=f(\Lambda)$ to numerous transition metal oxides; the average electronic oxide polarizability was calculated from the energy gap $E_{g}$. It should be noted that Dimitrov and Duffy took for $\alpha_{\text {cation }}$ the value of the free cation and not that of the cation in the oxide, which is only available for a very limited number of cations recently investigated.

Courtine [28] has completed and improved an optical basicity table of ionic-covalent oxides and oxysalts, despite the lack of data for these solids. Values of optical basicity for most covalent transition metal oxides were indeed missing or wrongly assessed. Correlations 
between the ionic-covalent parameter ICP defined by Portier [16] and optical basicity values obtained by Duffy and Dimitrov (mainly for weakly covalent transition metal oxides) have been established.

This author has determined for binary oxides five linear correlations between $\Lambda$ and ICP depending on the electronic configuration of the cations $\left(s-p, d^{1}-d^{9}, d^{10}, d^{10} s^{2}\right.$ and $\left.d^{0}\right)$ and obtained the optical basicity value for each valence and coordination number of cations in the oxides. This allows the optical basicity to be calculated for any mixed oxides, taking into account the structure, i.e. the coordination of the component cations.

\subsubsection{Acidity Scale for Binary Oxides}

A numerical scale for acidity/basicity for binary oxides has been constructed from thermochemical data for oxoacid salts by Smith [29]. This author assigned to a binary oxide a constant $P_{a}$ which is a measure of its tendency to accept an oxide ion (i.e. its acidity) and wrote the empirical expression

$$
\left[P_{a}(A)-P_{a}(B)\right]^{2}=h(A, B)
$$

where $h(A, B)$ is equal to $-\Delta H^{0}$ (in $\mathrm{kJ} \mathrm{mol}^{-1}$, at $25^{\circ} \mathrm{C}$ ) for the reaction between the acid oxide $A$ and the basic oxide $B$ to give a salt. This equation may be written as: $P_{a}(A)-P_{a}(B)=h(A, B)^{1 / 2}$ so that the experimental values of $h(A, B)^{1 / 2}$ for salts which have a cation or anion in common should exhibit subtractive relationships, for example:

$$
h\left(\mathrm{CaO}, \mathrm{SO}_{3}\right)^{1 / 2}-h\left(\mathrm{BaO}, \mathrm{SO}_{3}\right)^{1 / 2}=h\left(\mathrm{CaO}, \mathrm{CO}_{2}\right)^{1 / 2}-h\left(\mathrm{BaO}, \mathrm{CO}_{2}\right)^{1 / 2} .
$$

Smith performed a least-squares analysis from data for 250 oxoacid salts involving 70 binary oxides to find the best values of $P_{a}$. The value 0 for $P_{a}\left(\mathrm{H}_{2} \mathrm{O}\right)$ has been chosen in order to establish the absolute values of $P_{a}$.

A similar study performed on mixed oxides from recent thermochemical data [30-32] gives an acidity scale which agrees fairly well with that of Smith (Tab. I).

\subsubsection{Charge on the Oxide(-II) Ion}

Sanderson [33] calculated the partial charges for halides and oxides from the principle of electronegativity equalization: when two or more atoms initially different in electronegativity form a compound, their electronegativities change to the same intermediate value in the compound. There is a systematic decrease of the oxygen charge in the series: $M_{2} \mathrm{O}(M=\mathrm{Rb}, \mathrm{K}$, $\mathrm{Na}, \mathrm{Li}), M \mathrm{O}(M=\mathrm{Ba}, \mathrm{Sr}, \mathrm{Ca}, \mathrm{Mg}, \mathrm{Be}), \mathrm{CdO}, \mathrm{Al}_{2} \mathrm{O}_{3}, \mathrm{ZnO}, \mathrm{B}_{2} \mathrm{O}_{3}, \mathrm{SiO}_{2}$ and $\mathrm{SnO}_{2}$.

A similar classification has been established by Duffy [25] from the equation:

$$
q_{\mathrm{o}}=-1.15 \Lambda
$$

obtained from $\mathrm{CNDO}$ calculations for the isoelectronic series consisting of $\mathrm{ClO}_{4}^{-}, \mathrm{SO}_{4}^{2-}$, $\mathrm{PO}_{4}^{3-}$ and $\mathrm{SiO}_{4}^{4-}$ and extended to binary oxides, where the oxidation number of the metal corresponds to a noble-gas electronic configuration. Experimental data show that $\Lambda$ increases as the basicity of oxide increases:

\begin{tabular}{lccccccccc}
\hline Oxides & $\mathrm{P}_{2} \mathrm{O}_{5}$ & $\mathrm{SiO}_{2}$ & $\mathrm{Al}_{2} \mathrm{O}_{3}$ & $\mathrm{MgO}$ & $\mathrm{CaO}$ & $\mathrm{Li}_{2} \mathrm{O}$ & $\mathrm{Na}_{2} \mathrm{O}$ & $\mathrm{BaO}$ & $\mathrm{K}_{2} \mathrm{O}$ \\
$\Lambda[25]$ & 0.40 & 0.48 & 0.60 & 0.78 & 1 & 1 & 1.15 & 1.15 & 1.40 \\
\hline
\end{tabular}


TABLE I Values of $P_{a}$ for Binary Oxides (Relative to $\mathrm{H}_{2} \mathrm{O}$ ).

\begin{tabular}{|c|c|c|c|c|c|}
\hline & \multicolumn{2}{|c|}{$P_{a}$ value of oxide } & & \multicolumn{2}{|c|}{$P_{a}$ value of oxide } \\
\hline & Ref. [29] & This study & & Ref. [29] & This study \\
\hline $\mathrm{Rb}_{2} \mathrm{O}$ & -15 & -15.5 & $\mathrm{Fe}_{2} \mathrm{O}_{3}$ & -1.7 & -2.1 \\
\hline $\mathrm{K}_{2} \mathrm{O}$ & -14.6 & -15 & $\mathrm{Cu}_{2} \mathrm{O}$ & -1.0 & -2 \\
\hline $\mathrm{Na}_{2} \mathrm{O}$ & -12.5 & -13 & $\mathrm{ZrO}_{2}$ & 0.1 & -1.7 \\
\hline $\mathrm{BaO}$ & -10.8 & -11.4 & $\mathrm{Ga}_{2} \mathrm{O}_{3}$ & -1.6 & -1 \\
\hline $\mathrm{SrO}$ & -9.4 & -10.1 & $\mathrm{Al}_{2} \mathrm{O}_{3}$ & -2.0 & -0.8 \\
\hline $\mathrm{Li}_{2} \mathrm{O}$ & -9.2 & -10.2 & $\mathrm{Cr}_{2} \mathrm{O}_{3}$ & & -0.3 \\
\hline $\mathrm{CaO}$ & -7.5 & -8.7 & $\mathrm{SnO}_{2}$ & 2.2 & 0 \\
\hline $\mathrm{La}_{2} \mathrm{O}_{3}$ & -6.1 & -8.7 & $\mathrm{Mn}_{2} \mathrm{O}_{3}$ & & 0.4 \\
\hline $\mathrm{Y}_{2} \mathrm{O}_{3}$ & -6.5 & -7.7 & $\mathrm{PbO}_{2}$ & & 0.5 \\
\hline $\mathrm{MgO}$ & -4.5 & -6 & $\mathrm{Nb}_{2} \mathrm{O}_{5}$ & & 0.5 \\
\hline $\mathrm{MnO}$ & -4.8 & -5.7 & $\mathrm{TiO}_{2}$ & 0.7 & 0.6 \\
\hline $\mathrm{CdO}$ & -4.4 & -5.1 & $\mathrm{SiO}_{2}$ & 0.9 & 1.2 \\
\hline $\mathrm{CoO}$ & -3.8 & -4.8 & $\mathrm{GeO}_{2}$ & & 1.3 \\
\hline $\mathrm{Ag}_{2} \mathrm{O}$ & -5 & -4.8 & $\mathrm{~B}_{2} \mathrm{O}_{3}$ & 1.5 & 1.7 \\
\hline $\mathrm{FeO}$ & -3.4 & -4.4 & $\mathrm{~V}_{2} \mathrm{O}_{5}$ & 3.0 & 2.2 \\
\hline $\mathrm{ZnO}$ & -3.2 & -3.8 & $\mathrm{Sb}_{2} \mathrm{O}_{5}$ & & 3.2 \\
\hline $\mathrm{NiO}$ & -2.4 & -3.6 & $\mathrm{MoO}_{3}$ & 5.2 & 3.9 \\
\hline $\mathrm{HgO}$ & -3.5 & -3.3 & $\mathrm{WO}_{3}$ & 4.7 & 4.1 \\
\hline $\mathrm{HfO}_{2}$ & & -3.1 & $\mathrm{As}_{2} \mathrm{O}_{5}$ & 5.4 & 5.5 \\
\hline $\mathrm{CuO}$ & -2.5 & -2.8 & $\mathrm{CrO}_{3}$ & 6.6 & 6.1 \\
\hline $\mathrm{BeO}$ & -2.2 & -2.8 & $\mathrm{P}_{2} \mathrm{O}_{5}$ & 7.5 & 7.5 \\
\hline $\mathrm{In}_{2} \mathrm{O}_{3}$ & -2.4 & & $\mathrm{SO}_{3}$ & 10.5 & 11 \\
\hline
\end{tabular}

The electronegativity is an important factor when considering oxidic systems and it is useful to summarize the situation for binary oxides. Denoting the electronegativities of cation and anion by $\chi_{M}$ and $\chi_{\mathrm{O}}$, respectively, the following principles hold:

- high ionicity if $\left(\chi_{O}-\chi_{M}\right)$ is large and ionicity decreases in a series of binary compounds ranked in order of decreasing $\left(\chi_{O}-\chi_{M}\right)$,

- predominantly covalent bonding when $\left(\chi_{O}-\chi_{M}\right)$ is small (usually below approximately 1.7) but $\chi_{\mathrm{O}}$ greater than 2 ,

- predominantly metallic bonding when $\left(\chi_{O}-\chi_{M}\right)$ is small (usually below approximately 1 ) but $\chi_{\mathrm{O}}$ and $\chi_{M}$ less than 2 .

For oxides the trend from ionic to covalent bonding, accompanying decreasing $\left(\chi_{O}-\chi_{M}\right)$, is illustrated by the series:

\begin{tabular}{llllll}
\hline & $\mathrm{CaO}$ & $\mathrm{MgO}$ & $\mathrm{Al}_{2} \mathrm{O}_{3}$ & $\mathrm{SiO}_{2}$ & $\mathrm{P}_{2} \mathrm{O}_{5}$ \\
\hline$\chi_{\mathrm{O}}-\chi_{M}$ & 1.97 & 1.92 & 1.86 & 1.67 & 1.47 \\
$\chi_{M}$ & 1 & 1.2 & 1.5 & 1.8 & 2.1 \\
\hline
\end{tabular}

(the values of $\left(\chi_{O}-\chi_{M}\right)$ are calculated by the Pauling method from heats of formation).

It can be seen that although oxygen electronegativity is around 3.5 for $\mathrm{SiO}_{2}$ and $\mathrm{P}_{2} \mathrm{O}_{5}$, it gradually decreases as the compounds become more ionic. Nevertheless, the ionic $\mathrm{Na}_{2} \mathrm{O}$ or $\mathrm{K}_{2} \mathrm{O}$ oxides and covalent $\mathrm{SiO}_{2}$ have almost the same electronegativity difference. Consequently, electronegativity difference is not necessarily a guide to the ionic-covalent nature of the bonding.

Duffy [22] proposed a new appraisal of the chemical bonding of binary oxides. It is argued that the electronegativity of oxygen is a better indication of ionicity (falling with 
decreasing covalency) than the electronegativity difference. Metallic bonding in oxides is treated from the point of view of polarization, and it is shown how experimental parameters of polarization and of band theory are closely related. These parameters are used for charting the proximity of oxides to the onset of metallization, while, simultaneously, the oxygen electronegativity is used for charting ionic/covalent bonding.

The two above-mentioned acidity scales reveal very significant relationships between the acidity parameter $P_{a}$ and $\chi_{M}$ which are expressed by:

$$
\begin{array}{ll}
P_{a}=-23.43+13.21 \chi_{M} & (\text { a: Ref. [29]) } \quad R=0.937 \\
P_{a}=-24.81+13.81 \chi_{M} & \text { (a: This study) } \quad R=0.939
\end{array}
$$

Table II presents a comparison of the acid-base properties of binary oxides with the $P_{a}$ values presented in this study. Well-marked periodic trends are evident. $P_{a}$ tends to decrease along any group and increases more or less steadily along each period. It also increases with increasing oxidation number. These trends are consistent with the definition of $P_{a}$ as a measure of the tendency of the oxide to accept $\mathrm{O}^{2-}$.

Oxides with $P_{a}$ less than about -5 are all purely basic. In the range between -5 and 0 , the oxides appear to be amphoteric or amphoteric with a weak basic character. Amphoteric oxides with a weak acidic character and purely acidic oxides all have positive values.

\subsection{Scales of Ionicity}

We shall limit our survey to a discussion of the thermochemical approach of Pauling, to the spectroscopic approach of Phillips.

The first major scheme, due to Pauling $[1,35,36]$ is thermochemically based. Suppose the formation energy of a diatomic molecule $X Y$ is written $E_{X Y}$. Then, for molecule $A B$, the quantity:

$$
\varepsilon_{A B}=E_{A B}-\left[\text { mean of } E_{A A}, E_{B B}\right]
$$

is a measure of the electronegativity difference $\left(\chi_{A}-\chi_{B}\right)$ of $A$ and $B$, insofar as it corresponds to electron transfer from the less to more electronegative atom. The concept is ionic, i.e. covalent contributions are implicit only. The two working postulates giving fractional ionic character $f_{A B}$ are designed to be both intuitively sensible and to satisfy the obvious constraints $f_{A B}=f_{B A}$ and $0 \leq f_{A B} \leq 1$, with $f_{A B}=1$ the ionic extreme. In this case Pauling's algorithms are:

$$
\left(\chi_{A}-\chi_{B}\right)^{2}=\gamma \varepsilon_{A B}
$$

where $\gamma$ ensures that the dimensionless $\chi_{A}$ and $\chi_{B}$ change by 0.5 with each unit valence change in the first row of the periodic table:

$$
f_{A B}=1-\exp \left[-\frac{1}{4}\left(\chi_{A}-\chi_{B}\right)^{2}\right]=1-\exp \left(-\frac{1}{4} \gamma \varepsilon_{A B}\right)
$$

It is this quantity that has been used to understand a very wide range of chemical behavior. 


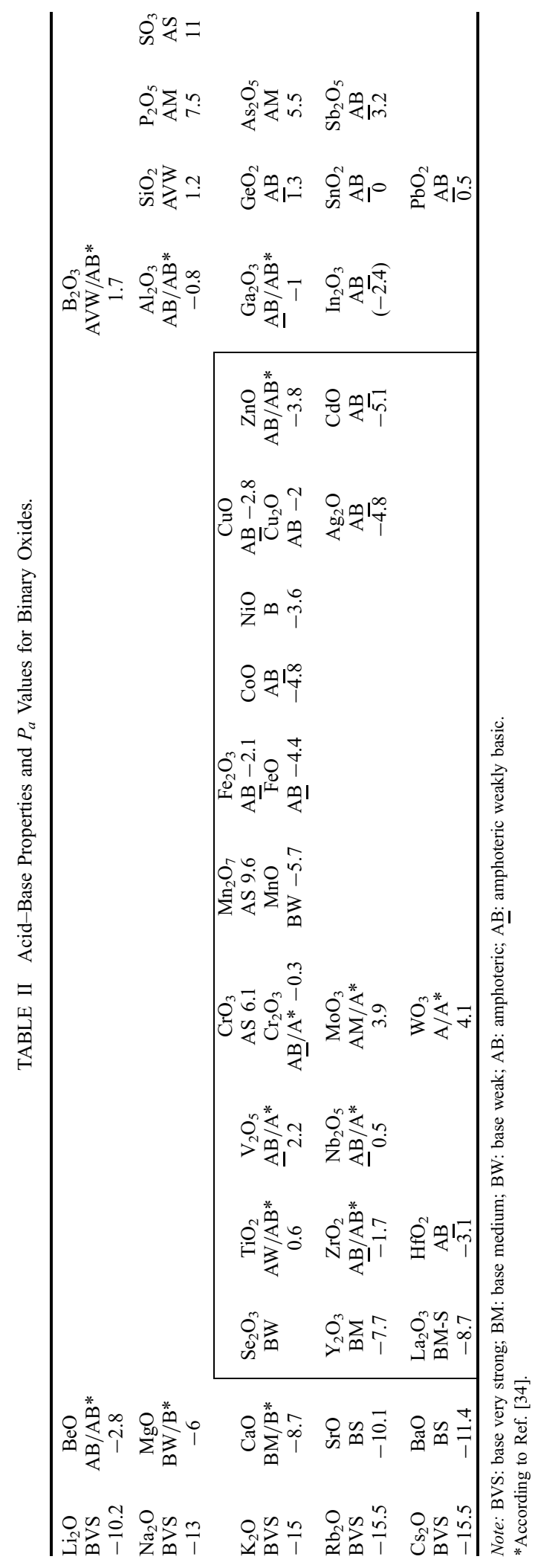


Phillips [37,38] and van Vechten [39] chose a spectroscopic definition, defining a "total energy gap" with two components

$$
E_{g}^{2}=E_{h}^{2}+E_{c}^{2}
$$

The total gap is obtained from the optic dielectric constant

$$
E_{g}=\frac{\hbar \omega_{p}}{\left(\varepsilon_{x}-1\right)^{1 / 2}}
$$

with $\hbar \omega_{p}$ the plasma frequency for the valence electrons; the covalent gap $E_{h}$ is obtained from $E_{g}$ for the non-polar system in the same row of the periodic table, with a correction for the interatomic spacing. The ionic part, $E_{c}$, is obtained as $\left(E_{g}^{2}-E_{h}^{2}\right)^{1 / 2}$. Phillips defines an ionic character

$$
f_{i}=\frac{E_{c}^{2}}{\left(E_{h}^{2}+E_{c}^{2}\right)} .
$$

It is this parameter that has been used to classify, divide and identify trends in many solid state properties.

Levine $[40,41]$ extended the dielectric theory of ionicity to diverse structures, $d$-electron systems such as the noble-gas halides, transition metal compounds and multibond compounds (Tab. III). More recently, Christensen et al. [42] have reported theoretical investigations on the bonding properties of semiconductors which have been most widely studied in experimental as well as theoretical solid-state physics (systematic theoretical studies of the electronic structures, optical properties and charge distributions have been reported previously, Refs. [38,43-45]). The results show that the ionicities calculated in Christensen's model based on self-consistent band structure calculations exhibit the same chemical trends as those found in the values derived from the Phillips-van Vechten theory. Nevertheless, their ionicities tend to be somewhat larger:

\begin{tabular}{lccccc}
\hline \multicolumn{5}{c}{ Ionicity $f_{i}$ of compound } & \\
\hline $\mathrm{BeO}$ & $B N$ & $\mathrm{MgS}$ & $\mathrm{ZnS}$ & $\mathrm{CdS}$ & Ref. \\
\hline 0.798 & 0.383 & 0.828 & 0.764 & 0.794 & {$[42]$} \\
0.602 & 0.256 & 0.786 & 0.623 & 0.685 & {$[38]$} \\
0.620 & 0.264 & & 0.621 & 0.679 & {$[41]$} \\
\hline
\end{tabular}

Plots of $\Lambda$ and $P_{a}$ versus the $f_{i}$ values of Table III show that some data relative to $f_{i}$ and $\Lambda$ are erroneous. A satisfactory agreement is obtained with the values proposed hereafter (Figs. 3 and 4):

\begin{tabular}{lcccccc}
\hline & $f_{i}$ & Ref. & Modified values & $\Lambda$ & Ref. & Modified values \\
\hline $\mathrm{Li} \mathrm{i}_{2} \mathrm{O}$ & 0.766 & {$[41]$} & $\mathbf{0 . 8 7 5}$ & & & \\
$\mathrm{BeO}$ & 0.602 & {$[38]$} & $\mathbf{0 . 7 5}$ & & & \\
$\mathrm{MgO}$ & & & & 0.78 & {$[25]$} & $\sim \mathbf{0 . 9 5}$ \\
$\mathrm{ZnO}$ & 0.616 & {$[38]$} & $\mathbf{0 . 7 5}$ & 0.95 & {$[25]$} & $\sim \mathbf{0 . 8 0}$ \\
& 0.653 & {$[41]$} & & 0.92 & {$[28]$} & $\sim \mathbf{0 . 9 5}$ \\
$\mathrm{CdO}$ & & & & & \\
$\mathrm{Cr}_{2} \mathrm{O}_{3}$ & 0.777 & {$[41]$} & $\mathbf{0 . 7 0}$ & & & \\
$\mathrm{Fe}_{2} \mathrm{O}_{3}$ & 0.677 & {$[41]$} & $\mathbf{0 . 7 5}$ & & & \\
\hline
\end{tabular}


TABLE III $f_{i}$ Values Predicted by the Dielectric Theory for 21 Binary Oxides.

\begin{tabular}{|c|c|c|c|c|}
\hline & \multicolumn{4}{|c|}{$f_{i}$} \\
\hline & $a$ & $b$ & $c$ & $d$ \\
\hline \multicolumn{5}{|l|}{$M_{2} \mathrm{O}$} \\
\hline $\mathrm{Li}_{2} \mathrm{O}$ & 0.766 & & & \\
\hline \multicolumn{5}{|l|}{$M O$} \\
\hline $\mathrm{BeO}$ & 0.620 & & 0.602 & \\
\hline $\mathrm{MgO}$ & 0.839 & & 0.841 & \\
\hline $\mathrm{CaO}$ & 0.916 & & 0.913 & \\
\hline $\mathrm{SrO}$ & 0.928 & & 0.926 & \\
\hline $\mathrm{BaO}$ & 0.931 & & & \\
\hline $\mathrm{MnO}$ & & 0.887 & & \\
\hline $\mathrm{FeO}$ & & 0.873 & & \\
\hline $\mathrm{CoO}$ & & 0.858 & & \\
\hline $\mathrm{NiO}$ & & 0.841 & & \\
\hline $\mathrm{ZnO}$ & 0.653 & & 0.616 & \\
\hline $\mathrm{CdO}$ & 0.778 & & 0.785 & \\
\hline \multicolumn{5}{|l|}{$M_{2} \mathrm{O}_{3}$} \\
\hline $\mathrm{Al}_{2} \mathrm{O}_{3}$ & 0.796 & & & 0.64 \\
\hline $\mathrm{Cr}_{2} \mathrm{O}_{3}$ & 0.777 & & & \\
\hline $\mathrm{Fe}_{2} \mathrm{O}_{3}$ & 0.677 & & & \\
\hline $\mathrm{In}_{2} \mathrm{O}_{3}$ & & & & 0.80 \\
\hline \multicolumn{5}{|l|}{$M \mathrm{O}_{2}$} \\
\hline $\mathrm{SiO}_{2}$ & 0.57 & & & 0.50 \\
\hline $\mathrm{GeO}_{2}$ & $\begin{array}{l}0.51 \\
0.73\end{array}$ & & & 0.65 \\
\hline $\mathrm{TiO}_{2}$ & & 0.686 & & \\
\hline $\mathrm{SnO}_{2}$ & 0.784 & & & 0.74 \\
\hline $\mathrm{PbO}_{2}$ & & & & 0.78 \\
\hline
\end{tabular}

Note: a: Levine [Ref. 41]; b: Levine [Ref. 40]; c: Phillips [Ref. 38]; d: Barr [Ref. 46].

\section{EXPERIMENTAL DETERMINATION OF IONIC CHARGES}

\subsection{Experimental Charge Distribution in Crystals by X-ray Diffraction}

The net atomic charge is one of the most widely used notions in crystal chemistry, solid state physics, etc. It plays an important role in the ionic crystal model and connects with many characteristics of the electron structure by correlational equations: for example, with the exponential parameter in the AO radial part. However, there are serious methodological reasons to criticize this conceptual value. The atomic charge concept results from the simplest method of ED approximation. As has already been noted, it is impossible to determine unambiguously in a bonded system the atomic boundary inside which the atomic charge is located. The charge values appear to be dependent on the form and the size of integration volume (or on the type of AO used); they are indirectly measured values in contrast to ED and only approximate the charge distribution. Nevertheless, an approach which permits us to understand the crystal properties in terms of atoms and their interaction is very attractive. The traditional quantum mechanics which operates with wave-functions is unable to do this because it can explain the properties of the whole system but not its parts. The atomic crystal chemical models, nevertheless, are widely used: the atomic parameters are used in the pseudopotential method, the atomic and ionic wave-functions are successfully applied as initial guesses in quantum chemical calculations, etc. Fortunately, quantum 


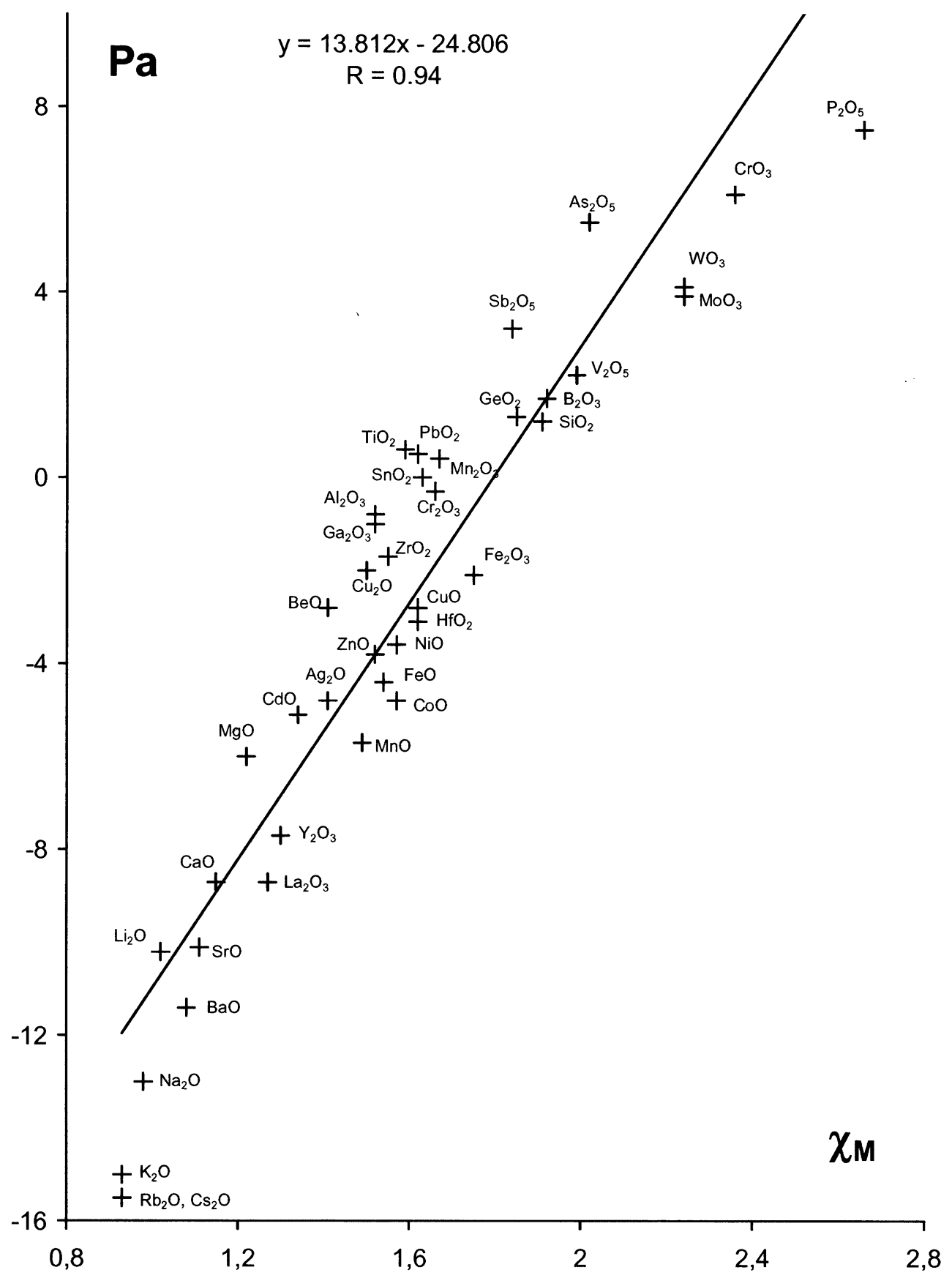

FIGURE 2 Plot of $P_{a}$ vs. $\chi_{M}\left(P_{a}\right.$ are those calculated is this study and $\chi_{M}$ are issued from Ref. [7]).

chemical description of a bonded atom appears to be possible via ED but not the wavefunction. This had been performed by Bader [47] in the framework of quantum topological theory of atoms in molecules. In this theory both the free and the bonded atom is represented as the unity of a nucleus and its electron basin. The whole system is presented 


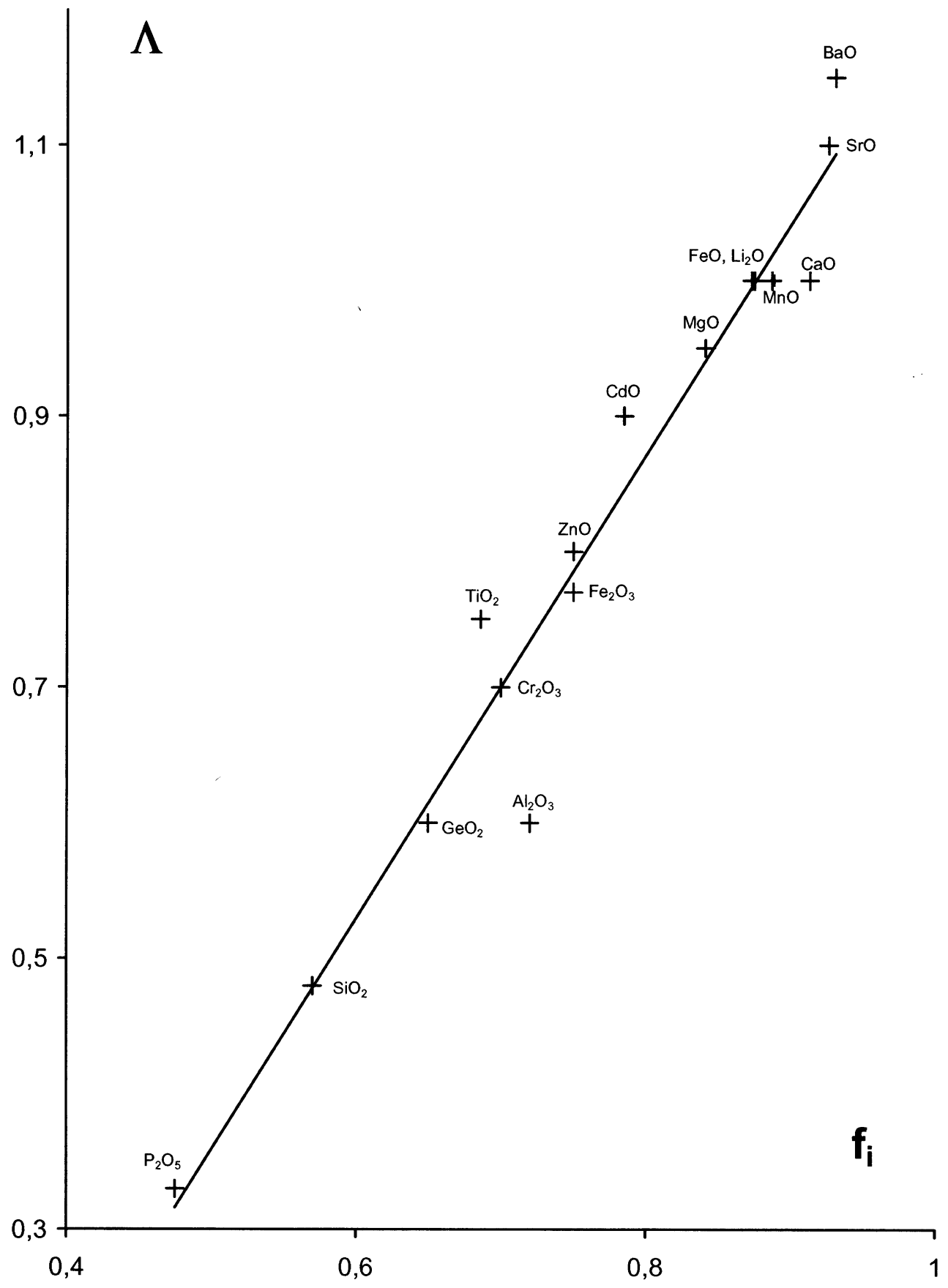

FIGURE 3 Plot of $\Lambda$ vs. $f_{i}$ ( $f_{i}$ for $\mathrm{Al}_{2} \mathrm{O}_{3}$ is the average value from Refs. [41] and [46]).

as a sum of non-overlapping atomic fragments. Identification of a bonded atom in some region of real space is realized by topological analysis of the ED. According to Bader, the bonded atom (pseudoatom) is the spatial region which contains a nucleus with its electron and which comprises a unique surface of zero flux of $\nabla \rho$. 


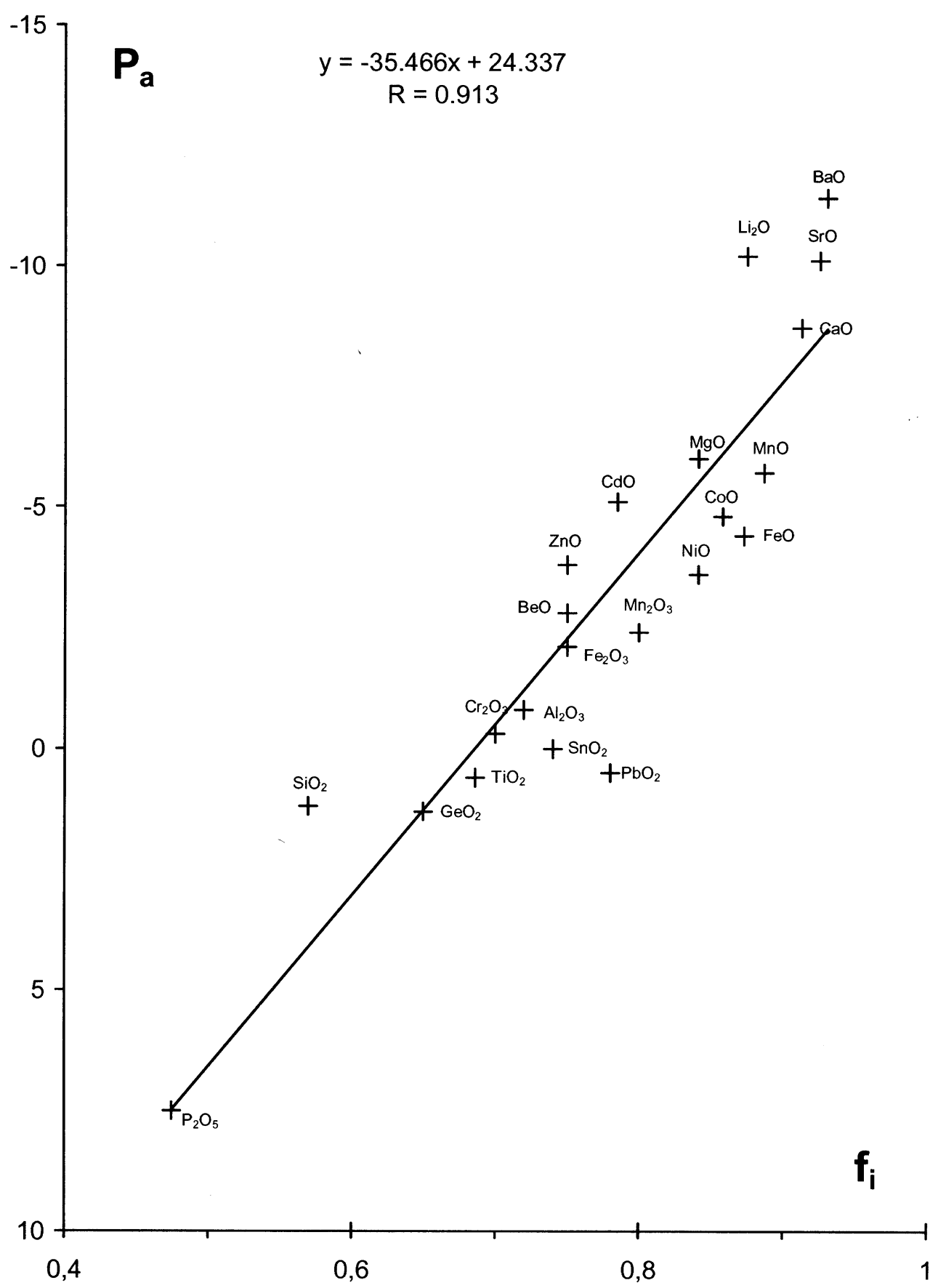

FIGURE 4 Plot of $P_{a}$ vs. $f_{i}$.

All of this justifies the studies that are devoted to accurate experimental determination of the electron density in order to estimate the net atomic charges and atomic volumes in crystals for which ab initio calculations are still not reliable enough. Two methods can be used for the determination of the electron density: the maximum-entropy method [48] and the 
multipole expansion $[49,50]$. The multipole model is the most suitable for topological analysis. Coppens [51,52] proposed a model which uses an expansion of the electron density around each nucleus. The use of the experimental electron density in the study of chemical bonds and the modelling of crystal properties is presented in two recent books [53,54].

\subsubsection{Alkaline-earth Series}

The comparison of the results on the alkaline-earth oxides shows a systematic variation in the nature of the oxygen ion:

\begin{tabular}{lllllll}
\hline & \multicolumn{5}{c}{ Oxides } & \\
\cline { 2 - 5 } & $\mathrm{BeO}$ & $\mathrm{MgO}$ & $\mathrm{CaO}$ & $\mathrm{SrO}$ & $\mathrm{BaO}$ & Ref. \\
\hline$q\left(e^{-}\right)$ & & 1.85 & & & & {$[55]$} \\
& & 1.36 & 1.5 & & & {$[56]$} \\
$4 \pi r^{2} \rho_{0}$ & & 1.36 & & & & {$[57]$} \\
& 4.46 & 2.8 & 2.3 & 1.2 & 1.2 & {$[58]$} \\
& & & & & & {$[58]$} \\
\hline
\end{tabular}

It is best reflected in the radial charge density $\left(4 \pi r^{2} \rho_{0}\right)$ at the radius of best separation which is a qualitative indication of the separability of oxygen from its surroundings. The above-mentioned values can be understood to indicate decreasing ionicity of $\mathrm{O}^{2-}$ in the series from the heavier to the lighter compounds. In all the cubic compounds oxygen can be described as a separable $\mathrm{O}^{2-}$ entity with different degrees of deformation. It is only in $\mathrm{BeO}$ that the deformations are strong and accentuated enough to create density bridges as an indication of covalency [58].

An evaluation of $\rho\left(r_{c}\right)$ and $\nabla^{2} \rho\left(r_{c}\right)$ at the saddle points between the $\mathrm{SiO}$ and $\mathrm{BO}$ bonds indicates that these bonds in danburite $\mathrm{CaB}_{2} \mathrm{Si}_{2} \mathrm{O}_{8}$ are of intermediate bond type between ionic and covalent while the $\mathrm{CaO}$ bond is indicated to be predominantly ionic in character [59]. A similar analysis for $\mathrm{BeO}$ indicates that the $\mathrm{BeO}$ bond is more ionic in character than the $\mathrm{SiO}$ and the $\mathrm{BO}$ bonds but more covalent than the $\mathrm{CaO}$ bond, as expected from electronegativity considerations [60].

Tsirelson et al. [57] used the $\mathrm{K}$ model to describe the ED distribution in $\mathrm{MgO}$. Interionic charge transfer was found, resulting in ionic charges of $\pm 1.36 e$. In spite of the large uncertainty in the charges resulting from the large correlation in the refinement, these values are close to the charges obtained by direct integration of the ED by Vidal-Valat et al. [56]: $+1.36 e$ cation and $-1.14 e$ anion and agree well with the results of a model $\mathrm{K}$ refinement of the $\mathrm{ED}$ of the $\mathrm{MgO}$ molecule [61]. Nevertheless, the value of the mean inner-cell electrostatic potential, $15.05 \mathrm{~V}$ calculated from the model of the ED according to reference [62], is between the holographic experimental value of $13.01 \mathrm{~V}$ and the neutral-atom procrystal value of $18.41 \mathrm{~V}$. This means that the ionicity of the bond in $\mathrm{MgO}$ crystal is underestimated by the $\mathrm{K}$ model fitted to the $\mathrm{X}$-ray structure amplitudes [63].

\subsubsection{Silicates}

Compared with the previous studies of the natural zeolites natrolite [75] and scolecite [76], which both belong to the tectosilicate group and display connected Si and Al tetrahedra in helicoidal chains, the study of spodumene and topaz should provide an insight on the charge density of the $\mathrm{Al}$ octahedra in aluminosilicates materials [77]. 


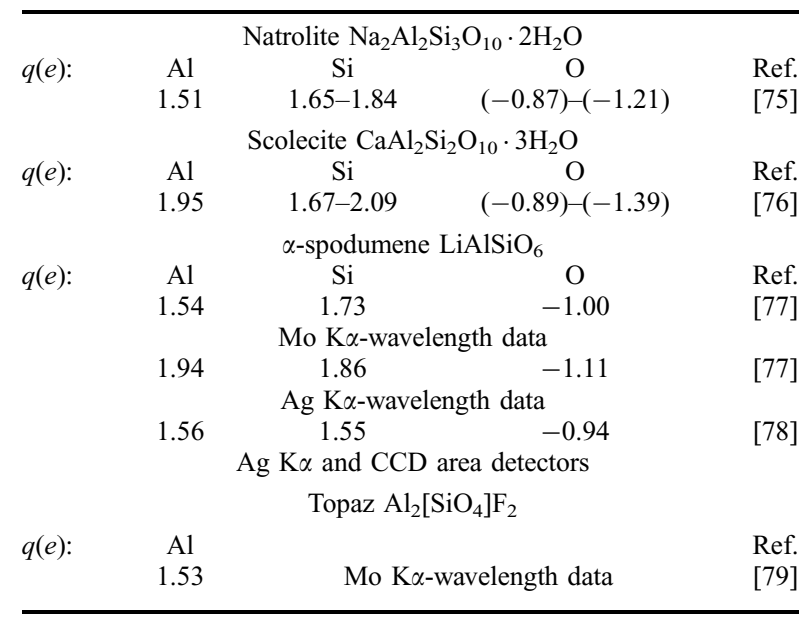

The study of the nature of the $\mathrm{Si}-\mathrm{O}$ bond through analysis of its charge density is based on net ionic charges, heights of peaks in atom deformation density maps and, more recently, topological analysis of the total charge density.

There is a considerable spread in the reported net charges on $\mathrm{Si}$ and $\mathrm{O}$, in part because of variations in bonding, but also because basis-functions may vary between analyses. However, the $\mathrm{K}$ refinement of experimental data provides a standard for comparison of $\mathrm{Si}$ and $\mathrm{O}$ atoms in different bonding environments. Net charges on the oxygen and silicon are similar in orthosilicates and the chain-structure pyroxenes: respectively $\sim-1.3 e$ and $2.3 e$ (Tab. IV). The analysis of the radial density distribution does not give a uniform approach to the separation of atoms in the molecule and crystal position space. Moreover, with increasing bond covalency, part of the ED is out of the atomic spheres. Nevertheless, Sasaki [68] came to the conclusion that the same cation in different compounds has nearly the same separation radius. These radii systematically exceed the values of both classical and Shannon crystal radii [80]. Consequently, the atomic net charges derived with these radii should be considered cautiously, in comparison with those observed in aluminosilicates.

The framework silicates lack counterions, therefore two oxygen charges must exactly counterbalance the charge on silicon, leading to lower net oxygen charges. The reanalysis of the data on coesite [81], a high pressure of $\mathrm{SiO}_{2}$, by Downs [82], gives an average oxygen net charge of $-0.74 e$ for the five non-equivalent oxygen atoms. The oxygen charges in stishovite (Tab. IV) show that the rutile-type structure of stishovite is more ionic than the low-pressure tetrahedral structure. The topological analysis of the total density has the advantage of being independent of a reference model. In coesite, the bond critical points are found at about $0.67 \AA$ from $\mathrm{Si}$ and $\sim 0.94 \AA$ from $\mathrm{O}$, in contrast to the deformation density peaks which are closer to the oxygen atoms. The values of $\nabla^{2} \rho$ at the bond critical point are positive. Positive values are not typical for pure covalent bonds, and indicate a significant ionic contribution to the $\mathrm{Si}-\mathrm{O}$ bonding in silicates [83].

\subsubsection{3d-Metal Oxides}

The estimation of atomic charges by the X-ray method for some $3 d$-metal oxides is presented below. 


\begin{tabular}{|c|c|c|c|c|c|c|c|c|c|c|}
\hline \multirow{4}{*}{$\begin{array}{l}q_{M}(e) \\
\text { Ref. }\end{array}$} & \multirow{3}{*}{$\begin{array}{c}\mathrm{Ti}_{2} \mathrm{O}_{3} \\
0.84^{*}\end{array}$} & \multirow{3}{*}{$\frac{\mathrm{V}_{2} \mathrm{O}_{3}}{1.07^{*}}$} & & & \multicolumn{2}{|c|}{$\mathrm{Fe}_{3} \mathrm{O}_{4}$} & \multirow[b]{2}{*}{$\mathrm{MnO}$} & \multirow[b]{2}{*}{$\mathrm{CoO}$} & \multirow[b]{2}{*}{$\mathrm{NiO}$} & \multirow[b]{2}{*}{$\mathrm{Cu}_{2} \mathrm{O}$} \\
\hline & & & \multicolumn{2}{|c|}{$\mathrm{Fe}_{2} \mathrm{O}_{3}$} & Tetra & Octa & & & & \\
\hline & & & $1.05^{*}$ & $0.90 *$ & 1.93 & 1.47 & 1.51 & 1.4 & 0.90 & 0.60 \\
\hline & [84] & [84] & [84] & {$[85]$} & [86] & & [69] & [55] & [55] & [73] \\
\hline
\end{tabular}

*Deduced from cation $3 d$-orbital electron population.

The charge values obtained for $\mathrm{Mn}, \mathrm{Co}$ and $\mathrm{Ni}$ cations in silicates and monoxides are all less ionic than $\mathrm{Mg}$ cations in the corresponding compounds. The charge difference between the $\mathrm{A}$ and $\mathrm{B}$ sites in magnetite is $0.46 e$ and coincides very well with an ideal difference of $0.5 e$ in agreement with the commonly accepted concept of mixed-valence oxide.

The experimental determination of the charge density in rutile, $\mathrm{TiO}_{2}$ has been the object of several publications. Gonschorek $[87,88]$ concluded from his room-temperature study using four crystals and $\mathrm{Pd}$-filtered $\mathrm{Ag} \mathrm{K} \alpha$ radiation that the $\mathrm{Ti}-\mathrm{O}$ bonds are highly covalent. However, the difference Fourier and deformation maps appear to show important differences between the inequivalent $\mathrm{Ti}-\mathrm{O}$ bonds: the main density maxima are near the short equatorial ones and the axial bond does not show a density maximum. Restori's study [89] revealed that invariant features of the resulting static deformation maps are: residual density maxima of about $0.3 e \AA^{-3}$ on both types of $\mathrm{Ti}-\mathrm{O}$ bonds and a region of negative density at Ti indicating an electron transfer from $\mathrm{Ti}$ to $\mathrm{O}$.

The recent synchrotron $\mathrm{X}$-ray studies of C-type rare earth oxides and $R \mathrm{FeO}_{3}$ oxides $(R=\mathrm{Y}$, Ho, $\mathrm{Nd}$ and Dy) [90-94] indicate that, in compounds with a high heavy atom content, the basic question of the feasibility of an experimental charge-density study has not yet been unambiguously answered.

The cation $3 d$-orbital electron populations for $3 d$-metal sesquioxides $\left(\mathrm{Ti}_{2} \mathrm{O}_{3}, \mathrm{~V}_{2} \mathrm{O}_{3}\right.$ and $\mathrm{Fe}_{2} \mathrm{O}_{3}$ ) [84] indicate a more covalent character of the $M-\mathrm{O}$ bonds than that deduced from the Mulliken population data of electron charge distribution obtained by means of a periodic unrestricted Hartree-Fock study (see the next section).

\subsection{Study of Covalency of $3 d^{3}, 3 d^{5}$ and $3 d^{8}$ Systems by Neutron Diffraction}

Valuable information on charge distribution is provided by polarized neutron scattering experiments. These allow one to obtain maps of unpaired spin density, which may be related to covalency parameters [95]. The method has been especially useful for covalency in transition metal oxides and fluorides $[96,97]$. However, the method is confined to studies of openshell systems, and it yields information on spin delocalisation only on the partially filled orbitals. As such, the technique is clearly limited. Spin-resonance techniques (EPR and ENDOR) similarly yield information on unpaired spin distributions $[98,99]$. Both neutron and spinresonance methods give useful upper bounds on covalency in the nearly ionic limit. Most results are for the spin-only $d^{8}, d^{5}$ and $d^{3} 3 d$-transition metal ions (Tab. V(a)-V(c)).

If there are $n \mathrm{e}_{\mathrm{g}}$ and $m \mathrm{t}_{2 \mathrm{~g}}$ antibonding electrons then neglecting $2 s$ covalency, the net charge transfer $C$ towards the metal is:

$$
\begin{aligned}
& C=\lambda_{\sigma}^{2}(4-n)+\lambda_{\pi}^{2}(6-m) \\
& f_{\sigma}=\frac{1}{3} \lambda_{\sigma}^{2}, \quad f_{s}=\frac{1}{3} \lambda_{s}^{2}, \quad f_{\pi}=\frac{1}{4} \lambda_{\pi}^{2} .
\end{aligned}
$$

The data presented in Tables $\mathrm{V}(\mathrm{a})$ and $\mathrm{V}(\mathrm{b})$ show there is no significant difference in covalency parameters for $\mathrm{Mn}^{2+}-\mathrm{F}^{-}$and $\mathrm{Mn}^{2+}-\mathrm{O}^{2-}$. This agrees with the neutron diffraction data for $\mathrm{NiO}$. Although $f_{\sigma}$ is much less than for $\mathrm{Ni}^{2+}$, the total ligand-to-metal charge transfer 


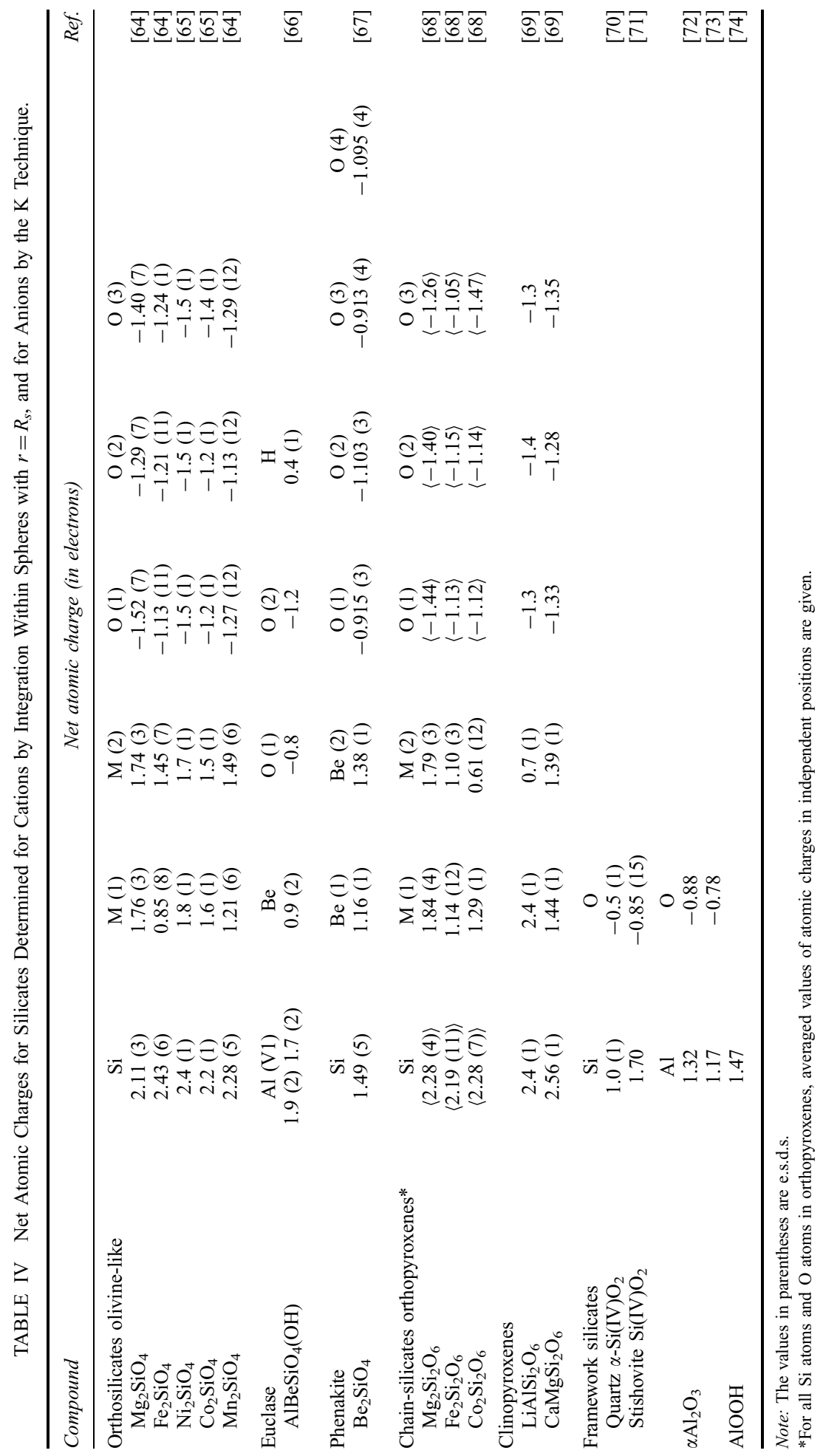


TABLE V (a) Spin Transfer Coefficients for $\mathrm{Ni}^{2-}$.

\begin{tabular}{|c|c|c|c|c|c|}
\hline & \multicolumn{2}{|c|}{ Fluorides } & & \multicolumn{2}{|r|}{ Oxides } \\
\hline & Method & Covalency & & Method & Covalency \\
\hline $\mathrm{KNiF}_{3}$ & Neutrons [100] & $f_{\sigma}+f_{s}=2.6 \%$ & $\mathrm{NiO}$ & Neutrons [102] & $f_{\sigma}+f_{s}=3.8 \%$ \\
\hline $\mathrm{KNiF}_{3}$ & NMR [101] & $f_{\sigma}=3.8 \%, f_{s}=0.54 \%$ & $\mathrm{MgO}$ & ENDOR [103] & $f_{\sigma}=8.5 \%, f_{s}=0.7 \%$ \\
\hline $\mathrm{KMgF}_{3}$ & EPR [98] & $f_{\sigma}=3.1 \%, f_{s}=0.53 \%$ & & & \\
\hline
\end{tabular}

by $\sigma$ and $\pi$ bonding is very similar for the two ions: $\sim 0.2 e$. A charge transfer of $\sim 0.9 e$ has been estimated for low spin $\mathrm{Ni}^{3+}$ in $\mathrm{MgO}$.

For $\mathrm{Fe}^{3+}$ this similarity for fluoride and oxide coordination no longer holds, as might be expected in a more covalent, higher oxidation state situation. Such an effect was observed also for $\mathrm{Cr}^{3+}$ (charge transfer $\sim 0.6 e$ for fluoride and $\sim 0.9 e$ for oxide) but in contrast to $\mathrm{Cr}^{3+}$ the covalent interaction for $\mathrm{Fe}^{3+}$ is a predominantly $\sigma$-bonding one. Apparently the relative importance of ligand-to-metal $\pi$-bonding decreases sharply across the first transition series, especially for divalent or higher oxidation state ions. As expected, both $\mathrm{Fe}^{3+}$ fluorides and oxides are considerably more covalent than the $\mathrm{Mn}^{2+}$ compounds. Charge transfers of $\sim 0.4 e$ and $\sim 0.8 e$, respectively, are estimated.

Studies of $\mathrm{Fe}^{3+}$ tetrahedral $[108,109]$ indicate that the covalency per bond is greater for the tetrahedral situation than for the octahedral one.

\subsection{Ionic Charges Derived from Ligand Filled Spectroscopy}

The Racah parameter $B$ for a specific ion is known to vary as a function of the ligands bound to that ion. The value of this parameter is always reduced from that observed with the free spherical ion. The reduction of $B$ has been explained by certain covalency effects. Measured values of $B$ for complexed metal ions are very useful in discussing the ionic/covalent nature of the bond and for estimating the magnitude of the positive and negative charges borne by the ions. The extent to which $B$ falls depends on both the metal ion and the surrounding ligands. However, irrespective of the metal ion, it is nearly always found that $B$ decreases progressively for the same sequence of ligands, which is known as the nephelauxetic series.

In interpreting such data it is necessary to take note of the fact that it is possible to postulate two types of contribution towards the nephelauxetic effect - central field covalency, and symmetry restricted covalency. The former relates to the screening effect of the ligands on the central field of the metal cation which results in a decrease of the effective positive charge on the metal and a consequent expansion of the radial function, whilst the latter arises from the actual involvement of the metal, $\mathrm{t}_{2 \mathrm{~g}}$ and $\mathrm{e}_{\mathrm{g}}$ orbitals in molecular orbital formation with ligand orbital combinations of the appropriate symmetry, which should also lead to a reduction in the parameters of inter-electronic repulsion. The relative contributions which these two effects are postulated to make will considerably influence the conclusions which may be drawn concerning effective charge densities on the metal.

In LCAO description symmetry restricted covalency may be represented as $\psi_{\mathrm{MO}}=a \psi_{d}+$ $b \psi_{\text {ligands }}$ where $\psi_{d}$ is a metal $d$ orbital $\left(\mathrm{e}_{\mathrm{g}}\right.$ or $\left.\mathrm{t}_{2 \mathrm{~g}}\right), \psi_{\text {ligands }}$ is an appropriate matching ligand orbital combination, and $a$ and $b$ are their respective contributing coefficients, usually known as the Stevens' [111] delocalisation coefficients.

Although it is possible to argue that central-field covalency arises only as a necessary consequence of the bonding of the ligand, i.e. as a result of symmetry restricted covalency, 


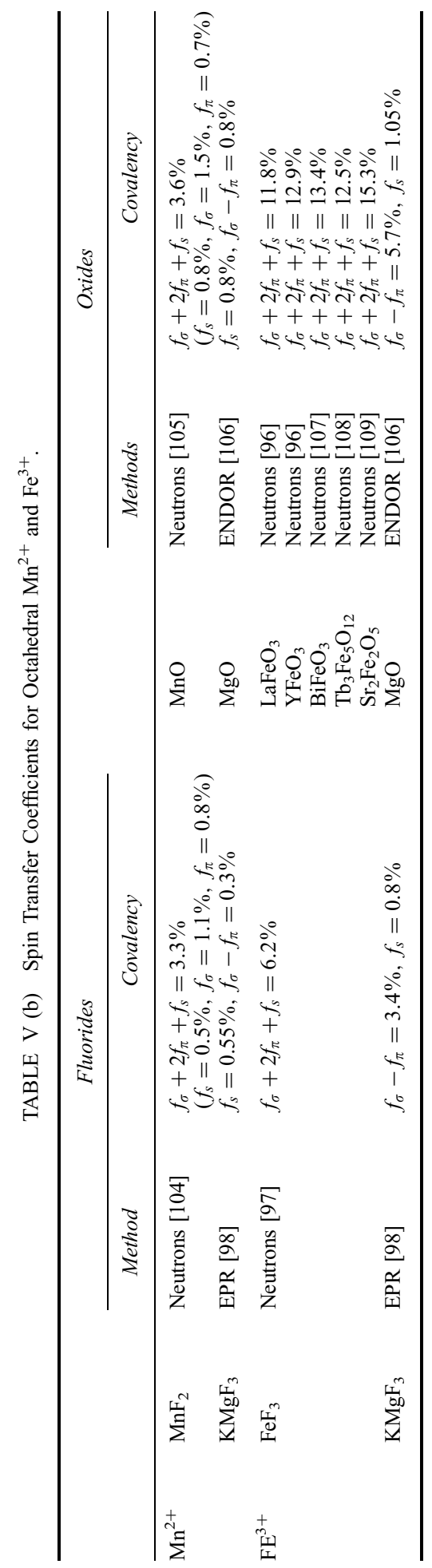




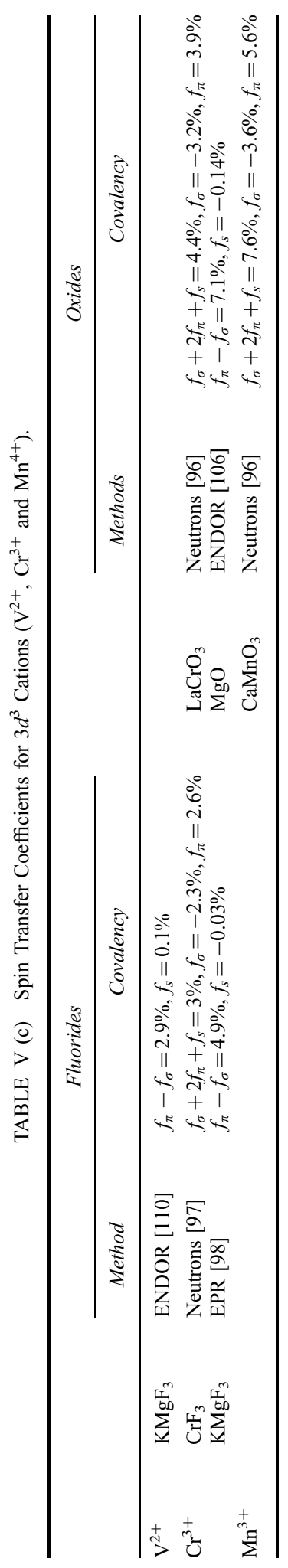


it is nevertheless highly desirable that we should be able to make some attempt to assess the relative magnitudes of their respective contributions. Unfortunately, this is far from being a simple matter. Jørgensen [112] has shown that for a gaseous ion the $F_{K}$ parameters, and hence $B$, show an approximate proportionality to $(z+Z)$ where $z$ is the ionic charge and $Z$ a small constant, whilst in a complex the corresponding proportionality is to $a^{4}\left(z_{\text {eff }}+Z\right)$, where $a$ is the Stevens' delocalisation coefficient, and $z_{\text {eff }}$ is the effective cationic charge in the complex. Since $z_{\text {eff }}$ will depend upon the extent of the central-field covalency it is clear that we cannot ascribe all the reduction in $B$, below the gas phase value, to symmetry restricted covalency, yet on the other hand we must not assume that all the nephelauxetic effect arises from the reduction of $z$ to $z_{\text {eff }}$ occasioned by the central-field effect.

However, these two extreme assumptions do enable us to obtain the limiting possibilities for any given complex. Thus, if we interpret $\beta$ as arising solely from central-field effects we can derive the minimum value of $z_{\text {eff }}$ for the complex, whilst conversely, if $\beta$ is assumed to be due only to symmetry restricted covalency we shall obtain the minimum value for the coefficient of presence, $a^{2}$, for the metal atom wave-function. In this connection it is well to remember that the Stevens' coefficients $a$ and $b$ are not strictly normalized by the relationship $a^{2}+b^{2}=1$, since the metal and ligand orbitals are not orthogonal, even though $S$ is usually quite small.

Jørgensen [112] has though proposed that a reasonable solution to the problem is to assume that central-field and symmetry restricted covalency are of equal importance and to assign $(\beta)^{1 / 2}$ to each of the two effects, thus obtaining intermediate values of $z_{\text {eff }}$ and $a^{2}$ as compared with the two extreme cases cited above. It is worth nothing here that a rough justification of the $(\beta)^{1 / 2}$ approximation can in fact be derived from results of octahedral $d^{3}$ systems [113, 114].

The purpose of this section is to show that the physical interpretation of the Racah parameter in terms of so-called covalency effects should be viewed with some caution: the inductive effect and the influence of magnetic interactions should be taken into account.

The $B$ values have been selected from the literature as follows: on the one hand, we have wished to include in Tables VI(a) and VI(b) the largest number of values but, on the other, we discarded unreliable data which might have masked eventual trends in the the Racah parameters. Therefore, whenever the reported values were too imprecise or whenever they derived from bands whose assignments seemed doubtful, they were not tabulated. One may reasonably argue that the greater reduction in $B$ as represented by the nephelauxetic ratio $\beta=B$ (in compound) $/ B$ (in free ion), the greater the covalency in the metal-ligand bond and the smaller the effective charge experienced by the $d$ electrons. Reduction in charge at the central ion is marked even for highly electronegative ligands such as fluoride ion. The reduction is much more marked even with the more polarisable ligand and the more polarizing cations, since it is this combination which gives rise to the greatest degree of covalency.

The purpose of this study is to establish the evidence of a new correlation between the Racah parameter and the inductive effect. The concept of the inductive effect, which is known in organic chemistry as the polarization of one bond caused by the polarization of an adjacent one, was first extended to silicates in order to explain small differences in average $\mathrm{Si}-\mathrm{O}$ bond lengths [166]. Shannon [167] interpreted the small variations of the average $\mathrm{Ge}-\mathrm{O}$ distances in germanates based upon the same principle.

An estimated approximation of the inductive effect of the $A^{m+}-\mathrm{O}$ bond on the $M^{n+}-\mathrm{O}$ in an $A_{x}^{m+} M_{y}^{n+} \mathrm{O}_{z}$ compound (mixed oxide or oxysalt) can be obtained from the difference between the polarizing power of $M^{n+}$ and that of $A^{m+}$. According to this definition, a large 
TABLE VI (a) Nephelauxetic Ratios $\beta$ and Charges $Z_{\text {eff }}$ (According to the Jørgensen's Compromise) Defined in the Text for Selected $3 d^{3}$ and $3 d^{5}$ Group Compounds.

\begin{tabular}{|c|c|c|c|c|c|c|c|}
\hline & $\beta_{35}$ & $Z_{\text {eff }}$ & Ref. & & $\beta_{35}$ & $Z_{\text {eff }}$ & Ref. \\
\hline \multicolumn{8}{|c|}{$3 d^{3}$} \\
\hline $\mathrm{Cr}(\mathrm{III}) \mathrm{O}_{6}$ & & & & $\mathrm{Cr}(\mathrm{III}) \mathrm{O}_{6}$ & & & \\
\hline \multirow{4}{*}{$\mathrm{Al}_{2} \mathrm{O}_{3}: \mathrm{Cr}^{3+}$} & 0.70 & 1.80 & [115] & $\mathrm{Li}_{0.5} \mathrm{Al}_{2.5} \mathrm{O}_{4}: \mathrm{Cr}^{3+*}$ & 0.81 & 2.15 & {$[121]$} \\
\hline & 0.70 & 1.80 & [116] & $\mathrm{Li}_{0.5} \mathrm{Ga}_{2.5} \mathrm{O}_{4}: \mathrm{Cr}^{3+*}$ & 0.80 & 2.10 & {$[121]$} \\
\hline & 0.73 & 1.90 & [117] & $\mathrm{Li}_{0.5} \mathrm{Ga}_{0.5} \mathrm{Cr}_{2} \mathrm{O}_{4}$ & 0.62 & 1.45 & {$[121]$} \\
\hline & 0.705 & 1.80 & [118] & $\mathrm{Y}_{3}\left(\mathrm{Al}_{1.8} \mathrm{Cr}_{0.2}\right) \mathrm{Al}_{3} \mathrm{O}_{12}$ & 0.72 & 1.85 & {$[117]$} \\
\hline $\mathrm{Ga}_{2} \mathrm{O}_{3}: \mathrm{Cr}^{3+}$ & 0.68 & 1.75 & [117] & $\mathrm{Y}_{3} \mathrm{Cr}_{2} \mathrm{Al}_{3} \mathrm{O}_{12}$ & 0.65 & 1.60 & {$[117]$} \\
\hline \multirow[t]{4}{*}{$\mathrm{MgO}: \mathrm{Cr}^{3+}$} & 0.69 & 1.75 & [119] & $\mathrm{Y}_{3} \mathrm{Ga}_{5} \mathrm{O}_{12}: \mathrm{Cr}^{3+}$ & 0.705 & 1.80 & {$[125]$} \\
\hline & 0.705 & 1.80 & [116] & $\mathrm{Y}_{3} \mathrm{Cr}_{2} \mathrm{Ga}_{3} \mathrm{O}_{12}$ & 0.68 & 1.75 & {$[117]$} \\
\hline & 0.705 & 1.80 & [118] & $\mathrm{Ca}_{3} \mathrm{Al}_{1.7} \mathrm{Cr}_{0.3} \mathrm{Ga}_{3} \mathrm{O}_{12}^{*}$ & 0.78 & 2.05 & {$[117]$} \\
\hline & 0.705 & 1.80 & [120] & $\mathrm{Be}_{3} \mathrm{Al}_{2} \mathrm{Si}_{6} \mathrm{O}_{18}: \mathrm{Cr}^{3+*}$ & 0.85 & 2.35 & {$[126]$} \\
\hline \multirow[t]{2}{*}{$\mathrm{Cr}_{2} \mathrm{O}_{3}$} & 0.51 & 1.05 & [117] & & 0.77 & 2.05 & {$[115]$} \\
\hline & 0.52 & 1.10 & [121] & $\mathrm{Cr}(\mathrm{III}) \mathrm{F}_{6}$ & & & \\
\hline $\mathrm{LaCrO}_{3}$ & 0.55 & 1.20 & [117] & $\mathrm{K}_{3} \mathrm{CrF}_{6}$ & 0.81 & 2.15 & {$[127]$} \\
\hline $\mathrm{YCrO}_{3}$ & 0.59 & 1.35 & [117] & $\mathrm{K}_{2} \mathrm{NaCrF}_{6}$ & 0.83 & 2.25 & {$[116]$} \\
\hline \multirow{2}{*}{$\mathrm{MgAl}_{2} \mathrm{O}_{4}: \mathrm{Cr}^{3+}$} & 0.705 & 1.80 & {$[122]$} & $\mathrm{CrF}_{6}^{3-}$ & 0.80 & 2.10 & {$[128]$} \\
\hline & 0.76 & 2 & [123] & $\mathrm{CrF}_{3}$ & 0.805 & 2.10 & {$[116]$} \\
\hline $\mathrm{MgAl}_{1.7} \mathrm{Cr}_{0.3} \mathrm{O}_{4}$ & 0.73 & 1.90 & [117] & $\mathrm{Cr}(\mathrm{III}) \mathrm{Cl}_{6}$ & & & \\
\hline \multirow[t]{2}{*}{$\mathrm{MgCr}_{2} \mathrm{O}_{4}$} & 0.685 & 1.70 & [117] & $\mathrm{CrCl}_{3}$ & 0.59 & 1.3 & {$[116]$} \\
\hline & 0.66 & 1.60 & [121] & $\mathrm{Cr}(\mathrm{III}) \mathrm{Br}_{6}$ & & & \\
\hline $\mathrm{MgGa}_{2} \mathrm{O}_{4}: \mathrm{Cr}^{3+}$ & 0.69 & 1.75 & [121] & $\mathrm{CrBr}_{3}$ & 0.40 & 0.7 & {$[116]$} \\
\hline $\mathrm{ZnAl}_{2} \mathrm{O}_{4}: \mathrm{Cr}^{3+}$ & 0.76 & 2 & [118] & $\mathrm{Cr}(\mathrm{III}) \mathrm{S}_{6}$ & & & \\
\hline $\mathrm{ZnGa}_{2} \mathrm{O}_{4}: \mathrm{Cr}^{3+}$ & 0.73 & 1.90 & [124] & $\mathrm{ZnAl}_{2} \mathrm{~S}_{4}: \mathrm{Cr}^{3+}$ & 0.39 & 0.7 & {$[129]$} \\
\hline $\mathrm{ZnGa}_{1.6} \mathrm{Cr}_{0.4} \mathrm{O}_{4}$ & 0.72 & 1.85 & [117] & $\mathrm{ZnCr}_{2} \mathrm{~S}_{4}$ & 0.40 & 0.7 & {$[121]$} \\
\hline \multirow[t]{2}{*}{$\mathrm{ZnCr}_{2} \mathrm{O}_{4}$} & 0.70 & 1.80 & [117] & $\mathrm{NaCrS}_{2}$ & 0.49 & 0.95 & {$[121]$} \\
\hline & 0.66 & 1.60 & [121] & & & & \\
\hline \multicolumn{8}{|c|}{$3 d^{5}$} \\
\hline \multirow{4}{*}{$\begin{array}{c}\mathrm{Mn}(\mathrm{II}) \mathrm{O}_{6} \\
\mathrm{MnO}\end{array}$} & & & & $\mathrm{Mn}(\mathrm{II}) \mathrm{F}_{6}$ & & & \\
\hline & 0.62 & & {$[130]$} & $\mathrm{MnF}_{2}$ & 0.74 & 1.75 & {$[135]$} \\
\hline & 0.68 & $\sim 1.50$ & [131] & $\mathrm{Mn}(\mathrm{II}) \mathrm{Cl}_{6}$ & & & \\
\hline & 0.71 & & [132] & $\mathrm{MnCl}_{2}$ & 0.66 & 1.50 & {$[136]$} \\
\hline $\mathrm{MgAl}_{2} \mathrm{O}_{4}: \mathrm{Mn}^{2+}$ & 0.72 & 1.70 & [122] & $\mathrm{Mn}(\mathrm{II}) \mathrm{Br}_{6}$ & & & \\
\hline $\mathrm{MnSiO}_{3}^{*}$ & 0.70 & 1.60 & [133] & $\mathrm{MnBr}_{2}$ & 0.60 & 1.20 & {$[136]$} \\
\hline $\mathrm{Mn}_{2} \mathrm{SiO}_{4}$ & 0.68 & 1.50 & [134] & & & & \\
\hline
\end{tabular}

*Compounds which exhibit the largest $\beta_{35}$ ratios due to the inductive effect.

ionic character of the $M-\mathrm{O}$ bond should result from the following properties of the $A$ element:

- a large nominal charge: $\mathrm{S}^{6+}, \mathrm{Mo}^{6+}, \mathrm{P}^{5+}$,

- a small ionic radius: $\mathrm{B}^{3+}, \mathrm{S}^{6+}, \mathrm{P}^{5+}, \mathrm{Si}^{4+}$,

- a small coordination number, e.g. 4 for $\mathrm{S}^{6+}, \mathrm{Mo}^{6+}, \mathrm{P}^{5+}, \mathrm{Si}^{4+}$.

It can be readily seen that the three criteria are found together only in sulfates and phosphates. These oxysalts are precisely those which exhibit the largest nephelauxetic ratios.

To determine the correlation between $B$ and the inductive effect, we introduce the ionic-covalent parameter corresponding to the next nearest neighbors, $I C P_{\mathrm{nn}}$ and the global basicity $\Lambda_{\mathrm{th}} . B / I C P_{\mathrm{nn}}$ and $B / \Lambda$ correlations have been established for the following electronic configurations $3 d^{3}, 3 d^{7}$ tetrahedral and $3 d^{8}[168]$.

Menil [169] has shown that most of the ${ }^{57} \mathrm{Fe}$ Mössbauer isomer shifts in $\left(\mathrm{FeO}_{n}\right)$ and $\left(\mathrm{FeF}_{n}\right)$ polyhedra can be interpreted with the help of the concept of the inductive effect of the competing bond. 
TABLE VI (b) Nephelauxetic Ratios $\beta$ and Charges $Z_{\text {eff }}$ (According to the Jørgensen's Compromise) Defined in the Text for Selected $3 d^{7}$ and $3 d^{8}$ Group Compounds.

\begin{tabular}{|c|c|c|c|c|c|c|c|}
\hline & $\beta_{35}$ & $Z_{\text {eff }}$ & Ref. & & $\beta_{35}$ & $Z_{\text {eff }}$ & Ref. \\
\hline \multicolumn{8}{|c|}{$3 d^{7}$} \\
\hline \multirow{4}{*}{$\begin{array}{l}\mathrm{Co}(\mathrm{II}) \mathrm{O}_{6} \\
\quad \mathrm{MgO}: \mathrm{Co}^{2+}\end{array}$} & & & & $\mathrm{Co}(\mathrm{II}) \mathrm{O}_{4}$ & & & \\
\hline & 0.845 & 1.45 & {$[137]$} & $\mathrm{ZnO}: \mathrm{Co}^{2+}$ & 0.80 & 1.30 & [145] \\
\hline & 0.845 & 1.45 & [138] & & 0.78 & 1.25 & [146] \\
\hline & 0.84 & 1.45 & [139] & $\mathrm{MgAl}_{2} \mathrm{O}_{4}: \mathrm{Co}^{2+}$ & 0.84 & 1.45 & [147] \\
\hline $\mathrm{CoO}$ & 0.79 & 1.25 & [121] & & 0.825 & 1.40 & [122] \\
\hline $\mathrm{Co}_{2} \mathrm{GeO}_{4}^{*}$ & 0.845 & 1.45 & [140] & $\mathrm{ZnAl}_{2} \mathrm{O}_{4}: \mathrm{Co}^{2+}$ & 0.815 & 1.35 & [148] \\
\hline $\mathrm{Co}_{2} \mathrm{SiO}_{4}^{*}$ & 0.855 & 1.50 & [141] & $\mathrm{CoAl}_{2} \mathrm{O}_{4}$ & 0.815 & 1.35 & [121] \\
\hline $\mathrm{ZnWO}_{4}, \mathrm{MgWO}_{4}: \mathrm{Co}^{2+}$ & 0.83 & 1.40 & [142] & $\mathrm{CoGa}_{2} \mathrm{O}_{4}$ & 0.81 & 1.35 & [121] \\
\hline $\mathrm{Ba}\left(\mathrm{Co}_{0.1} \mathrm{Zn}_{0.4} \mathrm{~W}_{0.5}\right) \mathrm{O}_{3}$ & 0.80 & 1.30 & [143] & $\mathrm{CoCr}_{2} \mathrm{O}_{4}$ & 0.79 & 1.25 & [121] \\
\hline $\mathrm{CoWO}_{4}$ & 0.79 & 1.25 & {$[144]$} & $\mathrm{Co}_{0.05} \mathrm{Zn}_{1.95} \mathrm{GeO}_{4}$ & 0.79 & 1.25 & [143] \\
\hline \multicolumn{4}{|l|}{$\mathrm{Co}(\mathrm{II}) \mathrm{F}_{6}$} & $\mathrm{Co}(\mathrm{II}) \mathrm{Br}_{6}$ & & & \\
\hline $\mathrm{KCoF}_{3}$ & 0.91 & $\sim 1.70$ & {$[144]$} & $\mathrm{CoBr}_{2}$ & 0.78 & $\sim 1.25$ & [116] \\
\hline $\mathrm{KMgF}_{3}: \mathrm{Co}^{2+}$ & 0.94 & 1.80 & [144] & $\mathrm{Co}(\mathrm{II}) \mathrm{S}_{4}$ & & & \\
\hline $\mathrm{LiF}: \mathrm{Co}^{2+}$ & 0.94 & 1.80 & [139] & $\mathrm{ZnS}: \mathrm{Co}^{2+}$ & 0.63 & $\sim 0.80$ & [145] \\
\hline \multicolumn{8}{|l|}{$\mathrm{Co}(\mathrm{II}) \mathrm{Cl}_{6}$} \\
\hline \multirow[t]{2}{*}{$\mathrm{CoCl}_{2}$} & 0.80 & $\sim 1.30$ & [116] & & & & \\
\hline & & & $3 d^{8}$ & & & & \\
\hline \multicolumn{4}{|l|}{$\mathrm{Ni}(\mathrm{II}) \mathrm{O}_{6}$} & $\mathrm{Ni}(\mathrm{II}) \mathrm{O}_{4}$ & & & \\
\hline $\mathrm{MgO}: \mathrm{Ni}^{2+}$ & 0.83 & 1.425 & [149] & $\mathrm{ZnO}: \mathrm{Ni}^{2+}$ & 0.74 & 1 & {$[156]$} \\
\hline $\mathrm{NiO}$ & 0.77 & 1.20 & {$[150,151]$} & & 0.75 & 1.05 & [157] \\
\hline $\mathrm{MgAl}_{2} \mathrm{O}_{4}: \mathrm{Ni}^{2+}$ & 0.865 & 1.575 & {$[152]$} & & 0.75 & 1.05 & [158] \\
\hline $\mathrm{NiAl}_{2} \mathrm{O}_{4}$ & 0.84 & 1.475 & [152] & & 0.775 & 1.20 & [152] \\
\hline $\mathrm{NiGa}_{2} \mathrm{O}_{4}$ & 0.845 & 1.5 & [153] & $\mathrm{Mg}_{0.9} \mathrm{Ni}_{0.1} \mathrm{Al}_{2} \mathrm{O}_{4}$ & 0.80 & 1.30 & [152] \\
\hline $\mathrm{Ni}_{0.75} \mathrm{Zn}_{1.25} \mathrm{GeO}_{4}$ & 0.83 & 1.425 & {$[143]$} & $\mathrm{NiAl}_{2} \mathrm{O}_{4}$ & 0.79 & 1.25 & {$[152]$} \\
\hline $\mathrm{Ni}_{2} \mathrm{GeO}_{4}$ & 0.83 & 1.425 & [121] & $\mathrm{Li}_{0.5} \mathrm{Ni}_{0.5} \mathrm{Cr}_{1.5} \mathrm{Ge}_{0.5} \mathrm{O}_{4}^{*}$ & 0.82 & 1.35 & [159] \\
\hline $\mathrm{Mg}_{1.5} \mathrm{Ni}_{0.5} \mathrm{SnO}_{4}$ & 0.84 & 1.475 & [149] & $\mathrm{Ni}_{1.8} \mathrm{Cr}_{0.4} \mathrm{Ge}_{0.8} \mathrm{O}_{4}^{*}$ & 0.82 & 1.35 & [159] \\
\hline $\mathrm{MgWO}_{4}, \mathrm{ZnWO}_{4}: \mathrm{Ni}^{2+*}$ & 0.88 & 1.65 & {$[154]$} & $\mathrm{Ni}_{1.5} \mathrm{CrGe}_{0.5} \mathrm{O}_{4}$ & 0.79 & 1.25 & [159] \\
\hline $\mathrm{CdWO}_{4}: \mathrm{Ni}^{2+*}$ & 0.855 & 1.55 & {$[154]$} & $\mathrm{NiCr}_{2} \mathrm{O}_{4}$ & 0.77 & 1.20 & [143] \\
\hline $\mathrm{NiMoO}_{4}$ & 0.855 & 1.55 & [155] & $\mathrm{Ni}_{0.05} \mathrm{Zn}_{1.95} \mathrm{GeO}_{4}^{*}$ & 0.82 & 1.35 & [143] \\
\hline $\mathrm{NiNb}_{2} \mathrm{O}_{6}$ & 0.84 & 1.475 & [149] & $\mathrm{NiCrGaO}_{4}^{*}$ & 0.82 & 1.35 & [153] \\
\hline & $\mathrm{Ni}(\mathrm{II}) \mathrm{Cl}_{6}$ & & & \\
\hline \multirow{2}{*}{$\mathrm{NiF}_{2}$} & 0.94 & 1.80 & {$[160]$} & $\mathrm{NiCl}_{2}$ & 0.79 & 1.25 & [161] \\
\hline & 0.95 & 1.85 & [161] & $\mathrm{CdCl}_{2}: \mathrm{Ni}^{2+}$ & 0.79 & 1.25 & [164] \\
\hline $\mathrm{KMgF}_{3}: \mathrm{Ni}^{2+}$ & 0.94 & 1.80 & [162] & $\mathrm{CsCdCl}_{3}: \mathrm{Ni}^{2+}$ & 0.77 & 1.20 & [165] \\
\hline $\mathrm{Ba}_{2} \mathrm{NiF}_{6}$ & 0.93 & 1.75 & [163] & $\mathrm{Ni}(\mathrm{II}) \mathrm{Br}_{6}$ & & & \\
\hline $\mathrm{KNiF}_{3}$ & 0.93 & 1.75 & {$[162]$} & $\mathrm{NiBr}_{2}$ & 0.73 & 1 & [164] \\
\hline $\mathrm{SrNiF}_{4}$ & 0.93 & 1.75 & {$[163]$} & $\mathrm{Ni}(\mathrm{II}) \mathrm{S}_{4}$ & & & \\
\hline \multirow{2}{*}{$\begin{array}{l}\mathrm{Ni}(\mathrm{II}) \mathrm{Cl}_{4} \\
\quad \mathrm{Cs}_{2} \mathrm{ZnCl}_{4}: \mathrm{Ni}^{2+}\end{array}$} & & & & $\mathrm{ZnS}: \mathrm{Ni}^{2+}$ & $\sim 0.50$ & $\sim 0.60$ & {$[145]$} \\
\hline & 0.70 & 0.95 & [145] & & & & \\
\hline
\end{tabular}

*Compounds which exhibit the largest $\beta_{35}$ ratios due to the inductive effect.

This study has been completed for iron(III) compounds by associating optical data, Mössbauer isomer shifts with structural and magnetical data (Tab. VII).

The effects of covalency and overlap distortion on the spin and charge densities in mainly ionic materials have been discussed and related to the hyperfine interactions [173]. The parameters obtained by comparing isomer shifts, hyperfine field and neutron diffraction [96] results are listed below.

\begin{tabular}{llccc}
\hline & & 3d spin & 4s occ. & Total charge \\
\hline Ferrites $\mathrm{MF}_{2} \mathrm{O}_{4}$ & $\mathrm{Fe}(B)$ & $4.62 \mu_{B}$ & 0.13 & +2.44 \\
& $\mathrm{Fe}(A)$ & $4.31 \mu_{B}$ & 0.26 & +2.02 \\
Orthoferrites & $\mathrm{MFeO}_{3}$ & $4.45 \mu_{B}$ & 0.12 & +2.23 \\
\hline
\end{tabular}




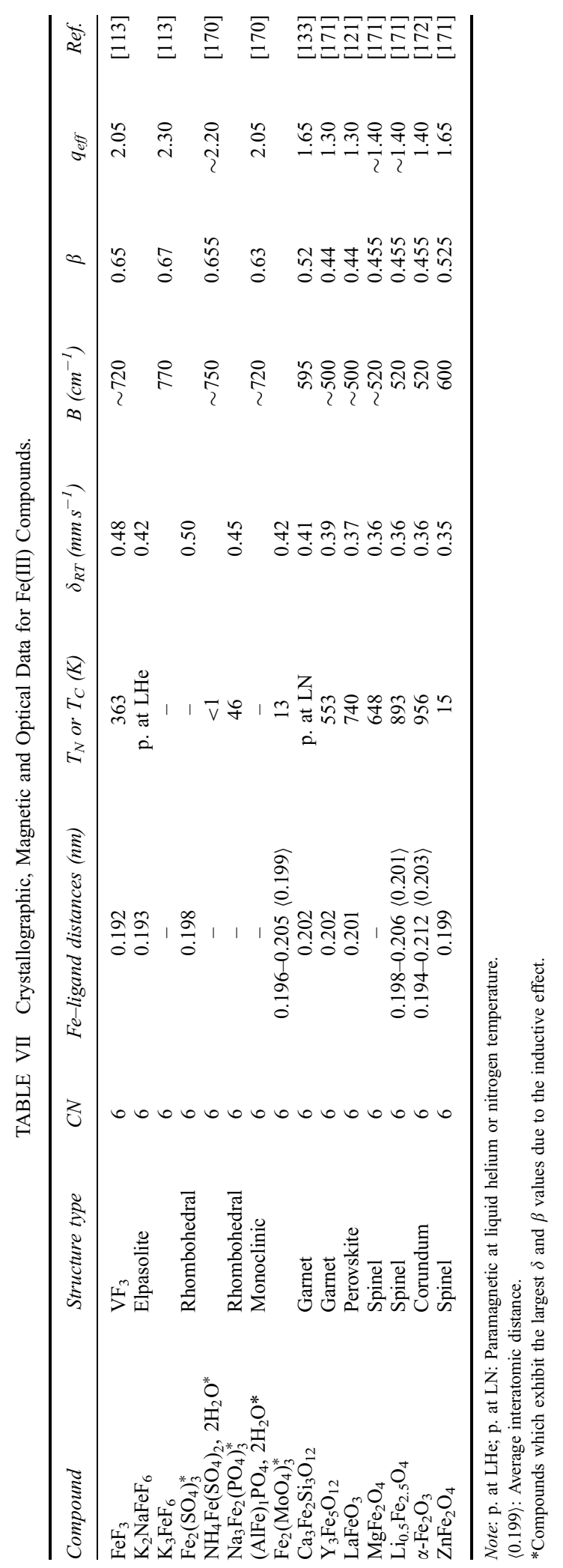


The concept of optical basicity supports the nephelauxetic ratio/inductive effect correlation. From experimental data relative to $\mathrm{M}^{n+}\left(\mathrm{Cr}^{3+}, \mathrm{Fe}^{3+}\right.$ and $\left.\mathrm{Ni}^{2+}\right)$ in octahedral coordination and $\left(\mathrm{Co}^{2+}, \mathrm{Ni}^{2+}\right)$ in tetrahedral coordination, it can be argued that the compounds with the largest $\beta_{35}$ values contain in the nearest coordination shells elements characterized by $\Lambda$ less than approximately 0.60: $\mathrm{P}^{5+}, \mathrm{W}^{6+}, \mathrm{Mo}^{6+}, \mathrm{S}^{6+}, \mathrm{Si}^{4+}$ and tetrahedral $\mathrm{Ge}^{4+}, \mathrm{Al}^{3+}, \mathrm{Ga}^{3+}$.

\subsubsection{Covalency and Magnetic Ordering}

Recent studies have revealed the influence of various antiferromagnetic interactions $\left(3 d^{3}-3 d^{3}\right.$ and $3 d^{5}-3 d^{5}$ in mixed oxides of corundum and spinel structures, $3 d_{\text {tetra }}^{5}-3 d_{\text {octa }}^{3}, 3 d^{5}-3 d^{n}$ in spinels, $3 d^{8}-3 d^{8}$ in $\mathrm{NaCl}$ structure... ) on electronic spectra of $3 d^{n}$ cations.

Several processes are observed:

- enhancement of transitions which are, in principle, both spin and parity forbidden $\left(\mathrm{Fe}^{3+}, \mathrm{Ni}^{2+}\right)$

- presence of new absorption features corresponding to the simultaneous excitations of exchange-coupled pairs of cations $\left(\mathrm{Cr}^{3+}, \mathrm{Fe}^{3+}\right)$

- growth of intense absorptions due to electron transfer: intervalence charge transfer or metal-metal charge transfer such as $\mathrm{Fe}^{2+} \rightarrow \mathrm{Fe}^{3+}, \mathrm{Co}^{2+} \rightarrow \mathrm{Fe}^{3+}, \mathrm{Ni}^{2+} \rightarrow \mathrm{Fe}^{3+}$ and $\mathrm{Cr}^{3+} \rightarrow \mathrm{Fe}^{3+}$.

A pronounced decrease of $\beta_{35}$ has been observed for $\mathrm{Cr}^{3+}, \mathrm{Fe}^{2+}, \mathrm{Co}^{2+}$ and $\mathrm{Ni}^{2+}$ due to antiferromagnetic interactions in different systems:

$-\mathrm{Al}_{2-x} \mathrm{Cr}_{x} \mathrm{O}_{3}[117]$

- $M \mathrm{CrO}_{3}(M=\mathrm{Y}, \mathrm{La})[117]$

- $\mathrm{Li}_{0.5} \mathrm{Ga}_{2.5-x} \mathrm{Cr}_{x} \mathrm{O}_{4}[174,175]$;

- $\mathrm{Li}_{0.5} \mathrm{Ga}_{2.5-x}(\mathrm{FeCr})_{x} \mathrm{O}_{4}$ [176],

$-\mathrm{Al}_{2-x} \mathrm{Fe}_{x} \mathrm{O}_{3}$, ferrites and garnets [171],

$-\mathrm{Mg}_{1-x} \mathrm{Co}_{x} \mathrm{O}[150]$,

$-\mathrm{Mg}_{1-x} \mathrm{Ni}_{x} \mathrm{O}[150,168]$

$-\mathrm{Mg}_{1-x} \mathrm{Ni}_{x} \mathrm{Al}_{2} \mathrm{O}_{4}$ [168].

These results show that the physical interpretation of the variations of the $B$ parameter in terms of so-called "covalency effects" should be viewed with some caution. The polarization of the ligand orbitals by the central ion and the next nearest neighbors is an important factor determining the magnitude of the ligand field parameters. A much closer correlation between the Racah parameters and the degree of covalency of $M-\mathrm{O}$ bonds is achieved when the inductive effect and the influence of magnetic interactions are taken into account.

\subsection{Effective Charges from Lattice Vibration Spectra}

The effective charges in solids which are directly related to the concept of ionicity may be determined using a formula established by Scott [177] in binary compounds of arbitrary complexity provided that all the transverse and longitudinal optical mode frequencies are available.

The determination of the strengths of individual bonds in solids by force-constant calculations has been performed since the early fifties. More recently, lattice dynamical calculations on spinel type $A B_{2} X_{4}(B=\mathrm{Cr}, \ln ; X=\mathrm{O}, \mathrm{S}, \mathrm{Se})$ have been obtained by various potential models (short-range model SRM, rigid-ion model RIM and polarizable-ion model PIM) [178-180]. The more significant results are listed in Tables VIII(a) and VIII(b). 
TABLE VIII (a) Effective Charges in Binary Oxides and Comparison of Reduced Effective Charge with Levine's Ionicity $f_{i}$.

\begin{tabular}{|c|c|c|c|c|}
\hline & $Z_{O x}$ & $Z / Z_{0}$ & $f_{i}$ & Ref. \\
\hline \multicolumn{5}{|l|}{$M O$} \\
\hline $\mathrm{BeO}$ & -1.03 & 0.51 & $0.620(0.75)$ & [181] \\
\hline $\mathrm{MgO}$ & -1.15 & 0.57 & 0.839 & [182] \\
\hline $\mathrm{CaO}$ & -1.2 & 0.60 & 0.916 & [183] \\
\hline $\mathrm{SrO}$ & -1.3 & 0.65 & 0.928 & [183] \\
\hline $\mathrm{BaO}$ & -1.4 & 0.70 & 0.931 & [183] \\
\hline $\mathrm{MnO}$ & -1.1 & 0.55 & 0.887 & [183] \\
\hline $\mathrm{ZnO}$ & -1.05 & 0.52 & $0.653(0.75)$ & [181] \\
\hline $\mathrm{CdO}$ & -1.2 & -0.60 & 0.778 & [183] \\
\hline \multicolumn{5}{|l|}{$M_{2} \mathrm{O}_{3}$} \\
\hline \multirow[t]{3}{*}{$\mathrm{Al}_{2} \mathrm{O}_{3}$} & -1.15 & 0.57 & & [183] \\
\hline & -0.95 & 0.47 & 0.796 & [184] \\
\hline & -1.3 & 0.65 & & [185] \\
\hline \multirow{2}{*}{$\mathrm{Cr}_{2} \mathrm{O}_{3}$} & -1.01 & 0.50 & & [183] \\
\hline & -0.93 & 0.46 & $0.777(0.70)$ & [185] \\
\hline $\mathrm{Fe}_{2} \mathrm{O}_{3}$ & -0.93 & 0.46 & $0.677(0.75)$ & [186] \\
\hline \multicolumn{5}{|l|}{$\mathrm{MO}_{2}$} \\
\hline \multirow[t]{4}{*}{$\mathrm{SiO}_{2}$} & -0.35 & 0.17 & 0.57 & [187] \\
\hline & -0.47 & 0.23 & & [188] \\
\hline & -0.35 & 0.17 & & [189] \\
\hline & -1.15 & 0.57 & & [183] \\
\hline \multirow[t]{2}{*}{$\mathrm{TiO}_{2}$} & -1.35 & 0.67 & 0.686 & [183] \\
\hline & -1.26 & 0.63 & & [190] \\
\hline $\mathrm{GeO}_{2}$ & -1.07 & 0.53 & 0.73 & [191] \\
\hline $\mathrm{SnO}_{2}$ & -1.13 & 0.57 & 0.784 & [192] \\
\hline
\end{tabular}

Note: $(0.75),(0.70)$ : modified values presented in Section 2.

The effective charges $Z_{\mathrm{Ox}}$ appear quite consistent for $M \mathrm{O}$ and $M_{2} \mathrm{O}_{3}$ oxides with Phillips' ionicity scale including the modified values presented in Section 2. These results suggest that the $M-\mathrm{O}(M=\mathrm{Mg}, \mathrm{Zn})$ bonds are more ionic in binary oxides than those in spinels in agreement with the fact that the $M-\mathrm{O}$ distances in $M \mathrm{O}$ are longer than in

TABLE VIII (b) Effective Charges in Ternary Oxides.

\begin{tabular}{ccccc}
\hline & $Z_{A}$ & $Z_{B}$ & $Z_{O x}$ & Ref. \\
\hline$A B_{2} \mathrm{O}_{4}$ & & & & \\
$\mathrm{MgAl}_{2} \mathrm{O}_{4}$ & 0.78 & 1.56 & -0.98 & {$[193]$} \\
& 1.25 & 1.85 & -1.24 & {$[193]$} \\
& 0.60 & 1.92 & -1.11 & {$[194]$} \\
$\mathrm{CoAl}_{2} \mathrm{O}_{4}$ & & & -0.94 & {$[195]$} \\
$\mathrm{CoCr}_{2} \mathrm{O}_{4}$ & & & -0.94 & {$[196]$} \\
$\mathrm{Co}_{3} \mathrm{O}_{4}$ & & & -0.59 & {$[195]$} \\
$\mathrm{ZnCr}_{2} \mathrm{O}_{4}$ & & & -0.91 & {$[196]$} \\
& 0.54 & 1.49 & -0.88 & {$[180]$} \\
$\mathrm{ZnFe}_{2} \mathrm{O}_{4}$ & & & -1 & {$[195]$} \\
& & & -1.10 & {$[197]$} \\
$\mathrm{ZnGa}_{2} \mathrm{O}_{4}$ & 0.72 & 1.68 & -1.02 & {$[193]$} \\
$A_{2} \mathrm{BO}_{4}$ & & & & \\
$\mathrm{Be}_{2} \mathrm{SiO}_{4}$ & 1.24 & 1.77 & -1.06 & {$[198]$} \\
$\mathrm{Mg}_{2} \mathrm{SiO}_{4}$ & 1.40 & 1.60 & -1.10 & {$[199]$} \\
& 0.93 & 0.70 & -0.64 & {$[200]$} \\
\hline
\end{tabular}


$A B_{2} \mathrm{O}_{4}$. The ionicity of normal spinels varies in the following order: ferrites, aluminates $>$ chromites.

Lutz et al. [178] observe the following trends of the ionicity of the chalcide spinels:

- the ionicity increases when proceeding from the selenide spinels to the sulfides, and when going from chromium spinels to the corresponding indium compounds,

- the ionicity decreases in a series from the manganese to the nickel compounds, but increases strongly when continuing to zinc and further to cadmium (in agreement with results obtained for binary chalcides),

- the ionicity of inverse spinels is smaller than that of normal spinels.

\section{COMPUTATIONAL METHODS}

\subsection{HF and DFT Theories}

Two major classes of methods have been applied: density functional theory and Hartree-Fock theory. Density functional theory is exact in principle for ground state properties, but in practice the Local Density Approximation (LDA) is used. Both classes of methods share many features, and they differ only in their treatments of the electron-electron interactions. In a non-magnetic system for a given configuration of nuclei, there is a single lowest energy configuration for the electron density $\rho(r)$. The electrons experience the potential due to the nuclei and to each other. Their interactions with each other can be separated in two parts. The first part is a self-consistent field, or so-called Hartree potential, which arises from the electrostatic field of the average electronic charge density. Up to this point, both LDA and Hartree-Fock (HF) are identical. The differences involve the treatments of the local correlation, which is due to the instantaneous interactions that cannot be ascribed to the average electrostatic field, and the quantum mechanical exchange interactions, which derive from the Pauli exclusion principle. The correlation is neglected in Hartree-Fock theory, but it is included in an average way in the LDA. The exchange interactions are treated exactly in Hartree-Fock theory (when completely converged), and in an average way in LDA. The Hartree-Fock method cannot be used with metallic systems, for which it gives crazy results due to the neglect of correlation effects. The LDA can be used for metals as well as insulators, and it also works well for ionic and covalent systems.

Both Hartree-Fock and the LDA can be applied self-consistently, which means that an iterative process is used to find the solution. One starts with a guess for the charge density (LDA) or orbital occupations (Hartree-Fock), and one then evaluates the potential and the output charge density (LDA) or the HF matrices and output orbitals (Hartree-Fock). If the output differs from the input, the input and output are mixed together, and this process is iterated until the input and output are identical.

However, all self-consistent calculations are not the same. The quality of a calculation is greatly affected by the basis set that is used. The basis set describes the orbitals, and the final result can depend strongly on the accuracy of this description. There are many different types of basis sets that can be used. The Hartree-Fock program for periodic crystals, called CRYSTAL, uses a gaussian basis set, which typically consists of a small number of gaussians centered at each atomic nucleus. A gaussian basis set is very efficient, but it is incomplete. Basis set superposition error is typical in such total energy calculations, and it results from changes in the quality of the description of the states on one atom as the basis functions of a second atom are moved closer. This might cause significant problems in studies of pressure effects or phonons if not tested. Gaussians are often used as a basis for LDA 
calculations as well, and a gaussian basis is usually called a linear combination of atomic orbitals, or LCAO, in such applications. Another commonly used basis for LDA crystal calculations is a plane wave basis, which is ideal in several ways and problematic in others. Plane wave bases are advantageous in that they are fast, and matrix elements (such as those needed to calculate forces, the dynamical matrix, or optical properties) are easily evaluated. Convergence is also straightforward because there is one primary parameter to vary to test convergence, related to the number of plane waves; this parameter simply relates the shortest distance that can be described accurately by the basis. The disadvantage of plane waves is that they cannot account for the rapid variations around the core and the nucleus of an atom. This drawback was solved by the development of pseudopotentials, which remove the core states from the problem and replace the real, rapidly varying potential with a smoother potential. The resulting pseudo-wave functions by construction agree with the correct functions outside some distance $r_{c}$ from the nucleus, but they differ inside $r_{c}$. Until recently, pseudopotentials that allowed for reasonable plane wave basis set sizes did not exist for oxides and many transition metals, but recently ultra-soft pseudopotentials have been developed that do allow application of plane wave methods to oxides and silicates. Thus we have the distinction between all-electron calculations and pseudopotential methods.

At this point it is necessary to discuss another concept, that of full-potential versus nonfull-potential methods. Full potential means that potential (and charge density) is described in a flexible way that allows all variations in the molecule or crystal being studied. On the other hand, "muffin-tin" potentials force the potential to be spherical inside a sphere around each atom (called a muffin-tin) and constant outside the sphere. In other methods, such as LCAO, the potential and/or charge density is sometimes sphericalized as well. The loss of accuracy that is entailed by such shape approximations is most acute for total energy calculations, which are used to calculate phase transitions, phonon frequencies, and equations of state.

The last two basis sets to be discussed are: the Linearized Muffin Tin Orbital (LMTO) and the Linearized Augmented Plane Wave (LAPW) methods. The LMTO method is applied in different degrees of accuracy ranging from muffin-tin potential and the atomic sphere approximation (ASA) to full potential methods, which appear to be as accurate as any self-consistent method. The basis set in LMTO consists of radial solutions to Schrodinger's equation inside the muffin-tin spheres, and Hankel functions, or muffin-tin orbitals, outside the spheres. The LAPW method uses the same kinds of basis inside the spheres, but in the interstitial volume between spheres plane waves are used, and the plane waves are joined smoothly onto the basis functions in the spheres. The LAPW method is probably the most accurate of basis sets, since it is ideally suited to both the interstitial regions and the rapidly varying regions in the interior of an atom.

A posteriori, theoretical quantum chemistry appears to have followed quite a linear development from the original formulation of the HF equations by Fock, Hartree and Slater [201,202] and their linearized expression by Roothaan and Hall [203,204]. The fundamentals of density functional theory were originally developed by Kohn and Sham [205].

A great variety of formal schemes, computational methods and techniques are adopted for the determination of the electronic structure of crystalline compounds; the various proposals differ in many respects, including the basis set (numerical, plane waves, localized, mixed), solution techniques of the basic equations, selected Hamiltonian and all its ingredients. The relative merits and limits of the various proposals are difficult to assess at the moment, as many of the computer codes are not available to the scientific community and are often in rapid evolution. The main reason for this situation is that 
computational solid state physics is a relatively young science with respect to the molecular quantum chemistry: ab initio methods appeared in the late seventies, and the first general, portable, publicly available code, CRYSTAL88 [206] was distributed only ten years ago.

In most recent versions, CRYSTAL can solve the HF as well as the KS equations; as regards the latter, the most popular local and non-local functionals are available, as well as hybrid schemes, such as the so-called B3-LYP which combines the HF exchange term with the Becke [207] and Lee-Yang-Parr [208] functionals according to the formula proposed by Becke [209]. As regards the former, the CS, RHF and UHF options are available. Schemes are also available that permit correction of the HF total energy by estimating the correlation energy a posteriori, integrating a correlation-only functional of the HF charge density. This latter scheme has been shown to provide accurate binding energies for a large family of compounds [210].

\subsection{CNDO Band Structure Method}

The investigation of the electronic structure made from a modified CNDO band structure analysis (Complete Neglect of the Differential Overlap) is based on the LCAO approach, whose computational scheme is reported in Ref. [211]. As an outstanding feature of this method, it is possible to use the density matrix elements in the basis of the atomic orbitals, to calculate the local properties of the electronic structure in terms of atomic charges, covalent bond orders and atomic valences.

Using the self-consistent density matrix calculated for the orthogonal atomic basis one obtains the following expressions for the atomic charge $Q_{A}$ [212], covalent bond order (Wiberg index) $W_{A B}$ [213], covalency $C_{A}$ [214], and full (or total) valency $V_{A}$ [211] of an atom in a crystal:

$$
\begin{aligned}
Q_{A} & =Z_{A}-\sum_{r \in A} P_{r r}^{00}, \\
W_{A B}^{0 n} & =\sum_{p \in A} \sum_{q \in B}\left|P_{p q}^{0 n}\right|^{2}, \\
C_{A} & =\sum_{B \neq A} W_{A B}^{00}+\sum_{n \neq 0} \sum_{B} W_{A B}^{0 n}=2 \sum_{r \in A} P_{r r}^{00}-\sum_{r^{\prime} \in A} \sum_{r \in A} \mid P_{r r^{\prime}}^{00}, \\
V_{A} & =\frac{1}{2}\left(C_{A}+\sqrt{C_{A}^{2}+4 Q_{A}^{2}}\right) .
\end{aligned}
$$

As one can see from Eq. (1) an absolute value of the calculated atomic charge is less than the maximal possible charge, which corresponds to the formal oxidation number. The ratio of the former to the latter can be considered as the ionicity degree of bonding.

\subsection{Tight Binding Analytical Model}

In oxides, the oxygens and cations bear charges of opposite signs, which induce strong electrostatic potentials on the electrons. A correction to the atomic orbital energies $\varepsilon_{i}^{0}(i=M, \mathrm{O})$ of the neutral atoms results, which depends upon the ionic charges, $Q_{i}$, and upon the atomic structure. Under the most simplifying Hartree approximation, when the eigenstates of the 
Hamiltonian are developed on an atomic orbital basis set, the diagonal terms of the Hamiltonian matrix, which represent effective atomic orbital energies, read (in atomic units):

$$
\varepsilon_{i}=\varepsilon_{i}^{0}-U_{i} Q_{i}-V_{i}
$$

with $-U_{i} Q_{i}$ the intra-atomic correction associated with the excess (on the oxygens) or loss (on the cations) of electron-electron repulsion ( $U_{i}$ is the intra-atomic electron-electron repulsion integral), and $V_{i}$ the electrostatic potential, called the Madelung potential, exerted on atom $i$ by all other ions. This expression may be used to estimate the ion integral energy, $E_{i}$, and to write down the Mulliken electronegativity, $\chi_{i}=-\partial E_{i} / N_{i}$; assuming that a single outer atomic orbital is involved in the chemical bond, $\chi_{i}$ reads:

$$
\chi_{i}=\chi_{i 0}+U_{i} Q_{i}+V_{i}
$$

This expression of $\chi_{i}$ contains a correction due to intra-atomic electron-electron interactions, although, in Eq. (6), the effective charge rather than the formal charge has to be used. In addition, solid state effects give a contribution to $\chi_{i}$, equal to the Madelung potential, $V_{i}$. Equation (6) thus gives a generalization of the concept of electronegativity, suited to processes which take place in a solid or on a surface. It accounts for the variations of electronegativity as a function of the charge state and as a function of the site environment. In this latter case, the variations of $\chi_{i}$ are driven by the changes in Madelung potential. For example, in absolute value, $V_{i}$ is smaller on surface atoms than on bulk atoms.

Equations (5) and (6) show that, in a Hartree scheme, there is a direct correspondence between $\chi_{i}$ and the position of the effective outer levels, $\varepsilon_{i}$. The effective atomic energies, $\varepsilon_{i}$, strongly determine the electron sharing between cations and oxygens in oxides. Noguera $[215,216]$ developed a quantum model suited to binary oxides of stoichiometry $M_{n} \mathrm{O}_{m}$, in which the atoms occupy the sites of an alternating lattice, which gives an explicit expression of the partial charges. This model is a tight-binding analytical approach, which relies on several assumptions:

(i) all the oxygens are assumed to have the same outer level effective energy, $\varepsilon_{O}$ and a similar hypothesis is made for the cations;

(ii) the non-diagonal terms of the Hamiltonian, $\beta$, called resonance integrals, which represent the probability of hopping of electrons between two atoms, are considered only when neighboring atoms of opposite types are involved;

(iii) finally, only local orbital hybridization is taken into account and long range band effects are neglected.

This model yields a simplified expression for the oxygen-cation charge transfer:

$$
\partial Q=\frac{n_{\mathrm{O}}}{m}\left(1-\frac{\varepsilon_{M}-\varepsilon_{\mathrm{O}}}{\sqrt{\left(\varepsilon_{M}-\varepsilon_{\mathrm{O}}\right)^{2}+4 Z \beta^{2}}}\right)
$$

with $n_{\mathrm{O}}$ the number of oxygen orbitals coupled to the cation levels and $Z$ the oxygen coordination number. According to Eq. (7), the absolute value of the oxygen charge $\left|Q_{\mathrm{O}}\right|=2-\partial Q$, is a decreasing function of the ratio $Z \beta^{2} /\left(\varepsilon_{M}-\varepsilon_{\mathrm{O}}\right)^{2}$ : when no electron delocalization occurs $(\beta=0)$, the oxide is fully ionic; the covalency of the oxygen-cation bond increases as $\beta$ gets larger or as the energy difference $\varepsilon_{M}-\varepsilon_{O}$ decreases. This model was checked for all the oxides considered here, by carefully comparing its predictions with the results of self-consistent numerical calculations [215]. The absolute values of the oxygen 
charges are equal to $1.45,1.43,1.33,1.24,0.74$ and 0.67 in the series: $\mathrm{BaO}(100)$, $\mathrm{SrO}\left(\begin{array}{lll}1 & 0 & 0\end{array}\right), \mathrm{CaO}\left(\begin{array}{lll}1 & 0 & 0\end{array}\right), \mathrm{MgO}\left(\begin{array}{lll}1 & 0 & 0\end{array}\right), \mathrm{TiO}_{2}\left(\begin{array}{lll}1 & 1 & 0\end{array}\right)$ and $\mathrm{SiO}_{2}\left(\begin{array}{lll}0 & 0 & 0\end{array}\right)$. The reduction of $\left|Q_{\mathrm{O}}\right|$ demonstrates that the cation-oxygen bond is more and more covalent: it is mainly due to the increase in the cation electronegativity, $\chi_{M}^{0}$. Yet two other effects are also relevant, although to a lesser extent. First, the cation ionic radius decreases in the series: this is directly reflected in the values of the oxygen-cation first neighbor distance, $R$, and thus in the strength of the resonance integrals, $\beta$, and of the Madelung potentials. Second, $\varepsilon_{\mathrm{O}}$ also varies in the series because it is a self-consistent function of the charge $Q_{\mathrm{O}}$. At this point it is interesting to note that, in a given atom, parallel shifts of the outer and inner atomic levels generally occur. The correlation between the variations of the $1 s$ core level shifts and the oxide ionicity pointed out by Vinek et al. may be rationalized in that way, provided that one neglects the final state effects in the photoemission process [219].

The alternating lattice model thus stresses that the relevant parameter to discuss the ionicity of a compound is $F_{B} /\left(\varepsilon_{M}-\varepsilon_{O}\right)^{2}, F_{B}=Z \beta^{2}$.

This conclusion is consistent with Phillip's definition of ionicity [38], which relies upon an analysis of the energy $E_{g}$, called gap in Ref. [38], which enters the expression of the optical dielectric constant $\varepsilon(\infty) \approx 1+\omega_{p}^{2} / E_{g}^{2} . E_{g}$ is generally larger than the smallest excitation energy $G$ (the true gap); it roughly represents the energy separation between the centers of gravity of the valence and conduction bands. Phillips proposed to analyze it as:

$$
E_{g}=\sqrt{E_{i}^{2}+E_{c}^{2}}
$$

$E_{i}$ and $E_{c}$ representing the ionic and covalent contributions to $E_{g}$, respectively. In addition, Phillips defined an ionicity scale of the compounds, in which the degree of ionicity is equal to the ratio:

$$
f=\frac{E_{i}^{2}}{E_{i}^{2}+E_{c}^{2}} .
$$

In the context of the alternating lattice approach, it is possible to estimate the value of $E_{g}$ from the positions of the two delta functions which constitute the local densities of states:

$$
E_{g}=\sqrt{\left(\varepsilon_{M}-\varepsilon_{O}\right)^{2}+4 F_{B}}
$$

so that the ionicity parameter $f$ is equal to:

$$
f=\frac{\left(\varepsilon_{M}-\varepsilon_{O}\right)^{2}}{\left(\varepsilon_{M}-\varepsilon_{O}\right)^{2}+4 F_{B}} .
$$

It is straightforwardly related to the charge transfer and to the oxygen electron number. The alternating lattice approach gives a microscopic prescription to estimate the covalent and ionic contributions to $E_{g}$.

The most significant results issued from literature are listed in Table IX for binary oxides $M_{2} \mathrm{O}, M \mathrm{O}, M_{2} \mathrm{O}_{3}$ and $M \mathrm{O}_{2}$ (electronic configuration of the cations $s-p, d^{0}$ and $d^{10}$ ) and in Tables $\mathrm{X}(\mathrm{a})-\mathrm{X}(\mathrm{c})$ for $3 d$-transition metal oxides. 
TABLE IX Net Oxygen Charges $\left(-Q_{\mathrm{Ox}}\right)$ for Binary Oxides from Various Sources (Electronic Configurations of the Cations: $s-p, d^{0}$ and $d^{10}$ ).

\begin{tabular}{|c|c|c|c|c|c|c|c|c|}
\hline \multirow{3}{*}{$\begin{array}{l}\text { Period } \\
2\end{array}$} & \multicolumn{4}{|c|}{$\mathrm{M}_{2} \mathrm{O}$} & & & & \\
\hline & \multicolumn{4}{|c|}{ Group Ia } & & & & \\
\hline & $\mathrm{Li}_{2} \mathrm{O}$ & 1.94 & $\mathrm{HF}$ & {$[220]$} & & & & \\
\hline \multirow[t]{2}{*}{4} & $\mathrm{~K}_{2} \mathrm{O}$ & 2 & $\mathrm{HF}$ & [220] & & & & \\
\hline & \multicolumn{8}{|c|}{$M O$} \\
\hline Period & \multicolumn{4}{|c|}{ Group IIa } & \multicolumn{4}{|c|}{ Group IIb } \\
\hline 2 & $\mathrm{BeO}$ & $\begin{array}{l}1.75 \\
1.76\end{array}$ & $\begin{array}{l}\text { HF } \\
\text { LDA }\end{array}$ & $\begin{array}{l}{[221]} \\
{[222]}\end{array}$ & & & & \\
\hline 3 & $\mathrm{MgO}$ & $\begin{array}{l}1.83 \\
1.22 \\
1.86 \\
1.78 \\
1.74\end{array}$ & $\begin{array}{l}\text { LDA } \\
\text { t.b. } \\
\text { HF } \\
\text { B3LYP } \\
\text { PP-DFT-LDA }\end{array}$ & $\begin{array}{l}{[223]} \\
{[215]} \\
{[224]} \\
{[225]} \\
{[226]}\end{array}$ & & & & \\
\hline 4 & $\mathrm{CaO}$ & $\begin{array}{l}1.83 \\
1.87 \\
1.31 \\
1.28\end{array}$ & $\begin{array}{l}\text { HF } \\
\text { HF } \\
\text { t.b. } \\
\text { PP-DFT-LDA }\end{array}$ & $\begin{array}{l}{[220]} \\
{[227]} \\
{[228]} \\
{[226]}\end{array}$ & $\mathrm{ZnO}$ & 1.88 & LDA & [222] \\
\hline 5 & $\mathrm{SrO}$ & $\begin{array}{l}1.41 \\
1.25\end{array}$ & $\begin{array}{l}\text { t.b. } \\
\text { PP-DFT-LDA }\end{array}$ & $\begin{array}{l}{[229]} \\
{[226]}\end{array}$ & & & & \\
\hline & \multicolumn{8}{|c|}{$\mathrm{M}_{2} \mathrm{O}_{3}$} \\
\hline Period & \multicolumn{4}{|c|}{ Group IIIa } & \multicolumn{4}{|c|}{ Group IIIb } \\
\hline 3 & & & & & $\overline{\mathrm{Al}_{2} \mathrm{O}_{3}}$ & $\begin{array}{l}1.19 \\
1.22 \\
1.53 \\
1.26\end{array}$ & $\begin{array}{l}\mathrm{HF} \\
\mathrm{HF} \\
\mathrm{HF} \\
\text { LDA }\end{array}$ & $\begin{array}{l}{[234]} \\
{[220]} \\
{[224]} \\
{[235]}\end{array}$ \\
\hline 4 & $\mathrm{Sc}_{2} \mathrm{O}_{3}$ & $\sim 1.52$ & LDA & [230] & $\mathrm{Ga}_{2} \mathrm{O}_{3}$ & $\sim 1.07$ & LDA & [230] \\
\hline 5 & $\mathrm{Y}_{2} \mathrm{O}_{3}$ & $\begin{array}{l}1.40 \\
1.07\end{array}$ & $\begin{array}{l}\text { LDA } \\
\text { t.b. }\end{array}$ & $\begin{array}{l}{[235]} \\
{[231]}\end{array}$ & $\mathrm{In}_{2} \mathrm{O}_{3}$ & 1.35 & DV-X $\alpha$ & [236] \\
\hline 6 & $\mathrm{La}_{2} \mathrm{O}_{3}$ & $\begin{array}{l}1.60 \\
1.80\end{array}$ & $\begin{array}{l}\text { CNDO } \\
\text { CNDO }\end{array}$ & $\begin{array}{l}{[232]} \\
{[233]}\end{array}$ & & & & \\
\hline & \multicolumn{8}{|c|}{$\mathrm{MO}_{2}$} \\
\hline Period & \multicolumn{4}{|c|}{ Group IVa } & \multicolumn{4}{|c|}{ Group IVb } \\
\hline 3 & & & & & $\overline{\mathrm{SiO}_{2}}$ & $\begin{array}{l}0.52 \\
1.02 \\
0.97 \\
1.02\end{array}$ & $\begin{array}{l}\text { t.b. } \\
\text { t.b. } \\
\text { HF } \\
\text { HF }\end{array}$ & $\begin{array}{l}{[229]} \\
{[238]} \\
{[239]} \\
{[220]}\end{array}$ \\
\hline 4 & $\mathrm{TiO}_{2}$ & $\begin{array}{l}0.81 \\
0.62 \\
1.24\end{array}$ & $\begin{array}{l}\text { t.b } \\
\text { LSDA } \\
\text { HF }\end{array}$ & $\begin{array}{l}{[229]} \\
{[240]} \\
{[241]}\end{array}$ & $\mathrm{GeO}_{2}$ & 1.05 & & [239] \\
\hline 5 & $\mathrm{ZrO}_{2}$ & 1.01 & t.b. & [237] & & & & \\
\hline
\end{tabular}




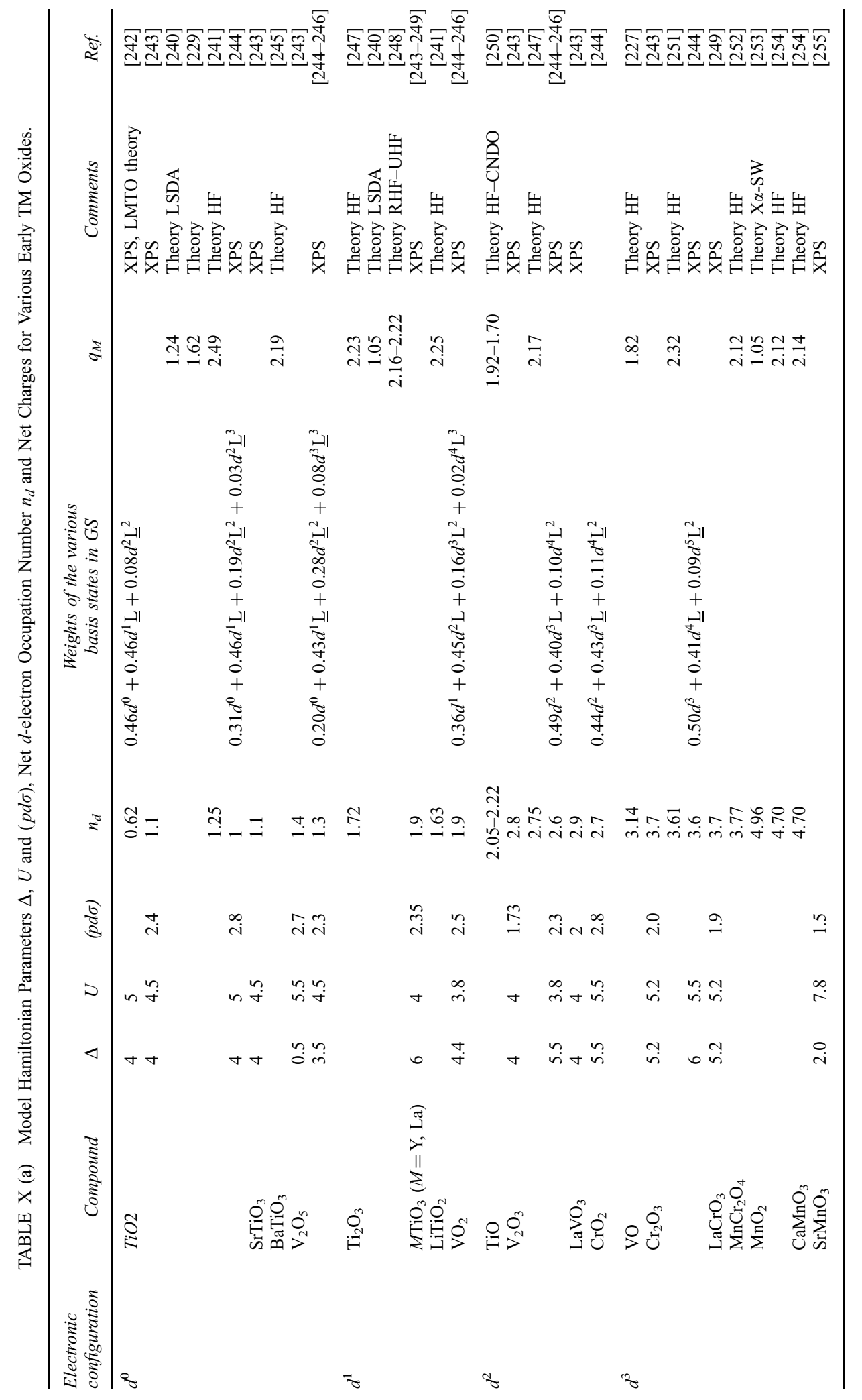




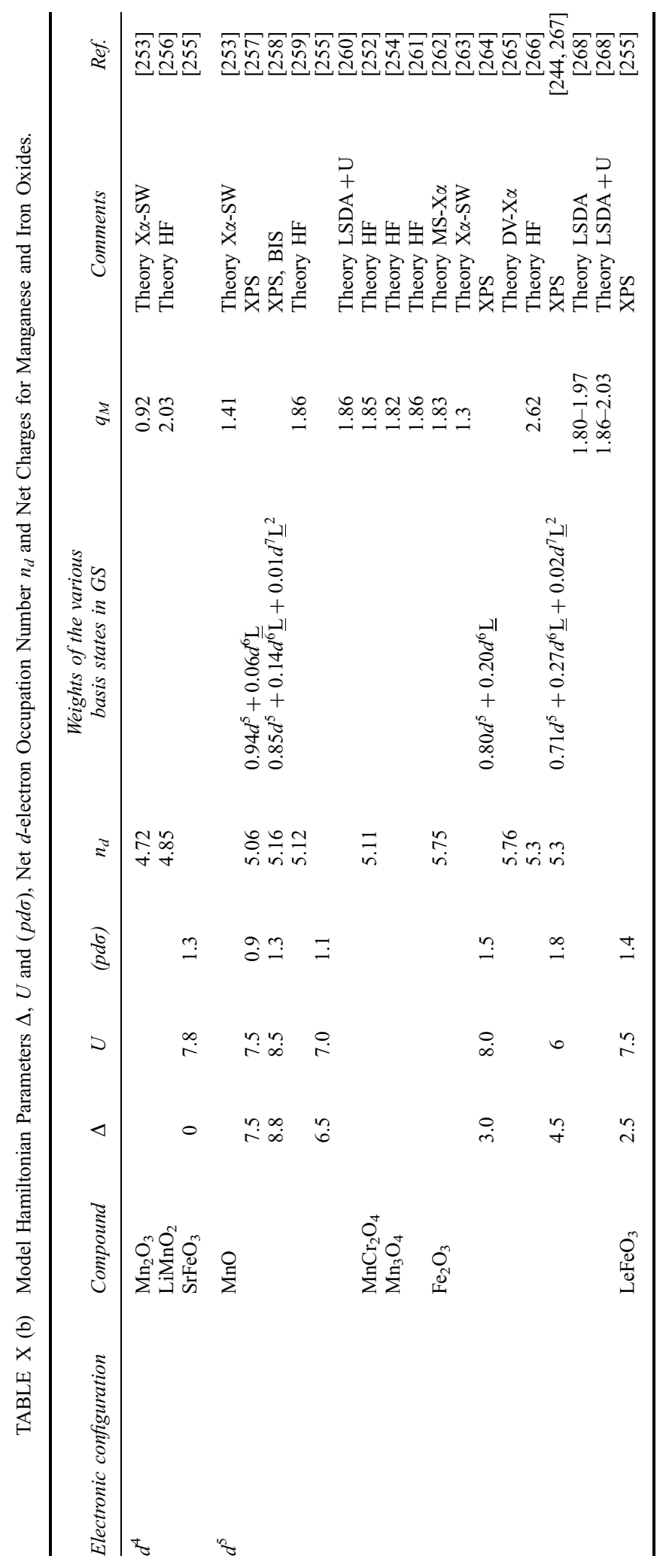




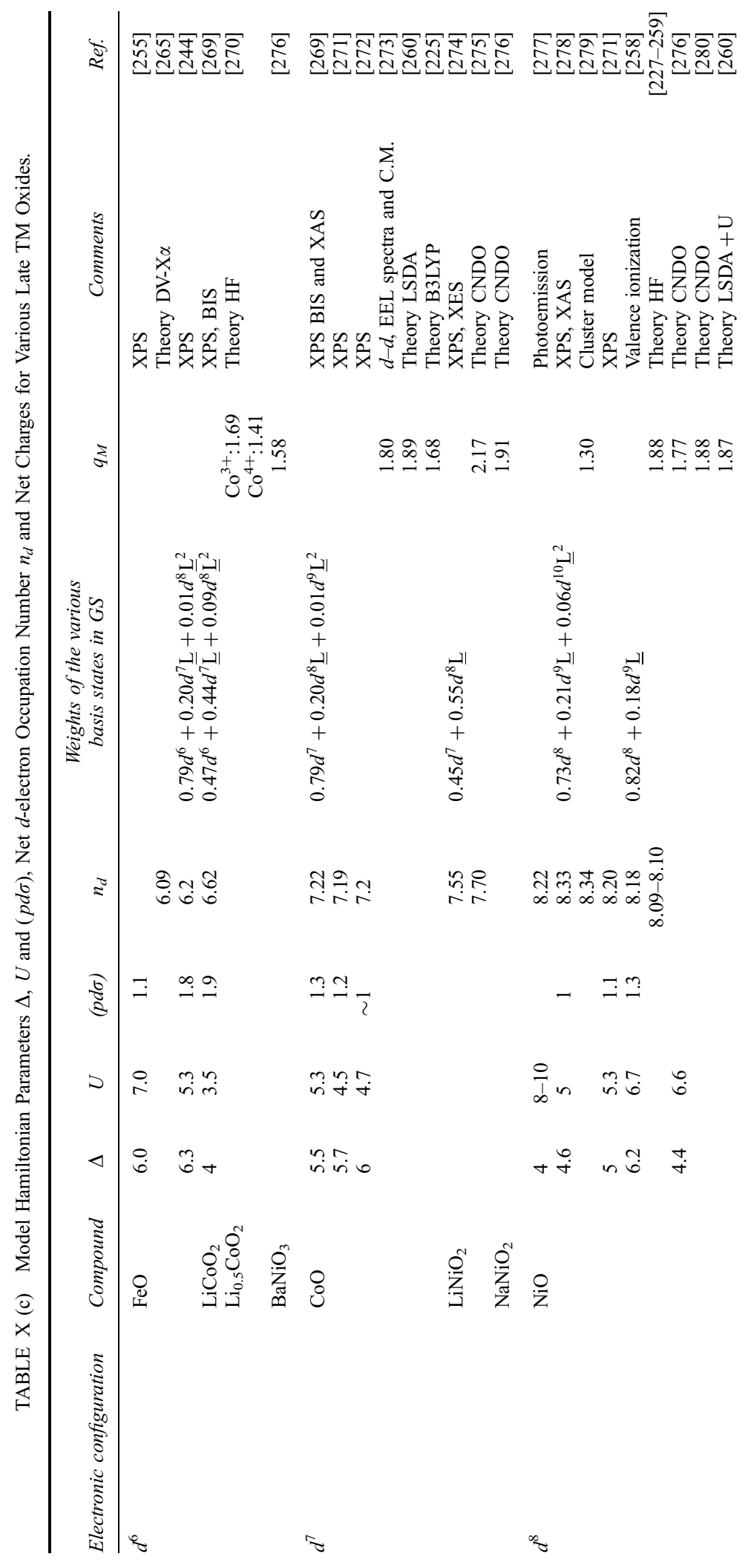




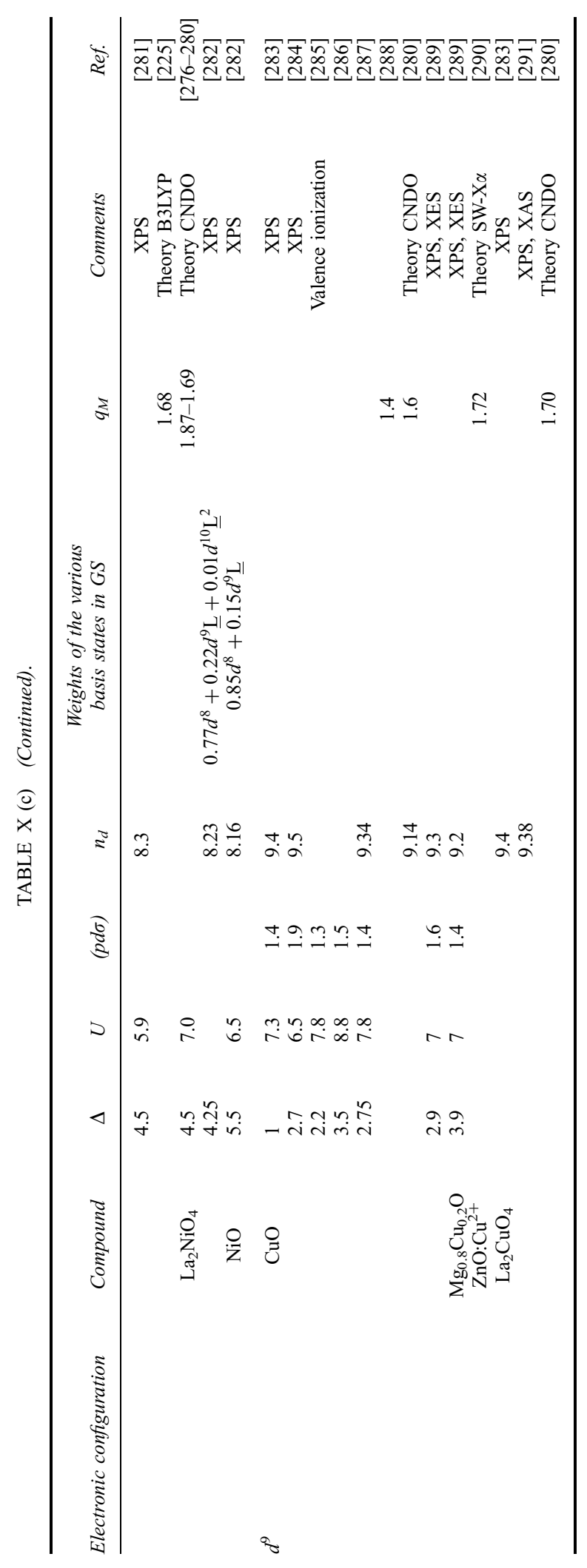




\section{DISCUSSION}

We now present a discussion of the parameters which fix the values of the ionic charges. As already discussed above, the purpose is not to obtain quantitative estimates for the bulk charges in a given oxide, because these quantities remain controversial in the literature. Different authors obtain different estimates of the ionicity for the same compound, e.g. in $\mathrm{Al}_{2} \mathrm{O}_{3}$ (Tab. IX), $\mathrm{Fe}_{2} \mathrm{O}_{3}$ or $\mathrm{NiO}$ (Tabs. $\mathrm{X}(\mathrm{b})$ and $\mathrm{X}(\mathrm{c})$ ), or even different trends in a given series, e.g. the alkaline-earth oxide series from $\mathrm{MgO}$ to $\mathrm{BaO}$. Yet, it is interesting to point out how the anion-cation charge transfer is related to the geometric characteristics of the oxide, to the cation electronegativity and to the value of the optical dielectric constant. Although the ionic charge cannot be unambiguously determined, it is worthwhile to stress the parameters upon which they depend because they characterize the ionicity of an insulator. As far as oxides are concerned, various physical parameters have been proposed: the cation ionic radius and formal charge; the cation electronegativity and the oxygen partial charge. In the previous section, the electronic structure of oxides has been analyzed by means of different theoretical models. Noguera [216] used them to point out how the arguments of electronegativity and partial charge are related.

Equations (5) and (6) in Section 4 show that, in a Hartree scheme, there is a direct correspondence between $\chi_{i}$ and the position of the effective outer levels $\varepsilon_{i}$. We have seen in the previous section that the effective atomic energies $\varepsilon_{i}$ strongly determine the electron sharing between cations and oxygen in oxides, the oxygen charge being a decreasing function of the ratio $Z \beta^{2} /\left(\varepsilon_{M}-\varepsilon_{0}\right)^{2}$. The parameters which fix $\varepsilon_{M}$ have just been discussed. The value of the cation ionic radius, on the other hand, is involved in the anion-cation first neighbor distance $R$, upon which depend the resonance integrals $\beta$ and, to a lesser extent, the Madelung potential values. On the other hand, $\varepsilon_{O}$ does vary from one oxide to another, because it is a self-consistent function of the charge $Q_{\mathrm{O}}$. At this point it is interesting to note that, in a given atom, parallel shifts of the outer and inner atomic levels are expected. This was shown, for example, by Pacchioni and Bagus [292], who assigned the variations in the oxygen $1 s$ binding energy in the alkaline-earth oxide series to the changes in the Madelung potential.

\subsection{Correlation Between $\boldsymbol{P}_{a}$ and Parameters Influencing the Ionicity of Binary Oxides: $\chi_{M}$ and $q_{0 x}$}

This discussion gives the bases to understand numerous experimental results in solid state chemistry, adhesion science and heterogeneous catalysis and to explain the empirical classifications of oxides based on the acid-base concept, optical basicity...

Various characterization methods have been developed to measure the number, the nature and the strength of acid and basic sites at the surface of solid catalysts. Acid-base strength distribution of solid metal-oxygen compounds such as metal oxides sulfates, phosphates, tungstates ... has been measured on a common $H_{0}$ (Hammet acidity function) scale by Yamanaka and Tanabe $[293,294]$. It had been found that the highest $H_{0}$ values for acid and basic sites generally coincide. The common value $H_{0, \max }$ is, thus, the relevant parameter representing the acid-base character of solid surfaces. A correlation has been found between $H_{0, \max }$ and the effective negative charges on combined oxygens.

The technique of microcalorimetry allows a simultaneous determination of the strength and energy distribution of adsorption sites [34]: relationships between the average adsorption 
heat of $\mathrm{NH}_{3}$ and $\mathrm{CO}_{2}$ have been found for 20 simple metallic oxides as a function of the ionic character percentage and of the charge radius ratio.

The decomposition of aliphatic alcohols (dehydrogenation versus dehydration) has been chosen as a test reaction to study the acid-base character of the catalytic sites of the oxides [295-297]. On the basis of the dehydration reaction, sets of oxides can be classified in scales of acid strength.

XPS measurements revealed a correlation of the position of the oxygen $1 s$ core levels in oxides with basicity. Oxides with weakly basic oxygens have their $1 s$ core levels shifted towards higher binding energy [219]. A correlation has been established between this energy and the IEPS of several oxides [298-300].

The relation between the $\mathrm{O} 1 s$ energy and the acid-base properties of oxides has been examined by numerous authors [219,301-304]. Barr and Brundle [304] have proposed to classify the metal oxides as covalent, ionic, or very ionic on the basis of $\mathrm{O} 1 \mathrm{~s}$ core-level binding energy. The ionicity of several oxides has been estimated theoretically using the modification of the Phillips-van Vechten electronegativity scale [38,39], proposed by Levine [40,41]; the ionic character estimated in this way has been correlated with the measured $\mathrm{O} 1 s$ core-level BEs. The underlying idea is that, when the electronic charge around the oxide anion is reduced by the bonding overlap with the neighboring cations, this will result in a more attractive potential at the oxygen nucleus and in a corresponding increase of the $\mathrm{O} 1 s$ core-level BE. According to the classification proposed by Barr and Brundle, normal ionic oxides with estimated ionicities ranging between 76-89\% according the Levine model exhibit an $\mathrm{O} 1 s$ BE of $530 \pm 0.5 \mathrm{eV}$. In this class of materials, transition-metal oxides are found. For oxides such as $\mathrm{SiO}_{2}$ and $\mathrm{Al}_{2} \mathrm{O}_{3}$, the $\mathrm{O} 1 \mathrm{~s} \mathrm{BE}$ is shifted to higher values, around $531-533 \mathrm{eV}$. The interpretation of this shift is that these oxides are more covalent and the $\mathrm{O} 1 s \mathrm{BE}$ is larger because the electron density around the oxygen is reduced. There are also oxides like $\mathrm{Cs}_{2} \mathrm{O}$, $\mathrm{BaO}, \mathrm{La}_{2} \mathrm{O}_{3} \ldots$, where the $\mathrm{O} 1 \mathrm{~s} \mathrm{BE}$ is shifted to lower values, about $528.5-529.5 \mathrm{eV}$. In these cases, the oxides are assumed to be very ionic and to have an ionicity around $95 \%$.

These authors explain that the valence bands of group A oxides, which fall within the ionic class (e.g. $\mathrm{Na}_{2} \mathrm{O}$ or $\mathrm{CaO}$ ), are thus almost entirely dominated by electron density from the $\mathrm{O}(2 p)$ orbitals, the only contributions from metal valence orbitals being from the small residual covalency. Within this group it has been found that this oxygen-dominated valence band shifts slightly closer to the pseudo-Fermi edge as the oxygen becomes more and more negative (i.e. as the percentage ionicity and the corresponding percentage $\mathrm{O}(2 p)$ contribution to the valence band increase). Thus, on moving to the left and down in the periodic table for oxides formed from group A metals, the progressive small increase in ionicity causes the leading edge of the valence band to move increasingly to lower binding energies.

This "movement" of the $\mathrm{O}(2 p)$ edge towards $E_{F}$ with increasing ionicity is stopped if large density metal $d$ bands are placed in the gap between the $\mathrm{O}(2 p)$ band and $E_{F}, e . g$. for the group-B transition-metal oxides $[305,306]$. Thus, most transition-metal oxides are considered as ionic oxides.

Figure 5 presents the correlation between the parameter $P_{a}$ and the $\mathrm{O} 1 s$ binding energy for oxides of IIIB group and various groups A and reveals a similar trend to that mentioned above.

The trend of ionic character in alkaline-earth oxides: $\mathrm{MgO}<\mathrm{CaO}<\mathrm{SrO}<\mathrm{BaO}$ is supported by the interpretation of several experiments like X-ray measures of charge density [55, 56, 69], elastic constants [309], infrared spectroscopy [310] and indirectly by experiments in heterogeneous catalysis [294,295,311], low-energy $\mathrm{D}^{+}$scattering [312] and band-structure calculations $[216,313]$. 


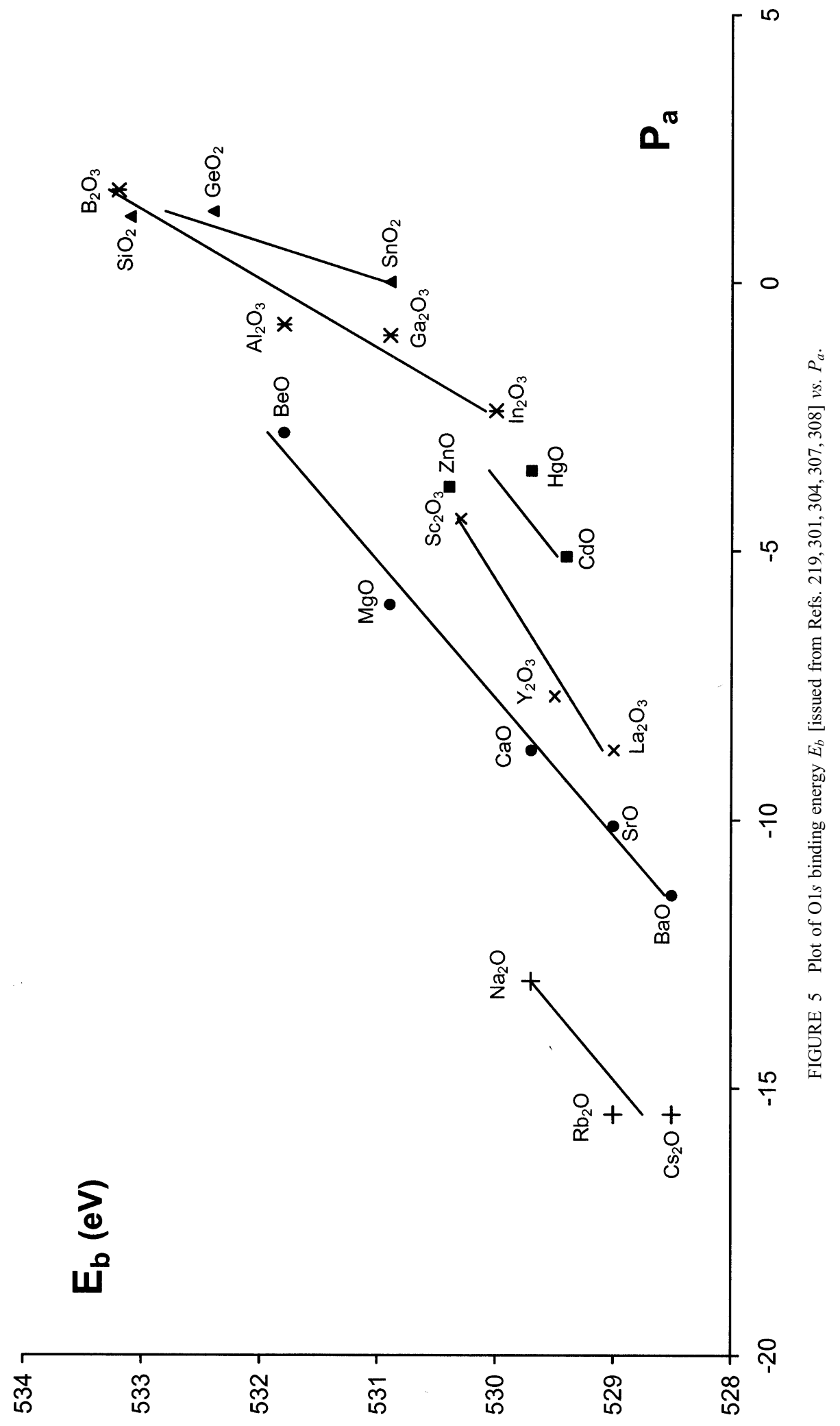


On the other hand, cluster model [292] and PP-DFT-LDA [226] calculations are in direct conflict with the conventional view and it is claimed that a covalent character increases as one goes from $\mathrm{MgO}$ to $\mathrm{BaO}$ :

\begin{tabular}{cccccc}
\hline & \multicolumn{5}{c}{ Oxide } \\
\cline { 2 - 5 } & $\mathrm{MgO}$ & $\mathrm{GaO}$ & $\mathrm{SrO}$ & $\mathrm{BaO}$ & Ref. \\
\hline$q_{M}$ & 1.95 & 1.88 & 1.85 & 1.82 & {$[292]$} \\
& 1.74 & 1.28 & 1.22 & & {$[226]$} \\
\hline
\end{tabular}

From the cluster-model calculations, Pacchioni et al. [292,313] concluded that the decrease of the lattice Madelung potential and the involvement of the low-lying $d$ levels of the cations play an important role in the covalent orbital hybridization. The discrepancy between these two approaches implies that the ionicity of the alkaline-earth oxides is a matter of great delicacy and the accuracy of the calculated results is limited by the validity of the assumptions made (see for example the discussion presented hereafter about $\mathrm{MgO}$ ).

The correlations of the parameter $P_{a}$ with $\chi_{M}$ (Fig. 2) and $q_{\mathrm{Ox}}$ (Fig. 6) show that:

- the cation electronegativity and the oxygen partial charge are the main parameters which determine the oxide ionicity,

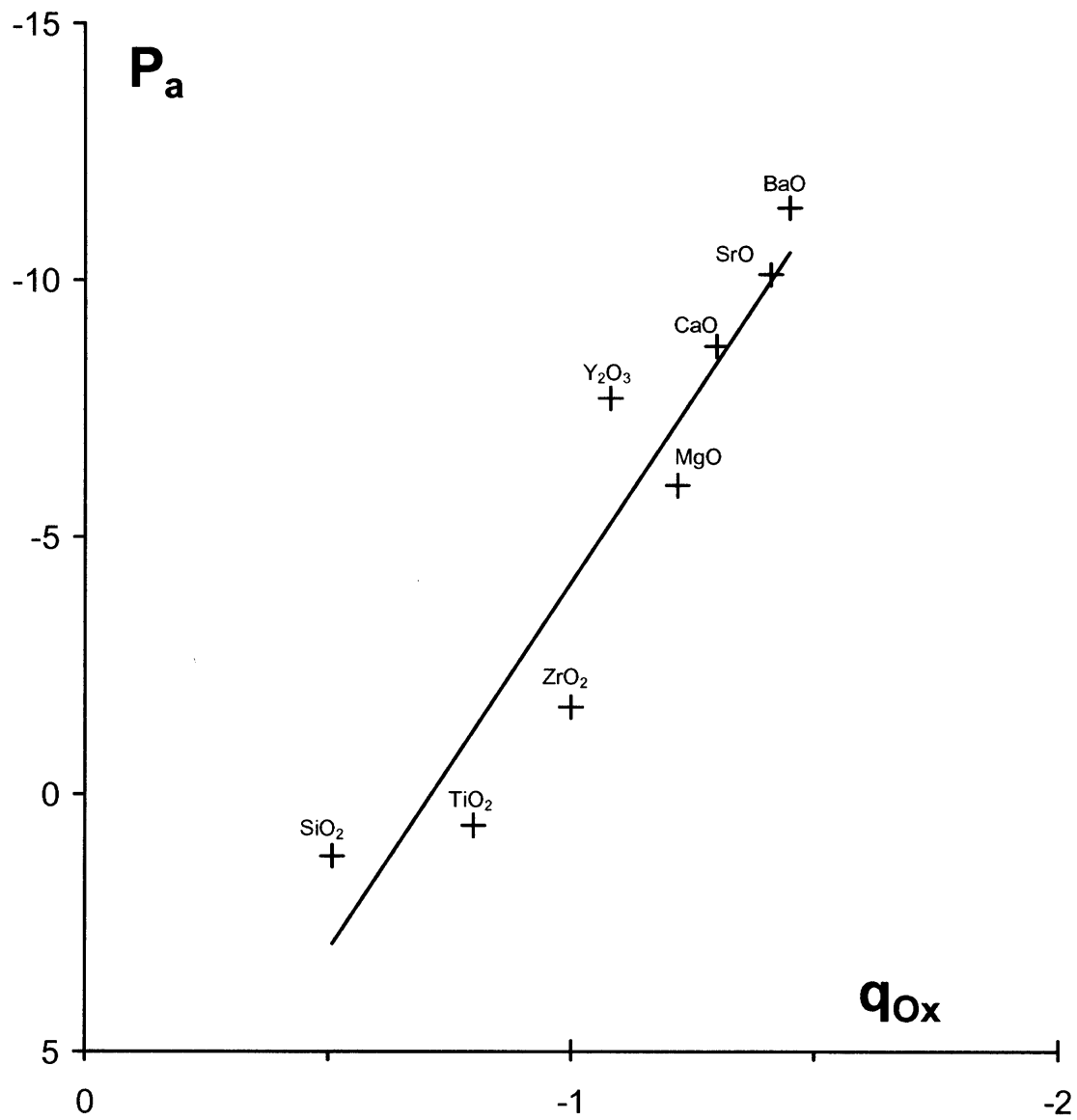

FIGURE 6 Plot of $P_{a}$ vs. $q_{\text {Ox }}$ (the oxygen partial charges have been established by Noguera et al. using an alternating lattice model). 
- the semi-empirical scale of acidity/basicity constructed from thermochemical data leads to the most reliable classification of binary oxides.

These conclusions are in agreement with the modern concepts of chemical reactivity: the oxidizing power, the acidity, the basicity and the reducing power are steps along a continuum, rather than distinct phenomena [314,315].

\subsection{Electronic Structure of Binary Oxides and Ionic Charges}

Zaanen and Sawatzky [316] have classified the distinction between charge-transfer oxides and correlated oxides and proposed a phase diagram for insulating systems relying upon the values of $\Delta$ and $U_{d d}$. This diagram is reproduced in Figure 7 [ $\Delta$ and $U_{d d}$ values are those of Refs. 243, 244 and 267].

For $U_{d d}>\Delta$, the band gaps of TM oxides are of a charge-transfer type essentially proportional to $\Delta$. The Mott-Hubbard regime is located in the region $U_{d d}<\Delta$ : it is generally accepted that early TM oxides are Mott-Hubbard insulators with a band gap of $d-d$ type and proportional to $U_{d d}$.

The variation of $U_{d d}$ is relatively ill known because this parameter hides various phenomena non-directly related to the $d$ orbitals [317]. The rule that early transition metal oxides are insulators of the Mott-Hubbard type should not be applied without care.

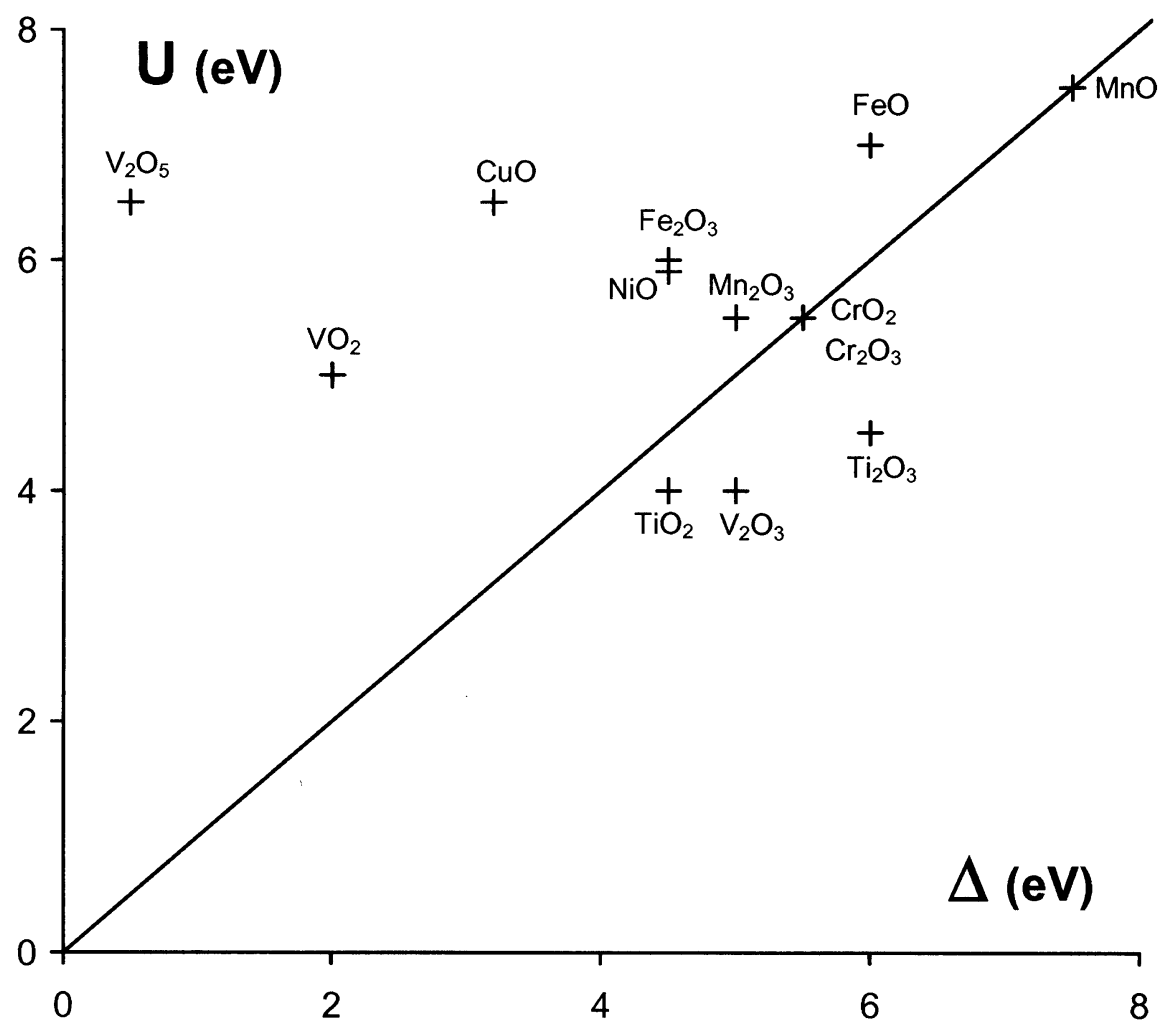

FIGURE 7 Zaanen-Sawatzky $\Delta$ - $U_{d d}$ diagram for various $3 d$-transition-metal oxides giving the nature of the insulating state as a function of the cation-cation charge fluctuation energy $U_{d d}$ and the energy $\Delta$ for anion-cation charge transfer. 
In the classical models, the cations of some early transition metal compounds have a $d^{0}$ outer electronic configuration as for titanium in $\mathrm{TiO}_{2}$ or for yttrium in $\mathrm{Y}_{2} \mathrm{O}_{3}$. Two charge transfer excitations are then required to bring two cations in a $d^{1}$ state, before a charge fluctuation may occur $d^{1}+d^{1} \rightarrow d^{0}+d^{2}$ with an energy $U$. The total energy of this process is thus equal to $2 \Delta+U$, it is always much larger than $\Delta$. The effect is similar for cations with a $d^{10}$ configuration. Transition metal oxides with $d^{0}$ or $d^{10}$ configurations are generally chargetransfer insulators. Theoretical and experimental studies on the electronic structure of $\mathrm{M}_{2} \mathrm{O}_{3}$ oxides ( $M=\mathrm{Ti}, \mathrm{V}, \mathrm{Cr}, \mathrm{Mn}, \mathrm{Fe}$ ) by systematic analysis of high-energy spectroscopy (XPS and BIS) show that the $M_{2} \mathrm{O}_{3}$ oxides from $\mathrm{Ti}_{2} \mathrm{O}_{3}$ to $\mathrm{Mn}_{2} \mathrm{O}_{3}$ are classified as intermediate-type insulators between charge-transfer and Mott-Hubbard insulators, and $\mathrm{Fe}_{2} \mathrm{O}_{3}$ is in chargetransfer insulator [267].

Although the quantum methods require a much larger computational effort than classical approaches, they have now been applied to as wide a range of systems as the latter. For example, they have been used to describe not only the cohesive properties, such as the bulk structural parameters, the bulk modulus and the electronic structure, but also structural phase transitions under pressure, defects (substitutional impurities, vacancies, etc) and magnetism. Nevertheless, it is necessary to resolve the existing discrepancies between theory and experiment that still exist despite the large number of studies reported in the literature.

The calculations based on the DFT theory yield the band dispersion, the charge density around the atoms, and the gap width if states are expanded on an over-complete basis set. Yet, in the standard LDA approximation, the calculated band gaps are always narrower than measured ones.

The ab initio Hartree-Fock method yields the band structure, charge density maps, the gap width and the total energy. The calculated gap widths are always much larger than the experimental values and the Mulliken charges overestimated. Table XI presents the latest results for various transition metal oxides obtained by the $a b$ initio HF method and by densityfunctional theory calculations.

In a recent study, Bredow and Gerson [225] applied first-principles methods to quantumchemical calculations of bulk properties for the isostructural oxides $\mathrm{MgO}, \mathrm{NiO}$ and $\mathrm{CoO}$. The effect of electron correlation and exchange is studied by comparing results obtained with

TABLE XI Comparison of Electronic Properties for $3 d$-metal Oxides: Net Charges $\left(q_{M}\right)$, Number Electrons in the Md Shell $\left(n_{d}\right)$, Spin Moments $(\mu)$ and Band Gap $(\mathrm{eV})$.

\begin{tabular}{|c|c|c|c|c|}
\hline & \multicolumn{4}{|c|}{ Compound } \\
\hline & $\mathrm{TiO}_{2}$ & $\mathrm{Ti}_{2} \mathrm{O}_{3}$ & $\mathrm{Fe}_{2} \mathrm{O}_{3}$ & $\mathrm{NiO}$ \\
\hline \multicolumn{5}{|l|}{$\mathrm{HF}$} \\
\hline$q_{M}$ & 2.49 & 2.16 & 2.62 & 1.86 \\
\hline$n_{d}$ & 1.25 & & 5.3 & 8.1 \\
\hline$\mu$ & & & 4.74 & 1.91 \\
\hline Gap & & & & \\
\hline Ref. & {$[241]$} & [248] & {$[266]$} & {$[318]$} \\
\hline \multicolumn{5}{|c|}{ DFT-LSDA } \\
\hline$q_{M}$ & 1.24 & 1.05 & $1.86-2.03$ & 1.50 \\
\hline$n_{d}$ & & & & 8.44 \\
\hline$\mu$ & & & 3.85 & 1.19 \\
\hline Gap & 1.8 & & 1.42 & \\
\hline Ref. & {$[240]$} & [240] & {$[268]$} & {$[318]$} \\
\hline \multicolumn{5}{|c|}{ Experimental Values } \\
\hline$\mu$ & & & $4.9[319] ; 4.58-4.45[320]$ & $1.64-1.90[102,321,322]$ \\
\hline Gap & 3.0 & 0.02 & 2.0 & 3.8 \\
\hline
\end{tabular}


the Hartree-Fock (HF) method and approaches based on the density-functional theory (DFT). The accuracy of the various standard methods is investigated by a comparison of the calculated geometric, energetic, and electronic properties with experimental data from the literature.

The oxides were modeled with three-dimensional periodic structures using the crystallineorbital program CRYSTAL98 [323]. Six standard first-principles methods have been employed for the quantum-chemical calculations: (1) the HF method, which has been used in previous CRYSTAL studies, (2) HF and electron correlation described by the correlation functional of Lee, Yang and Parr (LYP) (HF + LYP) [208], (3) a combination of Becke's three-parameter exchange functional with the LYP correlation functional (B3LYP) [209], (4) the Becke-LYP (BLYP) DFT method [207], (5) the Perdew-Burke-Ernzerhof (PBE) DFT method [324], and (6) the Perdew-Wang PWGGA-DFT method [325] all based on the GGA. The comparison of the first two methods, HF and HF + LYP, allows for an investigation of correlation effects. The LYP functional was chosen since it is also part of the hybrid method B3LYP and the pure DFT method BLYP, and it is possible in this way to study different theoretical descriptions of exchange with the same correlation formalism. The two outer DFT methods, PBE and PWGGA, are examples of recent developments in DF theory and have been taken into account for further comparison.

The comparison of the bulk properties for $\mathrm{MgO}, \mathrm{NiO}$ and $\mathrm{CoO}$ calculated using the six standard first-principles methods with the experimental data is presented in Tables XII(a)-XII(c).

The HF method drastically underestimates all three binding energies, which indicates that important contributions of the metal-oxygen interaction are missing.

All three DFT methods strongly underestimate the band gaps of all three compounds and give a valence-band structure for $\mathrm{NiO}$ and $\mathrm{CoO}$, which is contrary to recent experimental considerations. This has been attributed to the theoretical description of exchange by the various density functionals, which is an approximation to the exact exchange potential.

The B3LYP method is the only approach among those investigated that gives reasonable-togood agreement with experiment for all properties that were taken into account in the present study. It is therefore the best choice for comparative investigations on different oxides of main-group elements and transition metals. Other methods, however, give better performance than B3LYP in particular cases.

De Graaf and Illas [331] have presented a combined periodic and cluster model approach to the electronic structure and magnetic interactions in the spin-chain compounds $\mathrm{Ca}_{2} \mathrm{CuO}_{3}$ and $\mathrm{Sr}_{2} \mathrm{CuO}_{3}$. Periodic calculations indicate that an interpretation in terms of a charge-transfer insulator is the most appropriate one, in contrast to a suggestion of a covalent correlated insulator recently reported in the literature.

TABLE XII (a) Calculated Bulk Properties for MgO: Lattice Constant $a$ ( $\AA$ ), Heat of Atomization per MgO Unit $\Delta H_{a}$, Band Gap, Fermi Level $E_{F}(\mathrm{eV})$, and Mulliken Charges $q$ (a.u.).

\begin{tabular}{lccccccc}
\hline & \multicolumn{7}{c}{ Method } \\
\cline { 2 - 7 } & $R H F$ & $R H F+L Y P$ & B3LYP & BLYP & PBE & PWGGA & Expt. \\
\hline$a$ & 4.20 & 4.09 & 4.23 & 4.28 & 4.25 & 4.25 & $4.212^{*}$ \\
$\Delta H_{a}$ & 7.28 & 9.51 & 9.59 & 9.56 & 10.09 & 10.22 & $10.26^{*}$ \\
Band gap & 16.5 & 17.5 & 7.6 & 5.3 & 5.3 & 5.2 & $7.8^{\dagger}$ \\
$E_{F}$ & -8.2 & -8.9 & -4.4 & -3.2 & -3.2 & -3.6 & \\
$q$ & 1.87 & 1.85 & 1.78 & 1.78 & 1.78 & 1.79 \\
\hline
\end{tabular}

*Ref. [326].

${ }^{\dagger}$ Ref. [327]. 
TABLE XII (b) Calculated Bulk Properties for $\mathrm{AF}_{2}$ Antiferromagnetic NiO: Lattice Constant $a$, Difference $\Delta a$ to Ferromagnetic State $(\AA)$, Heat of Atomization per NiO Unit $\Delta H_{a}$, Difference to Ferromagnetic State $\Delta \Delta H_{a}$, Band Gap, Fermi Level $E_{F}(\mathrm{eV})$, Mulliken Charges $q$ (a.u.), and Atomic Spin Moment $m_{s}\left(\mu_{B}\right)$.

\begin{tabular}{|c|c|c|c|c|c|c|c|}
\hline & \multicolumn{7}{|c|}{ Method } \\
\hline & $U H F$ & $U H F+L Y P$ & $B 3 L Y P$ & $B L Y P$ & $P B E$ & $P W G G A$ & Expt. \\
\hline$a$ & 4.26 & 4.16 & 4.23 & 4.23 & 4.18 & 4.18 & $4.177^{*}$ \\
\hline$\Delta a$ & -0.005 & -0.009 & -0.006 & -0.034 & -0.078 & -0.013 & \\
\hline$\Delta H_{a}$ & 5.93 & 8.43 & 8.11 & 8.17 & 8.90 & 9.00 & $9.5^{*}$ \\
\hline$\Delta \Delta H_{a}$ & +0.018 & +0.028 & +0.103 & +0.272 & +0.323 & +0.28 & \\
\hline Band gap & 14.7 & 15.2 & 4.2 & 0.4 & 0.5 & 0.4 & $3.8^{\dagger}$ \\
\hline$E_{F}$ & -8.2 & -8.9 & -4.2 & -2.2 & -2.3 & -2.4 & $-4.4^{*}$ \\
\hline$q$ & 1.88 & 1.86 & 1.67 & 1.53 & 1.55 & 1.54 & \\
\hline$m_{s}$ & 1.92 & 1.91 & 1.68 & 1.34 & 1.33 & 1.33 & $1.64-1.90^{\circ}$ \\
\hline
\end{tabular}

*Ref. [326].

${ }^{\dagger}$ Ref. [327].

*Ref. [328].

"Refs. [329, 330].

The most significant results are obtained using the B3LYP method:

\begin{tabular}{lccccc}
\hline & Band gap (eV) & $J_{1}(\mathrm{meV})$ & \multicolumn{3}{c}{ Mulliken charges } \\
\hline $\mathrm{Sr}_{2} \mathrm{CuO}_{3}$ & & & $\mathrm{Cu}$ & $\mathrm{Sr}$ & $\mathrm{O}$ \\
$\quad$ Exp. & 1.5 & -146 to -225 & & & \\
$\mathrm{UHF}$ & $\sim 16$ & -43.7 & +1.8 & +1.9 & -1.9 \\
$\mathrm{~B} 3 \mathrm{LYP}$ & 1.82 & -355 & +1.5 & +1.8 & -1.7 \\
$\mathrm{Ca}_{2} \mathrm{CuO}_{3}$ & & & $\mathrm{Cu}$ & $\mathrm{Ca}$ & $\mathrm{O}$ \\
$\mathrm{Exp}$ & 1.7 & -45.7 & +1.8 & +1.9 & -1.9 \\
$\mathrm{UHF}$ & $\sim 16$ & -339 & & & \\
$\mathrm{~B} 3 \mathrm{LYP}$ & 1.53 & & & & \\
\hline
\end{tabular}

For $3 d$ transition metal oxides, the strong mixing between the $\mathrm{M} 3 d$ and $\mathrm{O} 2 p$ levels is reflected by an enhancement of the ground-state occupation number $n_{d}$ relative to the

TABLE XII (c) Calculated Bulk Properties for $\mathrm{AF}_{2}$ Antiferromagnetic CoO: Lattice Constant $a$, Difference $\Delta a$ to Ferromagnetic State $(\AA)$, Heat of Atomization per CoO Unit $\Delta H_{a}$, Difference to Ferromagnetic State $\Delta \Delta H_{a}$, Band Gap, Fermi Level $E_{F}(\mathrm{eV})$, Mulliken Charges $q$ (a.u.), and Atomic Spin Moment $m_{s}\left(\mu_{B}\right)$.

\begin{tabular}{|c|c|c|c|c|c|c|c|}
\hline & \multicolumn{7}{|c|}{ Method } \\
\hline & $U H F$ & $U H F+L Y P$ & $B 3 L Y P$ & $B L Y P$ & $P B E$ & $P W G G A$ & Expt. \\
\hline$a$ & 4.35 & 4.24 & 4.29 & 4.26 & 4.22 & 4.22 & $4.260^{*}$ \\
\hline$\Delta a$ & -0.003 & -0.003 & -0.010 & & & & \\
\hline$\Delta H_{a}$ & 5.84 & 8.29 & 8.48 & 8.86 & 9.74 & 9.86 & $9.45^{*}$ \\
\hline$\Delta \Delta H_{a}$ & +0.008 & +0.016 & +0.074 & +0.171 & +0.182 & +0.274 & \\
\hline Band gap & 14.2 & 14.4 & 3.5 & 0.8 & 0.8 & 0.8 & $2.6^{\dagger}$ \\
\hline$E_{F}$ & -8.1 & -8.9 & -3.4 & -1.7 & -1.9 & -2.0 & -4.9 \\
\hline$q$ & 1.88 & 1.86 & 1.68 & 1.54 & 1.56 & 1.55 & \\
\hline$m_{s}$ & 2.91 & 2.88 & 2.69 & 2.42 & 2.42 & 2.32 & $3.35-3.8$ \\
\hline
\end{tabular}

*Ref. [326].

'Ref. [327]

Ref. [328].

${ }^{\top}$ Refs. [329, 330]. 
value in a purely ionic picture. For the formally $d^{0}$ compounds, the values of $n_{d}$ and $P_{a}$ indicate an increasing covalency from Ti to $\mathrm{Mn}$ :

\begin{tabular}{lcccc}
\hline & $\mathrm{TiO}_{2}$ & $\mathrm{~V}_{2} \mathrm{O}_{5}$ & $\mathrm{CrO}_{3}$ & $\mathrm{KMnO}_{4}$ \\
\hline$P_{a}$ & 0.6 & 2.2 & 6.1 & 9.6 \\
$n_{d}$ & $\sim 1$ & 1.3 & & $\begin{array}{c}2 \\
\text { Ref. }\end{array}$ \\
\hline 244$]$ & {$[244]$} & & {$[332]$} \\
\hline
\end{tabular}

In $\mathrm{Ti}$ and $\mathrm{V}$ series, the values of $n_{d}$ reveal a large covalency (except for $M \mathrm{O}$ oxides) mainly due to the large value of $(p d \sigma)$. Zimmermann et al. [246] obtain for $n_{d} 1.3,1.9$ and 2.6 instead of the formal occupations $0,1,2$ for $\mathrm{V}_{2} \mathrm{O}_{5}, \mathrm{VO}_{2}$ and $\mathrm{V}_{2} \mathrm{O}_{3}$, respectively.

A cluster-type molecular calculation by Sousa and Illas [333] using ab initio Hartree-Fock wave-functions for the $\mathrm{Ti}$ and $\mathrm{O}$ ions has also found a considerable hybridization along the $\mathrm{Ti}-\mathrm{O}$ bond, with an increasing covalency in the $\mathrm{TiO}, \mathrm{Ti}_{2} \mathrm{O}_{3}$ and $\mathrm{TiO}_{2}$ series. This study predicts an $85 \%$ ionic desorption for $\mathrm{TiO}, 78 \%$ for $\mathrm{Ti}_{2} \mathrm{O}_{3}$ and $57 \%$ for $\mathrm{TiO}_{2}$, with the net $d$-electron numbers being 2.3, 1.6 and 1.7, respectively. This is in agreement with the $n_{d}$ values of 2.6 and 1.1 found by Bocquet et al. [243] for $\mathrm{TiO}$ and $\mathrm{TiO}_{2}$, and the increasing order of ionicity from $d^{0}$ to $d^{2}$ matches the trend found for $\Delta$.

The early TM compounds are characterized by a large $p-d$ hybridization, making the distinction between the charge-transfer regime and the Mott-Hubbard regime less clear. Thus the strong covalency in these compounds arises from the strength of the hybridization, in spite of the general trend of increasing $\Delta$ within any series of compounds as we go from $\mathrm{Fe}$ to Ti. This is in contrast to the late TM compounds, where strong covalency arises from the closeness of the $p$ and $d$ levels, resulting in a small value of $\Delta$.

Mackrodt and Williamson have reported first principles periodic Hartree-Fock calculations of manganese oxides: $\mathrm{MnO}, \mathrm{LiMnO}_{2}, \mathrm{MnO}_{2}$ and $\mathrm{CaMnO}_{3}$ from which direct evidence is presented to indicate that the valence state remains essentially $d^{5}$ throughout the series.

In the past, $\mathrm{KMnO}_{4}$ or better $\left(\mathrm{MnO}_{4}^{-}\right)$has served as a model compound to test theoretical ab initio quantum calculations [334,335] of increasing sophistication. These calculations showed that the average $d$-occupation of the $\mathrm{Mn}$ ion is close to $3 d^{5}$. The deviation from the ionic picture, corresponding to an empty $\mathrm{Mn} 3 d$ shell, is due to electron-electron correlations at the metal ion site and its strong hybridization with the surrounding ligand shell. Reinert et al. [332] concluded from photoemission (core-level, valence band) data on $\mathrm{KMnO}_{4}$ that the $\mathrm{Mn} 3 d$ occupation is indeed close to $3 d^{5}$. These data suggest that all the valence states of manganese higher than $\mathrm{Mn}(\mathrm{I})$ have a predominant $d^{5}$ component:

\begin{tabular}{|c|c|c|c|c|c|c|c|}
\hline & $P_{a}$ & $n_{d}$ & $q_{M n}$ & $\mu$ & Ref. & $\mu_{\exp }$ & Ref. \\
\hline $\mathrm{MnO}$ & -5.7 & 5.11 & 1.86 & 4.92 & [254] & $\begin{array}{l}4.58 \\
4.79\end{array}$ & $\begin{array}{l}{[322]} \\
{[102]}\end{array}$ \\
\hline $\mathrm{Mn}_{2} \mathrm{O}_{3}$ & 0.4 & 4.72 & & & [253] & & \\
\hline $\mathrm{LiMnO}_{2}$ & & 4.85 & $\begin{array}{l}2.03 \\
1.82\end{array}$ & $\begin{array}{l}3.95 \\
4.82\end{array}$ & $\begin{array}{l}{[256]} \\
{[254]}\end{array}$ & & \\
\hline $\mathrm{Mn}_{3} \mathrm{O}_{4} \mathrm{II}$ & & 4.62 & $\begin{array}{l}1.86 \\
2.14\end{array}$ & $\begin{array}{l}4.90 \\
4.08\end{array}$ & $\begin{array}{l}{[261]} \\
{[254]}\end{array}$ & $4.65-5.34$ & $\begin{array}{r}{[336]} \\
\text { and }\end{array}$ \\
\hline $\begin{array}{l}\mathrm{Mn}_{3} \mathrm{O}_{4} \text { III } \\
\mathrm{MnO}_{2} \\
\mathrm{KMnO}_{4}\end{array}$ & $\begin{array}{l}4.7 \\
9.6\end{array}$ & $\begin{array}{l}5.10 \\
4.68 \\
\sim 5\end{array}$ & $\begin{array}{l}2.29 \\
2.14\end{array}$ & $\begin{array}{l}3.95 \\
3.28\end{array}$ & $\begin{array}{l}{[261]} \\
{[254]} \\
{[332]}\end{array}$ & $3.25-3.64$ & {$[337]$} \\
\hline
\end{tabular}


The agreement between $n_{d}$ and $P_{a}$ (limited to available data) is satisfactory for $M \mathrm{O}$ and $\mathrm{M}_{2} \mathrm{O}_{3}$ oxides:

\begin{tabular}{|c|c|c|c|c|c|c|c|}
\hline & $\mathrm{TiO}$ & VO & $\mathrm{MnO}$ & $\mathrm{FeO}$ & $\mathrm{CoO}$ & $\mathrm{NiO}$ & $\mathrm{CuO}$ \\
\hline \multirow[t]{2}{*}{$\begin{array}{l}n_{d} \\
P_{a}\end{array}$} & $2.05-2.22$ & 3.14 & $\begin{array}{l}5.11 \\
-5.7\end{array}$ & $\begin{array}{r}6.2 \\
-4.4\end{array}$ & $\begin{array}{r}7.2 \\
-4.8\end{array}$ & $\begin{array}{c}8.2 \pm 0.1 \\
-3.6\end{array}$ & $\begin{array}{l}9.4 \pm 0.1 \\
-2.8\end{array}$ \\
\hline & $\mathrm{Ti}_{2} \mathrm{O}_{3}$ & & & $\mathrm{Cr}_{2} \mathrm{O}_{3}$ & $\mathrm{Mn}_{2} \mathrm{O}_{3}$ & $\mathrm{Fe}_{2} \mathrm{O}_{3}$ & $\mathrm{CO}_{2} \mathrm{O}$ \\
\hline \multirow[t]{2}{*}{$\begin{array}{l}n_{d} \\
\text { Ref. } \\
P_{a}\end{array}$} & $\begin{array}{c}1.7 \\
{[247]}\end{array}$ & & & $\begin{array}{r}3.6 \\
{[244]} \\
-0.3\end{array}$ & $\begin{array}{c}4.72 \\
{[253]} \\
0.4\end{array}$ & $\begin{array}{r}5.3 \\
{[244]} \\
-2.1\end{array}$ & $\begin{array}{r}6.27 \\
{[338]}\end{array}$ \\
\hline & \multicolumn{2}{|c|}{$\mathrm{CO}^{3+}$ in $\mathrm{LiCoO}_{2}$} & \multicolumn{2}{|c|}{$\mathrm{Ni}_{2} \mathrm{O}_{3}$} & \multicolumn{3}{|c|}{$\mathrm{Ni}^{3+}$ in $\mathrm{LiNiO}_{2}$} \\
\hline $\begin{array}{l}n_{d} \\
\text { Ref. }\end{array}$ & \multicolumn{2}{|c|}{$\begin{array}{c}6.62 \\
{[269]}\end{array}$} & \multicolumn{2}{|c|}{$\begin{array}{c}7.25 \\
338]\end{array}$} & \multicolumn{3}{|c|}{$\begin{array}{c}\sim 7.65 \\
{[274,275]}\end{array}$} \\
\hline
\end{tabular}

Yet, the experimental results related to $\mathrm{LS} \mathrm{Co}^{3+}$ and $\mathrm{Ni}^{3+}$ in $\mathrm{Li}^{3} \mathrm{O}_{2}$ are incompatible with the conclusions of an ab initio HF study of corundum like $M_{2} \mathrm{O}_{3}$ oxides $(M=\mathrm{Ti}$, $\mathrm{V}, \mathrm{Cr}, \mathrm{Fe}, \mathrm{Co}, \mathrm{Ni}$ ) [338]: the analysis of the spin polarization of electron transfer from $\mathrm{O}^{2-}$ to $M^{3+}$ shows that only minority-spin electrons are transferred from $M=\mathrm{Fe}$, Co and $\mathrm{Ni}$, while the total transfer is doubled for the other oxides by the majority-spin contribution.

\subsection{Comparison of Calculated Ionic Charges and Observed Charges Deduced from Orbital Expansion Spectroscopy}

The ligand field theory has been successful in explaining the optical properties of transition metal ions in crystals. The multiplets of the TM ions in the octahedral (or tetrahedral) symmetry are expressed in terms of the Racah parameters $B$ and $C$ and the crystal-field parameter $(\Delta)$. However, these parameters are determined from the optical spectra under a certain trial assignment of the observed bands. Therefore, the correct parameters cannot be obtained unless the optical spectrum of the material is available and well understood. Even if the correct parameters are determined from the experimental data, the meanings of the parameters are somewhat ambiguous, since the different physical contributions, covalency, electron correlation and finite size of the ions, are absorbed in the empirical parameters during the fitting process, although this was one of the essential reasons for the great success of the ligand field theory as an empirical method.

Interestingly, when Figure 8 is compared with Table XIII, it is concluded that, for oxides:

- the ionic charges calculated by cluster molecular orbital methods are largely underestimated,

- hybrid methods, such as the so-called B3LYP which combines the HF exchange term with the Becke and Lee-Yang-Parr functionals yields the most significant results while ab initio HF calculations overestimate the Mulliken charges,

- the effective charges deduced from LF analysis of $d-d$ spectra are underestimated but present a satisfying coherence with calculated data. 

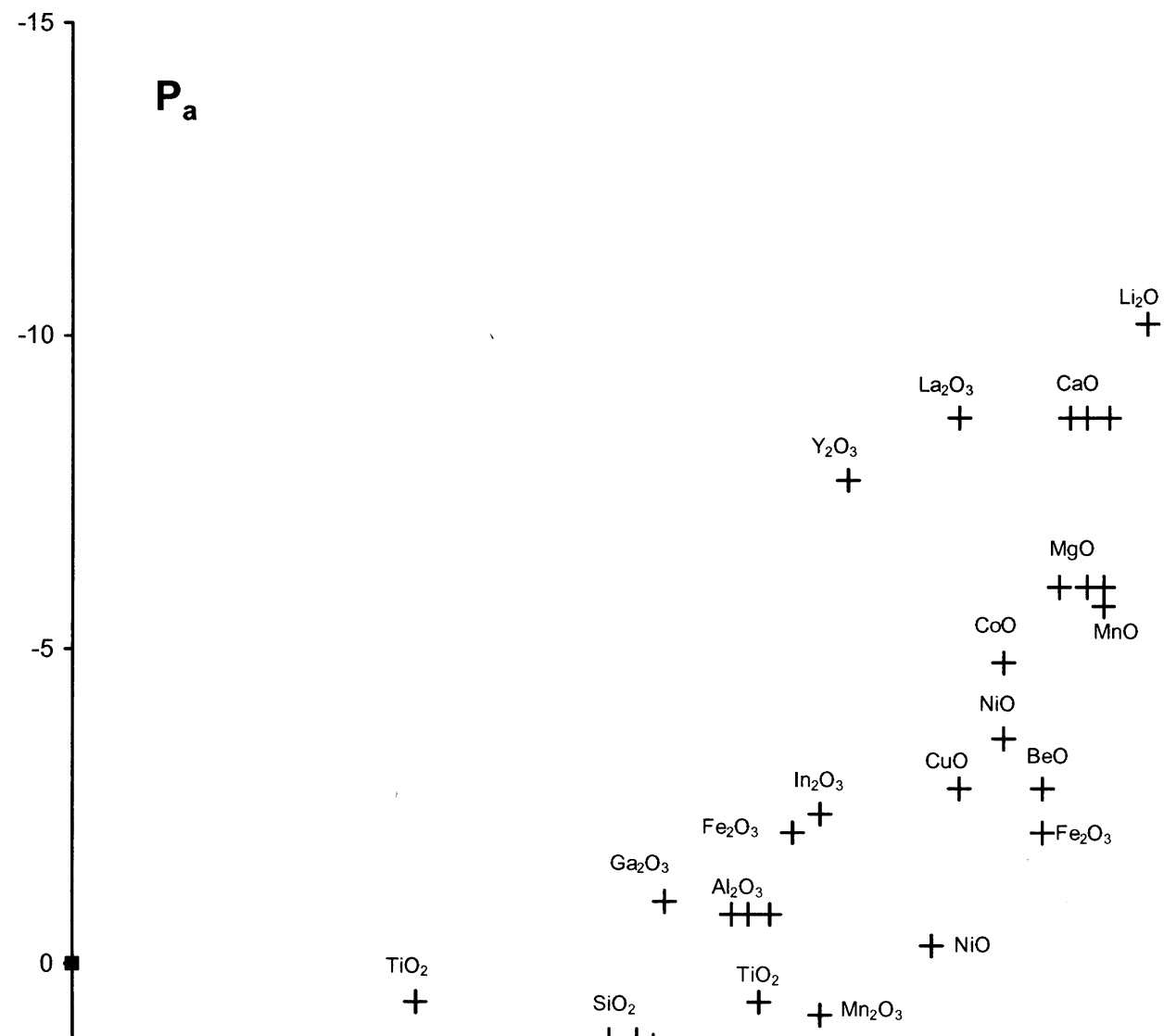
$+$

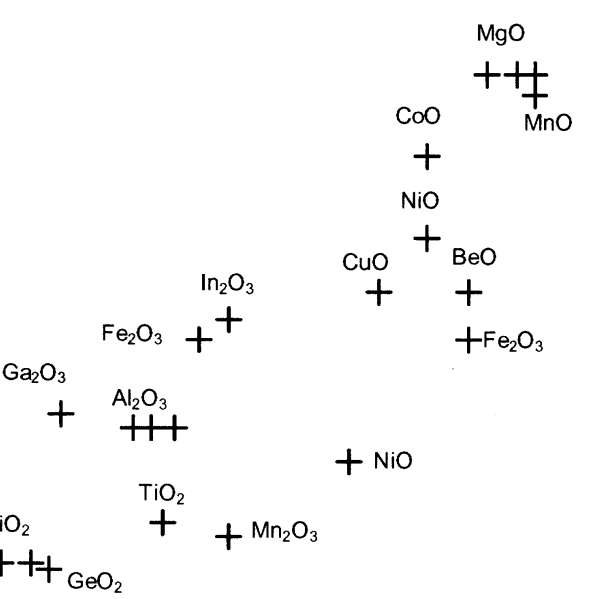

9ox 10

0

$-0,5$

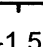

FIGURE 8 Plot of $P_{a} v s$. calculated ionic charges $q_{\mathrm{Ox}}$. 


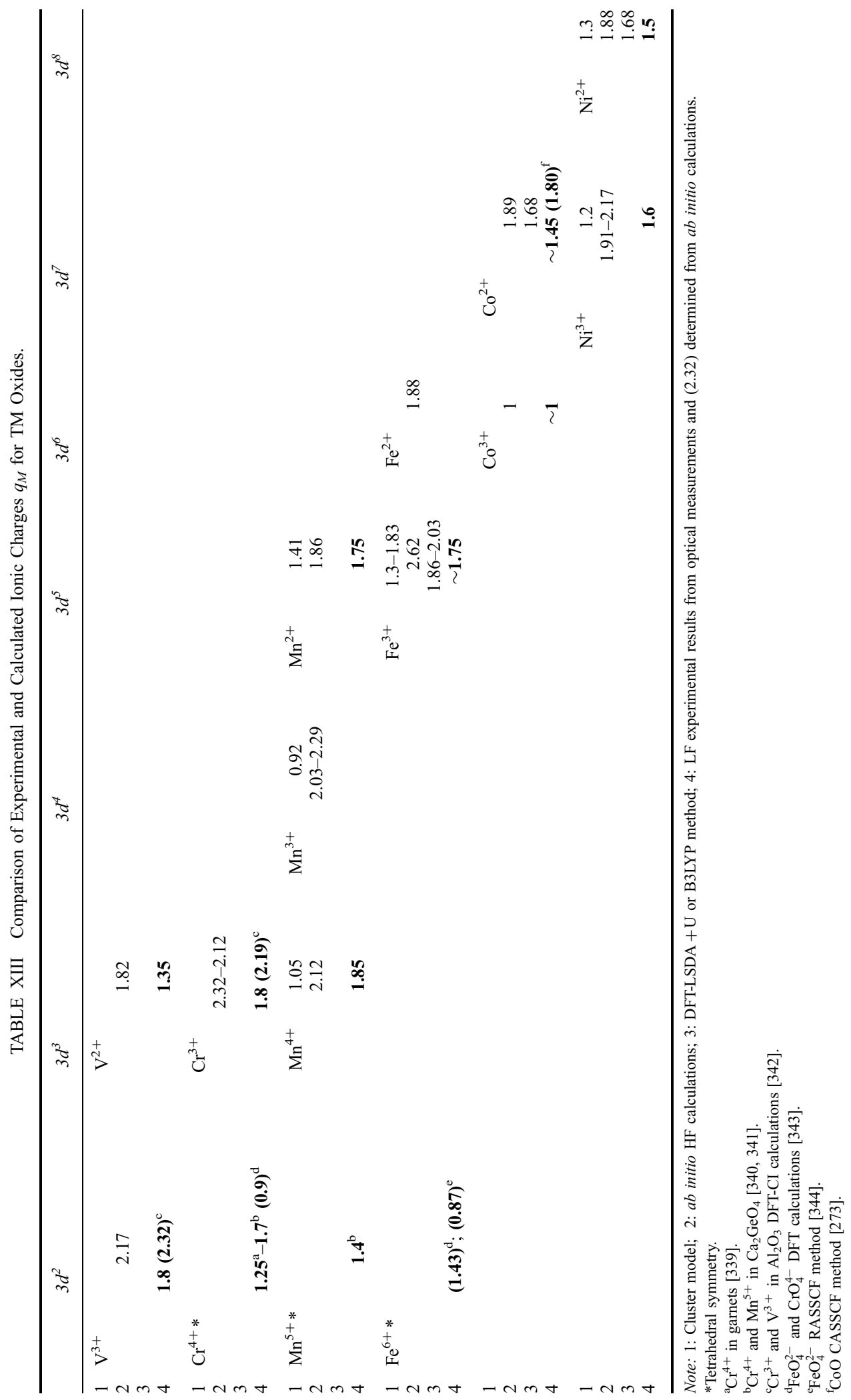


The changes in ground-state covalency with anion electronegativity has been interpreted for nickel oxides and halides using photon spectroscopies (XPS, UPS and XAS) and may be correlated with the results of ligand field spectroscopy:

\begin{tabular}{lcccc}
\hline & $n_{d}$ (Av. value) & $q_{N i}$ & $\beta_{35}$ & $\theta_{N}(K)$ \\
\hline $\mathrm{NiO}$ & 8.23 & $1.88^{*}-1.68^{\dagger}$ & 0.77 & 525 \\
$\mathrm{Mg}_{1-x} \mathrm{Ni}_{x} \mathrm{O}$ & & & 0.83 & \\
$\mathrm{KNiF}_{3}$ & 8.10 & $1.85^{* \mathrm{a}}$ & 0.93 & 275 \\
$\mathrm{KMgF}_{3}: \mathrm{Ni}^{2+}$ & & & 0.94 & \\
$\mathrm{NiF}_{2}$ & 8.11 & $1.85^{* \mathrm{~b}}$ & 0.94 & \\
$\mathrm{NiCl}_{2}$ & 8.31 & & 0.79 & \\
$\mathrm{NiBr}_{2}$ & 8.40 & & 0.73 & \\
${ }^{*}$ ab initio HF calculations: ${ }^{\mathrm{a}}$ Ref. [345]; ${ }^{\mathrm{b}}$ Ref. [346]. & & \\
${ }^{\dagger}$ B3LYP method.
\end{tabular}

In the ease of highly ionic bonds in fluorides, no significant influence of the magnetic structure on the nephelauxetic ratio has been observed $[162,163]$.

\section{CONCLUSION}

The electronegativity and acidity scales are the most significant semi-empirical concepts for predicting the trend of bonding character in iono-covalent binary oxides. A satisfactory correlation between the data issued from the acidity scale and the calculated ionic charges has been established.

Ionic charges deduced from $d-d$ spectra in their representation as point charges are underestimated and strongly influenced by magnetic interactions in ferrimagnetic or antiferromagnetic oxides and by the inductive effect of competing bonds.

It seems experimentally clear (from XPS and LF spectroscopies) that the covalency of divalent oxides is somewhat larger than that of fluorides.

The comparison of experimental and theoretical data for transition metal oxides supports the following conclusions:

- the strong hybridization in the early TMOs leads to a destabilization of an ionic ground state and to a pronounced mixing of configuration $\left|d^{n+q} \underline{L}^{q}\right\rangle$,

- in contrast, in the late TMOs characterized as charge transfer insulators, the $3 d$ electrons present a more localized character. The cross-over from the dominance of covalency to that of on-site Coulomb correlation occurs between $\mathrm{Cr}_{2} \mathrm{O}_{3}$ and $\mathrm{Fe}_{2} \mathrm{O}_{3}$.

Very recent studies show that the hybrid methods such as the B3LYP method, which is a combination of Becke's three parameter exchange functional and the Lee-Yang-Parr correlation functional lead to more reliable results for the description of structural, energetic and electronic properties of binary monoxides than those from standard methods.

\section{References}

[1] Pauling, L. (1932). J. Am. Chem. Soc., 54, 3570.

[2] Mulliken, R. S. (1934). J. Chem. Phys, 2, 782.

[3] Gordy, W. (1946). Phys. Rev., 69, 604.

[4] Sanderson, R. T. (1952). J. Chem. Educ., 29, 539.

[5] Allred, A. L. and Rochow, E. G. (1958). J. Inorg. Nucl. Chem., 5, 264.

[6] Zhang, Y. (1982). Inorg. Chem., 21, 3886. 
[7] Portier, J., Campet, G., Etourneau, J. and Tanguy, B. (1994). J. Alloys Comp., 209, 285.

[8] Mullay, J. (1987). Struct. Bond., 66, 1.

[9] Usanovitch, M. (1939). Zh. Obschei Khim., 9, 182.

[10] Pearson, R. G. (1963). J. Am. Chem. Soc., 85, 3533; (1968). J. Chem. Educ., 45, 581.

[11] Pearson, R. G. (1973). In: Dowden (Ed.), Hard and Soft Acids and Bases. Hutchinson and Ross Inc., Stroudsburg.

[12] Klopman, G. (1968). J. Am. Chem. Soc., 90, 223.

[13] Zhang, Y. (1982). Inorg. Chem., 21, 3889.

[14] Yingst, A. and McDaniel, D. H. (1967). Inorg. Chem., 6, 1076.

[15] Ahrland, S. (1968). Chem. Phys. Lett., 2, 303; (1966). Struct. Bond., 1, 207.

[16] Portier, J., Campet, G., Etourneau, J. and Tanguy, B. (1994). J. Alloys Comp., 209, 59.

[17] Pearson, R. G. (1988). Inorg. Chem., 27, 734.

[18] Parr, R. G., Donnelly, R. A., Levy, M. and Palke, W. E. (1978). J. Chem. Phys., 68, 3801.

[19] Parr, R. G. and Pearson, R. G. (1983). J. Am. Chem. Soc., 105, 7512.

[20] Pearson, R. G. (1986). Proc. Natl. Acad. Sci. USA, 83, 8440.

[21] Dimitrov, V. and Sakka, S. (1996). J. Appl. Phys., 79, 1736.

[22] Duffy, J. A. (1986). J. Solid State Chem., 62, 145.

[23] Duffy, J. A. and Ingram, M. D. (1971). J. Am. Chem. Soc., 93, 6448.

[24] Duffy, J. A. and Ingram, M. D. (1976). J. Non-Cryst. Solids, 21, 373.

[25] Duffy, J. A. (1990). Energy Levels and Bands in Inorganic Solids. Longmans, London.

[26] Duffy, J. A. (1989). Ironmak. Steelmak., 16, 426.

[27] Duffy, J. A. (1993). Geochim. Cosmochim. Acta, 57, 3961.

[28] Lebouteiller, A. and Courtine, P. (1998). J. Solid State Chem., 137, 94.

[29] Smith, D. W. (1987). J. Chem. Educ., 64, 480.

[30] Bard, A. J., Parsons, R. and Jordan, J. (1985). Standard Potentials in Aqueous Solutions UIPAC. Physical and Analytical Chemistry Divisions, M. Dekker, New York and Basel.

[31] Barin, I. (1989). Thermochemical Data of Pure Substances. VCH GmbH, Weinheim.

[32] Kubaschewski, O., Alcock, C. B. and Spencer, P. J. (1993). Materials Thermochemistry, 6th edn. revised. Pergamon Press, Oxford and New York.

[33] Sanderson, R. T. (1964). Inorg. Chem., 3, 925; Inorganic Chemistry, Reinhold, New York (1967).

[34] Auroux, A. and Gervasini, A. (1990). J. Phys. Chem., 94, 6371.

[35] Pauling, L. (1939). The Nature of the Chemical Bond, 1st edn. Cornell University Press, Ithaca, New York.

[36] Pauling, L. (1971). Phys. Today, 9.

[37] Phillips, J. C. and van Vechten, J. A. (1969). Phys. Rev. Lett., 22, 705.

[38] Phillips, J. C. (1970). Rev. Mod. Phys., 42, 317.

[39] van Vechten, J. A. (1969). Phys. Rev., 187, 1007.

[40] Levine, B. F. (1973). Phys. Rev. B, 7, 2591.

[41] Levine, B. F. (1973). J. Chem. Phys., 59, 1463.

[42] Christensen, N. E., Satpathy, S. and Pawlowska, Z. (1987). Phys. Rev. B, 36, 1032.

[43] Harrison, W. A. (1980). Electronic Structure and Properties of Solids. Freeman, San Francisco.

[44] Chelikowski, J. R. and Cohen, M. L. (1976). Phys. Rev. B, 14, 556.

[45] Wang, C. S. and Klein, B. M. (1981). Phys. Rev. B, 24, 3393.

[46] Barr, T. L., Mosenian, M. and Chen, L. M. (1991). Appl. Surf. Sci., 51, 71.

[47] Bader, R. F. W. (1990). Atoms in Molecules: A Quantum Theory. Clarence Press, Oxford.

[48] Roversi, P., Irwin, J. J. and Bricogne, G. (1998). Acta Cryst. A, 54, 971.

[49] Stewart, R. F. (1969). J. Chem. Phys., 51, 4569.

[50] Stewart, R. F. (1976). Acta Cryst. A, 32, 565.

[51] Hansen, N. K. and Coppens, P. (1978). Acta Cryst. A, 34, 909.

[52] Coppens, P., Guru Row, T. N., Leung, P., Stevens, E. D., Becker, P. J. and Wang, Y. W. (1979). Acta Cryst. A, 35, 63.

[53] Tsirelson, V. G. and Ozerov, R. P. (1996). Electron Density and Bonding in Crystals, Institute of Physics Publishing, Bristol, Philadelphia.

[54] Coppens, P. (1997). X-ray Charge Densities and Chemical Bonding. Oxford University Press, New York.

[55] Sasaki, S., Fujino, K. and Takeuchi, Y. (1979). Proc. Japan Acad., 55B, 43.

[56] Vidal-Valat, G., Vidal, J. P. and Kurki-Suonio, K. (1978). Acta Cryst. A, 34, 594.

[57] Tsirelson, V. G., Avilov, A. S., Abramov, Yu. A., Belokoneva, E. L., Kitaneh, R. and Feil, D. (1998). Acta Cryst. $B, \mathbf{5 4}, 8$.

[58] Vidal-Valat, G., Vidal, J. P., Kurki-Suonio, K. and Kurki-Suonio, R. (1987). Acta Cryst. A, 43, 540.

[59] Downs, J. W. and Swope, R. J. (1992). J. Chem. Phys., 96, 4834.

[60] Downs, J. W. (1990). Electronic Properties of Minerals from X-Ray Diffraction Data, Advances in Physical Geochemistry, Vol. 8. Springer Verlag, Berlin.

[61] Brown, A. S. and Spackman, M. A. (1991). Acta Cryst. A, 47, 21.

[62] Becker, P. and Coppens, P. (1990). Acta Cryst. A, 46, 254.

[63] O'Keefe, M. and Spence, J. C. H. (1994). Acta Cryst. A, 50, 33.

[64] Fujino, K., Sasaki, S., Takeuchi, Y. and Sadanaga, R. (1981). Acta Cryst. B, 37, 513.

[65] Tamada, O., Fujino, K. and Sasaki, S. (1983). Acta Cryst. B, 39, 692. 
[66] Downs, J. W., Hill, R. J., Newton, M. D., Tossel, J. A. and Gibbs, G. V. (1982). In: P. Coppens and M. Hall (Eds.), Electron Distribution and the Chemical Bond, Plenum Press, New York, 178.

[67] Downs, J. W. and Gibbs, G. V. (1987). Am. Mineral., 72, 769.

[68] Sasaki, S., Takeuchi, Y., Fujino, K. and Akimoto, S. (1982). Z. Kristallog., 158, 279.

[69] Sasaki, S., Fujino, K., Takeuchi, Y. and Sadanaga, R. (1980). Acta Cryst. A, 36, 904.

[70] Stewart, R. P., Whitehead, W. A. and Donnay, G. (1980). Am. Mineral., 65, 324.

[71] Hill, R. J., Newton, M. D. and Gibbs, G. V. (1983). J. Solid State Chem., 47, 185.

[72] Lewis, J., Schwarzenbach, D. and Black, H. D. (1982). Acta Cryst. A, 38, 733.

[73] Kirfel, A. and Eichhorn, K. (1990). Acta Cryst. A, 46, 271.

[74] Hill, R. J. (1979). Phys. Chem. Minerals, 5, 179.

[75] Ghermani, N. E., Lecomte, C. and Dusausoy, Y. (1996). Phys. Rev. B, 53, 5231.

[76] Kuntzinger, S., Ghermani, N. E., Dusausoy, Y. and Lecomte, C. (1998). Acta Cryst. B, 54, 819.

[77] Kuntzinger, S. and Ghermani, N. E. (1999). Acta Cryst. B, 55, 273.

[78] Kuntzinger, S., Dahaoui, S., Ghermani, N. E., Lecomte, C. and Howard, J. A. K. (1999). Acta Cryst. B, $55,867$.

[79] Ivanov, Yu. V., Belokoneva, E. L., Protas, J., Hansen, N. K. and Tsirelson, V. G. (1998). Acta Cryst. B, 54, 774.

[80] Shannon, R. (1976). Acta Cryst. A, 32, 451.

[81] Geisinger, K. H., Spackman, M. H. and Gibbs, G. V. (1987). J. Phys. Chem., 91, 3237.

[82] Downs, J. W. (1995). J. Phys. Chem., 99, 6849.

[83] Gibbs, G. V., Downs, J. W. and Boisen, M. B. (1994). Rev. Mineral., 29, 331.

[84] Tsirelson, V. G., Streltsov, V. A., Ozerov, R. P. and Yvon, K. (1989). Phys. Stat. Sol. (a), 115, 515.

[85] Maslen, E. N., Streltsov, V. A. and Streltsova, N. R. (1994). Acta Cryst. B, 50, 435.

[86] Sasaki, S. (1997). Acta Cryst. B, 53, 762.

[87] Gonschorek, W. (1982). Z. Kristallog., 160, 187.

[88] Gonschorek, W. and Feld, R. (1982). Z. Kristallog., 161, 1.

[89] Restori, R., Schwarzenbach, D. and Schneider, J. R. (1987). Acta Cryst. B, 43, 251.

[90] Du Boulay, D., Maslen, E. N. and Streltsov, V. A. (1995). Acta Cryst. B, 51, 921.

[91] Maslen, E. N., Streltsov, V. A. and Ishizawa, N. (1996). Acta Cryst. B, 52, 406.

[92] Maslen, E. N., Streltsov, V. A. and Ishizawa, N. (1996). Acta Cryst. B, 52, 414.

[93] Streltsov, V. A., Ishizawa, N. and Kishimoto, S. (1998). J. Synchrotron Rad., 5, 1309.

[94] Streltsov, V. A. and Ishizawa, N. (1999). Acta Cryst. B, 55, 1.

[95] Hubbard, J. and Marshall, W. (1965). Proc. Phys. Soc., 86, 561.

[96] Tofield, B. C. and Fender, B. E. F. (1970). J. Phys. Chem. Solids, 31, 2741.

[97] Jacobson, A. J., McBride, L. and Fender, B. E. F. (1974). J. Phys. C: Solid State Phys., 7, 783.

[98] Hall, T. P. P., Hayes, W., Stevenson, R. W. H. and Wilkins, J. J. (1963). J. Chem. Phys., 38, 1977.

[99] Owen, J. and Thornley, J. H. M. (1966). Rep. Prog. Phys., 29, 675.

[100] Hutchings, M. T. and Guggenheim, H. J. (1970). J. Phys. C, 3, 1303.

[101] Shulman, R. G. and Sugano, S. (1963). Phys. Rev., 130, 506.

[102] Fender, B. E. F., Jacobson, A. J. and Wedgwood, F. A. (1968). J. Chem. Phys., 48, 990.

[103] Freund, P. (1974). J. Phys. C, 7, L33.

[104] Nathans, R., Halperin, H. A., Pickart, S. J. and Brown, P. J. (1963). J. Appl. Phys., 34, 1182.

[105] Jacobson, A. J., Tofield, B. C. and Fender, B. E. F. (1973). J. Phys. C.: Solid State Phys., 6, 1615.

[106] Freund, P., Owen, J. and Hann, B. F. (1973). J. Phys. C: Solid State Phys., 6, L139.

[107] Jacobson, A. J. and Fender, B. E. F. (1975). J. Phys. C, 8, 844.

[108] Fuess, H., Bassi, G., Bonnet, M. and Delapalme, A. (1976). Solid State Commun., 18, 557.

[109] Greaves, C., Jacobson, A. J., Tofield, A. J. and Fender, B. E. F. (1975). Acta Cryst. B, 31, 641.

[110] Davies, J. J., Smith, S. R. P., Owen, J. and Hann, B. F. (1972). J. Phys. C, 5, 245.

[111] Stevens, K. W. H. (1953). Proc. Roy. Soc. (London) A, 219, 542.

[112] Jørgensen, C. K. (1962). Proc. lnorg. Chem., 4, 73.

[113] Allen, G. C. and Warren, K. D. (1972). Structure and Bonding, 9, 49.

[114] Jørgensen, C. K. (1969). Oxidation Numbers and Oxidation States. Springer Verlag, Berlin-Heidelberg.

[115] Fairbank, W. H., Klauminzer, G. K. and Schalow, A. L. (1975). Phys. Rev. B, 11, 60.

[116] Liehr, A. D. (1963). J. Phys. Chem., 67, 1314.

[117] Reinen, D. (1969). Structure and Bonding, 6, 30.

[118] MacFarlane, R. M. (1971). Phys. Rev. B, 3, 2129.

[119] Low, W. (1957). Phys. Rev., 105, 801.

[120] Schaffer, C. E. (1958). J. Inorg. Nucl. Chem., 8, 149.

[121] Lenglet, M. this study.

[122] Drifford, M. (1967). Thesis, Paris.

[123] Wood, D. L., Imbusch, G. B., MacFarlane, R. M., Kisliuk, P. and Larkin, D. M. (1968). J. Chem. Phys., 48, 5255 .

[124] Kahan, H. M. and MacFarlane, R. M. (1971). J. Chem. Phys., 54, 5197.

[125] Peterman, K. and Huber, G. (1984). J. Lum., 31-32, 71.

[126] MacFarlane, R. M. (1970). Phys. Rev. B, 1, 989.

[127] Allen, G. C., EI-Sharkawy, G. A. M. and Warren, K. D. (1971). Inorg. Chem., 10, 2538.

[128] Allen, G. C. and Warren, K. D. (1975). Coord. Chem. Rev., 16, 227.

[129] Broussel, I., Fortin, E., Kulyuk, L., Popov, S., Anedda, A. and Corpino, R. (1998). J. Appl. Phys., 84, 533. 
[130] Huffman, D. R., Wild, R. L. and Shinmei, H. (1969). J. Chem. Phys., 40, 4092.

[131] Iskenderov, R. N. and Ksendzov, Yu. M. (1968). Fiz. Tverd. Tela, 10, 2573.

[132] Jeng, S. P. and Henrich, V. E. (1992). Solid State Commun., 82, 879.

[133] Manning, P. G. (1970). Can. Miner, 10, 677.

[134] Powell, R. C., Elouadi, B., Xin, L., Loiacono, G. M. and Feigelson, R. S. (1986). J. Chem. Phys., 84, 657.

[135] Papalardo, R. (1960). J. Chem. Phys., 33, 613.

[136] Stout, J. W. (1960). J. Chem. Phys., 33, 303.

[137] Low, W. (1958). Phys. Rev., 109, 247 and 256.

[138] Reinen, D. (1964). Z. Anorg. Allg. Chem., 327, 238.

[139] Douglas, I. N. (1976). Phys. Stat. Sol. (b), 73, 641.

[140] Reinen, D. (1967). Theoret. Chim. Acta, 8, 260.

[141] Goodgame, M. and Cotton, F. A. (1961). J. Phys. Chem., 65, 791.

[142] Borromei, R. and Day, P. (1982). J. Chem. Soc., Faraday Trans., 2(78), 1705.

[143] Reinen, D. (1970). Structure and Bonding, 7, 114.

[144] Ferguson, J., Wood, D. L. and Knox, K. (1963). J. Chem. Phys., 39, 881.

[145] Weakliem, H. A. (1962). J. Chem. Phys., 36, 2117.

[146] Jugessur, S., Savard, J. Y. and Rai, R. (1970). Canad. J. Phys., 48, 2221.

[147] Gudel, H. U., Deren, P. J., Strek, W. and Oetliker, U. (1994). Phys. Stat. Sol. (b), 182, 2411.

[148] Ferguson, J., Wood, D. L. and van Uitert, L. G. (1969). J. Chem. Phys., 51, 2904.

[149] Reinen, D. (1966). Theoret. Chim. Acta, 5, 312.

[150] Reinen, D. (1965). Ber. Bunsenges Physik. Chem., 69, 82.

[151] Jørgensen, C. K., Lenglet, M. and Arsene, J. (1987). Chem. Phys. Letters, 136, 475.

[152] Schmitz-Dumont, O. and Reinen, D. (1965). Ber. Bunsen-Ges., 69, 76.

[153] Lenglet, M. and D'Huysser, A. (1990). C.R. Acad. Sci. Paris, 310, 483.

[154] Borromei, R. and Day, P. (1982). J. Chem. Soc. Faraday Trans., 2(77), 2249.

[155] Dolgov, V. Ya and Spiridoni, K. N. (1973). Russian J. Phys. Chem., 47, 1578.

[156] Weakliem, H. A. (1967). J. Appl. Phys., 33, 347.

[157] Kaufman U. and Koidi, P. (1973). J. Phys. C, 6, 310.

[158] Schultz, H. J. and Thiede, P. (1987). Phys. Rev. B, 35, 18.

[159] Lenglet, M. and Jørgensen, C. K. (1991). Chem. Phys. Letters, 185, 111.

[160] Ferguson, J., Guggenheim, H. J. and Wood, D. L. (1970). J. Chem. Phys., 53, 1613.

[161] Rosseinsky, D. R. and Dorroty. I. A. (1978). Inorg. Chem., 17, 1600.

[162] Knox, K., Shulman, R. G. and Sugano, S. (1963). Phys. Rev., 130, 512.

[163] Lute, A. and Schmitz-Dumont, O. (1973). Monatsh. Chem., 104, 1632.

[164] Ackerman, J. and Holt, S. M. (1972). Inorg. Chem., 11, 3118.

[165] Oetliker, U., Riley, M. J. and Gudel, H. U. (1995). J. Lum., 63, 63.

[166] Noll, W. (1963). Angew. Chem. Internat. Edit., 2, 73.

[167] Shannon, R. D. (1971). Chem. Comm., 881.

[168] Lenglet, M. (2000). Mat. Res. Bull., 35, 531.

[169] Menil, F. (1985). J. Phys. Chem. Solids, 46, 763.

[170] Lehmann, G. (1970). Z. Physik. Chem. Neue Folge, 72, 279.

[171] Lenglet, M., Hochu, F. and Simsa, Z. (1998). Mat. Res. Bull., 33, 1821.

[172] Music, S., Lenglet, M., Popovic, S., Hannoyer, B., Czako-Nagy, I., Ristic, M., Balzar, D. and Gashi, F. (1996). J. Mat. Sci., 31, 4067.

[173] Sawatzky, G. A. and van der Woude, F. (1974). J. Phys., 35, C6-47.

[174] Arsene, J., Lopitaux, J., Drifford, M. and Lenglet, M. (1979). Phys. Stat. Sol. (a), 52, K111.

[175] Arsene, J. and Lenglet, M. (1980). Mat. Res. Bull., 15, 1681.

[176] Hochu, F., Lenglet, M. and Jørgensen, C. K. (1995). J. Solid State Chem., 120, 244.

[177] Scott, J. F. (1974). Phys. Rev. B, 4, 1360.

[178] Lutz, H. D., Waschenbach, G., Kliche, G. and Haeuseler, H. (1983). J. Solid State Chem., 48, 196.

[179] Lutz, H. D., Himmrich, J. and Haeuseler, H. (1990). Z. Naturforsch., 45a, 893.

[180] Himmrich, J. and Lutz, H. D. (1991). Solid State Commun., 79, 447.

[181] Hiraishi, J. (1973). Bull. Chem. Soc. Japan, 46, 1334.

[182] Jasperse, J. R., Kahan, A., Plendl, L. N. and Mitra, S. S. (1966). Phys. Rev., 146, 526.

[183] Gervais, F. (1976). Solid State Commun., 18, 191.

[184] Iishi, K. (1978). Phys. Chem. Minerals, 3, 1.

[185] Renneke, D. R. and Lynch, D. W. (1965). Phys. Rev., 138, 530.

[186] Onari, S., Arai, I. and Kudo, K. (1977). Phys. Rev. B, 16, 1717.

[187] Barrow, T. H. K., Huan, C. C. and Pasternak, A. (1976)., J. Phys. C, 9, 3925.

[188] Striefler, M. E. and Barsch, G. R. (1975). Phys. Rev. B, 12, 4553.

[189] Iishi, K. (1978). Am. Mineral., 63, 1190.

[190] Traylor, G., Smith, H. G., Nicklow, R. M. and Wilkinson, H. K. (1971). Phys. Rev. B, 3, 3457.

[191] Hargreave, M. M. (1971). J. Phys. C, 4, 174.

[192] Roesseer, D. M. and Albers, W. A. (1972). J. Phys. Chem. Solids, 33, 293.

[193] Lauwers, H. A. and Herman, M. A. (1980). J. Phys. Chem. Solids, 41, 223.

[194] Ishii, M., Hiraishi, J. and Yamanaka, T. (1982). Phys. Chem. Minerals, 8, 64. 
[195] Shirai, H., Morioka, Y. and Nakagawa, I. (1982). J. Phys. Soc. Japan, 51, 592.

[196] Lutz, H. D., Müller, B. and Steiner, H. J. (1991). J. Solid State Chem., 90, 54.

[197] Katsnelson, E. Z., Karoza, A. G., Meleshchenko, L. A. and Bashkirov, L. A. (1989). Phys. Stat. Sol. (b), $152,657$.

[198] Gervais, F., Piriou, B. and Cabannes, F. (1973). Phys. Stat. Sol (b), 55, 143.

[199] Servoin, J. L. and Piriou, B. (1973). Phys. Stat. Sol. (b), 55, 677.

[200] Iishi, K. (1978). Am. Mineral., 63, 1198.

[201] Fock, V. (1930). Z. Phys., 61, 126.

[202] Slater, J. C. (1930). Phys. Rev., 35, 210.

[203] Roothaan, C. C. J. (1951). Rev. Mod. Phys., 23, 69.

[204] Hall, G. G. (1951). Proc. Roy. Soc. A, 205, 541.

[205] Kohn, W. and Sham, L. J. (1965). Phys. Rev., 140, A1133.

[206] Dovesi, R., Pisani, C., Roetti, C., Causa, M. and Saunders, V. R. (1989). Crystal 88, Program Number 577, QCPE, Indiana University, Bloomington.

[207] Becke, A. D. (1988). Phys. Rev. A, 38, 3098.

[208] Lee, C., Yang, W. and Parr, R. G. (1988). Phys. Rev. B, 37, 785.

[209] Becke, A. D. (1993). J. Chem. Phys., 98, 5648.

[210] Dovesi, K. (1996). In: Pisani, C. (Ed.), Quantum-Mechanical ab-initio Calculation of the Properties of Crystalline Materials, Lecture Notes Chem., Vol. 67. Springer Verlag, Berlin, p. 179.

[211] Evarestov, R. A. and Veryazov, V. A. (1991). Theor. Chim. Acta, 81, 95.

[212] Lowdin, P. (1970). Adv. Quantum Chem., 5, 185.

[213] Wiberg, K. B. (1968). Tetrahedron, 24, 1083.

[214] Armstrong, A. D., Perkins, P. G. and Stewart, J. J. (1972). J. Chem. Soc. Dalton Trans., 838.

[215] Goniakowski, J. and Noguera, C. (1994). Surf Sci., 319, 81.

[216] Noguera, C. (1995). Physics and Chemistry at Oxide Surfaces. Cambridge University Press, Cambridge.

[217] Julien, J. P., Mayou, D. and Cyrot-Lackmann, F. (1989). J. Phys. (France), 50, 2683.

[218] Moukouri, S. and Noguera, C. 1993, Z. Phys., D27, 79.

[219] Vinek, H., Noller, H., Ebel, M. and Schwartz, K. (1977). J. Chem. Soc. Faraday Trans. I, 73, 734.

[220] Dovesi, R., Roetti, C., Freyria-Fava, C., Apra, E., Saunders, V. R. and Harrison, N. M. (1992). Phil. Trans. R. Soc. London A, 341, 203.

[221] Lichanot, A., Chaillet, M., Larrieu, C., Dovesi, R. and Pisani, C. (1992). Chem. Phys., 164, 383.

[222] Xu, Y. N. and Ching, W. Y. (1993). Phys. Rev. B, 48, 4335.

[223] Xu, Y. N. and Ching, W. Y. (1991). Phys. Rev. B, 43, 4461.

[224] Catti, M., Valerio, G., Dovesi, R. and Causa, M. (1994). Phys. Rev. B, 49, 14179.

[225] Bredow, T. and Gerson, A. R. (2000). Phys. Rev. B, 61, 5194.

[226] Mankefors, S. (2000). J. Phys.: Condens. Matter, 12, 2423.

[227] Mackrodt, W. C., Harrison, M. N., Saunders, V. R., Allan, N. L., Towler, D., Apra, E. and Dovesi, R. (1993). Phil. Mag. A, 68, 653.

[228] Moukouri, S. and Noguera, C. (1993). Z. Phys. D, 27, 79.

[229] Goniakowski, J. and Noguera, C. (1994). Surf Sci., 319, 68.

[230] Xu, Y. N. and Ching, W. Y. (2000). Phys. Rev. B, 61, 1817.

[231] Jollet, F., Noguera, C., Thromat, N., Gautier, M. and Duraud, J. P. (1990). Phys. Rev. B, 42, 7587.

[232] Evarestov, R. A., Leko, A. V., Murin, I. V., Petrov, A. V. and Veryazov, V. A. (1992). Phys. Stat. Sol. (b), $170,145$.

[233] Evarestov, R. A. and Veryazov, V. A. (1990). Phys. Stat. Solidi (b), 158, 201.

[234] Salasco, L., Dovesi, R., Orlando, R., Causa, M. and Saunders, V. R. (1991). Mol. Phys., 72, 267.

[235] Xu, Y. N. and Ching, W. Y. (1999). Phys. Rev. B, 59, 10530.

[236] Tanaka, I., Mizuno, M. and Adachi, H. (1997). Phys. Rev. B, 56, 3536.

[237] Thromat, N., Noguera, C., Gautier, M., Jollet, F. and Duraud, J. P. (1991). Phys. Rev. B, 44, 7904.

[238] Pantelides, S. T. and Harrison, W. A. (1976). Phys. Rev. B, 13, 2667.

[239] Nada, R., Catlow, C. R. A., Dovesi, R. and Pisani, C. (1990). Phys. Chem. Minerals, 17, 353.

[240] Paxton, A. T. and Thien-Nga, L. (1998). Phys. Rev. B, 57, 1579.

[241] Mackrodt, W. C. (1999). J. Solid State Chem., 142, 428.

[242] Parlebas, J. C. (1993). Phys. Stat. Sol. (b), 178, 9.

[243] Bocquet, A. E., Mizokawa, T., Morikawa, K., Fujimori, A., Barman, S. R., Maiti, K., Sarma, D. D., Tokura, Y. and Onoda, M. (1996). Phys. Rev. B, 53, 1161.

[244] Zimmermann, R., Steiner, P., Claessen, R., Reinert, F., Hufner, S., Blaha, P. and Dufek, P. (1999). J. Phys. Condens. Matter, 11, 1657.

[245] Fu, L., Yaschenko, E., Resca, L. and Resta, R. (1999). Phys. Rev. B, 60, 2697.

[246] Zimmermann, R., Claessen, R., Reinert, F., Steiner, P. and Hufner, S. (1998). J. Phys.: Condens. Matter, $10,5697$.

[247] Catti, M., Sandrone, G. and Dovesi, R. (1997). Phys. Rev. B, 55, 16122.

[248] Evarestov, R. A. and Panin, A. I. (1999). Phys. Stat. Sol. (b), 214, R5.

[249] Saitoh, T., Bocquet, A. E., Mizokawa, T. and Fujimori, A. (1995). Phys. Rev. B, 52, 7934.

[250] Evarestov, R. A., Leko, A. V. and Veryazov, V. A. (1997). Phys. Stat. Sol (b), 203, R3.

[251] Catti, M., Sandrone, G., Valerio, G. and Dovesi, R. (1996). J. Phys. Chem. Solids, 57, 1735.

[252] Freyria, F., Baraille, I., Lichanot, A., Larrieu, C. and Dovesi, R. (1997). J. Phys.: Condens. Matter, 9, 10715. 
[253] Sherman, D. M. (1984). Am. Mineral., 69, 788.

[254] Mackrodt, W. C. and Williamson, E. A. (1997). Ber. Bunsenges. Phys. Chem., 101, 1215.

[255] Bocquet, A. E., Mizokawa, T., Saitoh, T., Namatame, H. and Fujimori, A. (1992). Phys. Rev. B, $46,3771$.

[256] Mackrodt, W. C. and Williamson, E. A. (1998). Phil. Mag. B, 77, 1077.

[257] Fujimori, A., Kimizuka, N., Akahane, T., Chiba, T., Kimura, S., Minami, F., Siratori, K., Taniguchi, M., Ogawa, S. and Suga, S. (1990). Phys. Rev. B, 42, 7580.

[258] Van Elp, J., Potze, R. H., Eskes, H., Berger, R. and Sawatzky, G. A. (1991). Phys. Rev. B, 44, 1530.

[259] Towler, M. D., Allan, N. L., Harrison, N. M., Saunders, V. R., Mackrodt, W. C. and Apra, E. (1994). Phys. Rev. $B, \mathbf{5 0}, 5041$.

[260] Hugel, J. and Kamal, M. (1996). Solid State Commun., 100, 457.

[261] Chartier, A., D’Arco, P., Dovesi, R. and Saunders, V. R. (1999). Phys. Rev. B, 60, 14042.

[262] Nagel, S. (1985). J. Phys. Chem. Solids, 46, 905.

[263] Sherman, D. M. (1985). Phys. Chem. Minerals, 12, 161.

[264] Fujimori, A., Saeki, M., Kimizuka, N., Taniguchi, M. and Suga, S. (1986). Phys. Rev. B, 34, 7318.

[265] Kawai, J., Suzuki, C., Adachi, H., Konishi, T. and Gohshi, Y. (1994). Phys. Rev. B, 50, 11347.

[266] Catti, M., Valerio, G. and Dovsei, R. (1995). Phys. Rev. B, 51, 7441.

[267] Uozumi, T., Okada, K., Kotani, A., Zimmermann, R., Steiner, P., Hufner, S., Tezuka, Y. and Shin, S. (1997). J. Electron. Spectrosc. Relat. Phenom., 83, 9.

[268] Punkkinen, M. P. J., Kokko, K., Herger, W. and Vayrynen, I. J. (1999). J. Phys.: Condens. Matter, $11,2341$.

[269] Van Elp, J., Wieland, J. L., Eskes, H., Kuiper, P., Sawatzky, G. A., De Groot, F. M. F. and Turner, T. S. (1991). Phys. Rev. B, 44, 6090.

[270] Catti, M. (2000). Phys. Rev. B, 61, 1795.

[271] Lee, G. and Oh, S. J. (1991). Phys. Rev. B, 43, 14674.

[272] Hufner, S. (1994). Advances in Physics, 43, 183.

[273] Shi, S. and Staemmler, V. (1995). Phys. Rev. B, 52, 12345.

[274] Galakhov, V. R., Kurmaev, E. Z., Uhlenbrock, S., Neumann, M., Kellerman, D. G., Gorshkov, V. S. (1995). Solid State Commun., 95, 347.

[275] Evarestov, R. A., Tupitsyn, I. I. and Veryazov, V. A. (1994). Int. J. Quant. Chem., 52, 295.

[276] Choisnet, J., Evarestov, R. A., Tupitsyn, I. I. and Veryazov, V. A. (1996). J. Phys. Chem. Solids, 57, 1839.

[277] Fujimori, A. and Minami, F. (1984). Phys. Rev. B, 30, 957.

[278] Van der Laan, G., Zaanen, J., Sawatzky, G. A., Karnatak, R. and Esteva, J. M. (1986). Phys. Rev. B, $33,4253$.

[279] Janssen, G. J. M. and Nieuwport, W. C. (1988). Phys. Rev. B, 38, 3449.

[280] Choisnet, J., Evarestov, R. A., Tupitsyn, I. I. and Veryazov, V. A. (1993). Phys. Stat. Sol. (b), $179,441$.

[281] Zimmermann, R. (1996). PhD thesis, Universität des Saarlandes, Germany.

[282] Matti, K., Mahadevan, P. and Sarma, D. D. (1999). Phys. Rev. B, 59, 12457.

[283] Shun, Z., Allen, J. W., Yeh, J. J., Kang, J. S., Ellis, W., Spicer, W., Lindau, I., Maple, M. B., Dalichaouch, Y. D., Torikachvili, M. S., Sun, J. Z. and Geballe, T. H. (1987). Phys. Rev. B, 36, 8414.

[284] Kissinger, V., Zimmermann, R., Hufner, S. and Steiner, P. (1992). Z. Phys. B, 89, 21.

[285] Ghijsen, J., Tjeng, L. H., van Elp, J., Eskes, H., Westerink, J., Sawatzky, G. A. and Czyzyk, M. T. (1988). Phys. Rev. $B, \mathbf{3 8}, 11322$.

[286] Van Veenendaal, M. A., Eskes, H. and Sawatzky, G. A. (1993). Phys. Rev. B, 47, 11462.

[287] Eskes, H., Tjeng, L. H. and Sawatzky, G. A. (1990). Phys. Rev. B, 41, 288.

[288] Kawai, J., Nihei, Y., Fujinami, M., Higashi, Y., Fukushima, S. and Gohshi, Y. (1989). Solid State Commun., 70, 567.

[289] Galakhov, V. R., Finkesltein, L. D., Zatsepin, D. A., Kormaev, E. Z., Samokhvalov, A. A., Naumov, S. V., Tatarinova, G. K., Demeter, M., Bartkowski, S., Neumann, M. and Moeves, A. (2000). Phys. Rev. B, 62, 4922.

[290] Mishra, K. C., Schmidt, P. C., Johnson, K. H., Deboer, B. G., Berkowitz, J. K. and Dale, E. A. (1990). Phys. Rev. $B, 42,1423$.

[291] Tranquada, J. M., Heald, S. M., Kunnmann, W., Moodenbaugh, A. R., Qiu, S. L., Xu, Y. and Davies, P. K. (1991). Phys. Rev. B, 44, 5176.

[292] Pacchioni, G. and Bagus, P. S. (1994). Phys. Rev. B, 50, 2576.

[293] Yamanaka, T. and Tanabe, K. (1975). J. Phys. Chem., 79, 2049.

[294] Yamanaka, T. and Tanabe, K. (1976). J. Phys. Chem., 80, 1723.

[295] Nollery, H. and Ritter, G. (1984). J. Chem. Soc. Faraday Trans. 1, 80, 275.

[296] Cunningham, J., Hodnett, B. K., Ilyas, M., Tobin, J., Leahy, E. L. and Fierro, J. L. G. (1981). Faraday Discuss. Chem. Soc., 72, 283.

[297] Gervasini, A. and Auroux, A. (1991). J. Catal., 131, 190.

[298] Mullins, W. M. and Averbach, B. L. (1988). Surf. Sci., 206, 41.

[299] Delamar, M. (1990). J. Electron Spectrosc. Relat. Phenom., 53, c11.

[300] Casamassina, M., Darque-Ceretti, E., Etcheberry, A. and Aucouturier, M. (1991). Appl. Surf. Sci., 52, 205.

[301] Nefedov, V. I., Gati, D., Dzhurinskii, B. F., Sergushin, N. P. and Salyn, Ya. V. (1975). Russ. J. Inorg. Chem., 20, 1279.

[302] Noller, H., Lercher, J. A. and Vinek, H. (1988). Mater. Chem. Phys., 18, 577.

[303] Barr, T. L. and Liu, Y. L. (1989). J. Phys. Chem. Solids, 50, 657.

[304] Barr, T. L. and Brundle, C. R. (1992). Phys. Rev. B, 46, 9199.

[305] Wertheim, G. K. and Hufner, S. (1972). Phys. Rev. Lett., 28, 1028. 
[306] Goodenough, J. B. (1971). In: Reiss, H. (Ed.), Progress in Solid State Chemistry, Vol. 5. Pergamon Press Ltd., Oxford, p. 145.

[307] Wagner, C. D. (1990). In: Briggs, D. and Seah, M. P. (Eds.), Practical Surface Analysis, 2nd edn. Wiley.

[308] Barr, T. L., Seal, S., Chen, L. M. and Kao, C. C., Thin Solid Films, 253, 277.

[309] Son, P. R. and Bartel, R. A. (1972). J Phys. Chem. Solids, 33, 819.

[310] Srivastava, S. P. and Singh, R. D. (1970). Chem. Phys. Lett., 7, 377.

[311] Tanabe, K. and Fukuda, Y. (1974). React. Kinet. Catal. Lett., 1, 21.

[312] Souda, R., Yamamoto, K., Hayami, W., Aizawa, T. and Ishizawa, Y. (1994). Phys. Rev. B, $50,4733$.

[313] Pandey, R., Jaffe, J. E. and Kunz, A. B. (1991). Phys. Rev. B, 43, 9228.

[314] Jensen, W. B. (1978). Chem. Rev., 78, 1.

[315] Jensen, W. B. (1980). The Lewis Acid-Base Concepts: an Overview. Wiley Interscience, New-York.

[316] Zaanen, J., Sawatzky, G. A. and Allen, J. W. (1985). Phys. Rev. Lett., 55, 418.

[317] Friedel, J. and Noguera, C. (1983). Int. J. Quantum Chem., 23, 1209.

[318] Dovesi, R., Orlando, R., Roetti, C., Pisani, C. and Saunders, V. R. (2000). Phys. Stat. Sol. (b), $217,63$.

[319] Kren, E., Szabo, S. and Konczos, G. (1965). Phys. Lett., 19, 103.

[320] Coey, J. M. D. and Sawatzky, G. A. (1971). J. Phys. C, 4, 2386.

[321] Alperin, H. A. (1962). J. Phys. Soc. Japan, Suppl. B, 17, 12.

[322] Cheetham, A. K. and Hope, D. A. O. (1983). Phys. Rev. B, 27, 6964.

[323] Saunders, V. R., Dovesi, R., Roetti, C., Causa, M., Harrison, N. M., Orlando, R. and Zicovich-Wilson, C. M. (1998). Crystal98 Users Manual. University of Torino, Torino.

[324] Perdew, J. P., Burke, K. and Ernzerhof, M. (1996). Phys. Rev. Lett., 77, 3865.

[325] Perdew, J. P. and Wang, Y. (1992). Phys. Rev. B, 45, 13244.

[326] Lide, D. R. (1998). CRC Handbook of Chemistry and Physics, 79th edn. CRC, Boca Raton, FL.

[327] Cox, P. A. (1995). Transition Metal Oxides: An Introduction to their Electronic Structure and Properties, The International Series of Monographs on Chemistry No 27. Clarendon, Oxford.

[328] Witte, G., Senet, P. and Toennies, J. P. (1998). Phys. Rev. B, 58, 13264.

[329] Kahn, D. C. and Erickson, R. A. (1970). Phys. Rev. B, 1, 2243.

[330] Hermann-Ronzaud, D., Burlet, P. and Rossat-Mignod, J. (1978). J. Phys. C, 11, 2123.

[331] De Graaf, C. and Illas, F. (2000). Phys. Rev. B, 63, 14404.

[332] Reinert, F., Steiner, P., Engel, Th. and Hufner, S. (1996). Z. Phys. B, 99, 223.

[333] Sousa, C. and Illas, F. (1994). Phys. Rev. B, 50, 13974.

[334] Johnson, K. M. and Smith, F. C. (1972). Phys. Rev. B, 5, 831.

[335] Nakai, H., Ohmori, Y. and Nakatsuji, H. (1991). J. Chem. Phys., 95, 8287.

[336] Boucher, B., Buhl, R. and Perrin, M. (1971). J. Phys. Chem. Solids, 32, 2429.

[337] Jensen, G. and Nielsen, O. (1974). J. Phys. C, 7, 409.

[338] Catti, M. and Sandrone, G. (1997). Faraday Discuss., 106, 189.

[339] Henderson, B., Gallagher, H. G., Han, T. P. J. and Scott, M. A. (2000). J. Phys.: Condens. Matter, $12,1927$.

[340] Hazenkamp, M. F., Gudel, H. U., Atanasov, M., Kesper, U. and Reinen, D. (1996). Phys. Rev. B, 53, 2367.

[341] Oetliker, U., Herren, M., Gudel, H. U., Kesper, U., Albrecht, C. and Reinen, D. (1994). J. Chem. Phys., $100,8656$.

[342] Ogasawara, K., Ishii, T., Tanaka, I. and Abachi, H. (2000). Phys. Rev. B, 61, 143.

[343] Missing, K., Barriuso, M. T., Aramburu, J. A. and Moreno, M. (1999). J. Chem. Phys., 111, 10217.

[344] Al-Abdalla, A., Seijo, L. and Barandiaran, Z. (1998). J. Chem. Phys., 109, 6396.

[345] Dovesi, R., Freyria-Fava, F., Roetti, C. and Saunders V. R. (1997). Faraday Discuss., 106, 173.

[346] Moreira, I., Dovesi, R., Roetti, C., Saunders, V. R. and Orlando, R. (2000). Phys. Rev. B, $62,7816$.

[347] Zhuang, M. and Halley, J. W. (2001). Phys. Rev. B, 64, 24413.

[348] Ching, W. Y., Xu, Y. N. and Brickeen, B. K. (2001). Phys. Rev. B, 63, 115101.

[349] Chartier, A., Meis, C. and Gale, J. D. (2001). Phys. Rev. B, 64, 85110.

[350] Thong, N. and Schwarzenbach, D. (1979). Acta Cryst. A, 35, 658.

[351] Peres, N., Boukhris, A., Souhassou, M., Gavoille, G. and Lecomte, C. (1999). Acta Cryst. A, 55, 1038.

\section{APPENDIX}

During the wording of this review, a number of interesting papers that provide new information have appeared. We shall briefly comment on their contents and give the references such as to allow the reader to have access also to the most recent literature in this field.

A self-consistent tight-binding method for the prediction of the magnetic-spin structures in solids has been introduced by Zhuang and Halley [347]. The Mulliken charges of manganese determined for $\mathrm{MnF}_{2}$ and $\beta \mathrm{MnO}_{2}$ are, respectively, 1.72 and $2.15 e$.

A comparative study of the electronic structure of two laser crystals: $\mathrm{BeAl}_{2} \mathrm{O}_{4}$ and $\mathrm{LiYF}_{4}$ reveals that $\mathrm{BeAl}_{2} \mathrm{O}\left(q_{\mathrm{Be}}=1.56 e ; q_{\mathrm{Al}}=1.8 e\right)$ has a significant amount of covalent mixing while $\mathrm{LiYF}_{4}$ is a highly ionic crystal [348]. 
An HF study of the $\mathrm{Si}-\mathrm{O}$ and $\mathrm{P}-\mathrm{O}$ bonds in three apatites $\left(\mathrm{Ca}_{10}\left(\mathrm{PO}_{4}\right)_{6} \mathrm{~F}_{2}\right.$, $\mathrm{Ca}_{4} \mathrm{La}_{6}\left(\mathrm{SiO}_{4}\right)_{6} \mathrm{~F}_{2}$ and $\left.\mathrm{Ca}_{2} \mathrm{La}_{8}\left(\mathrm{SiO}_{4}\right)_{6} \mathrm{O}_{2}\right)$ shows that these bonds appear to have a mostly covalent character as expected. The Mulliken charges for the atoms in the three apatites calculated within the HF method at the optimized geometries are in good agreement with different experimental data:

\begin{tabular}{lcc}
\hline & $q_{P}$ & $q_{S i}$ \\
\hline Calculated & +1.35 & $1.75-2$ \\
Experimental & $+1[350]+0.70[351]$ & $1.55-2.10[75-78]$. \\
\hline
\end{tabular}



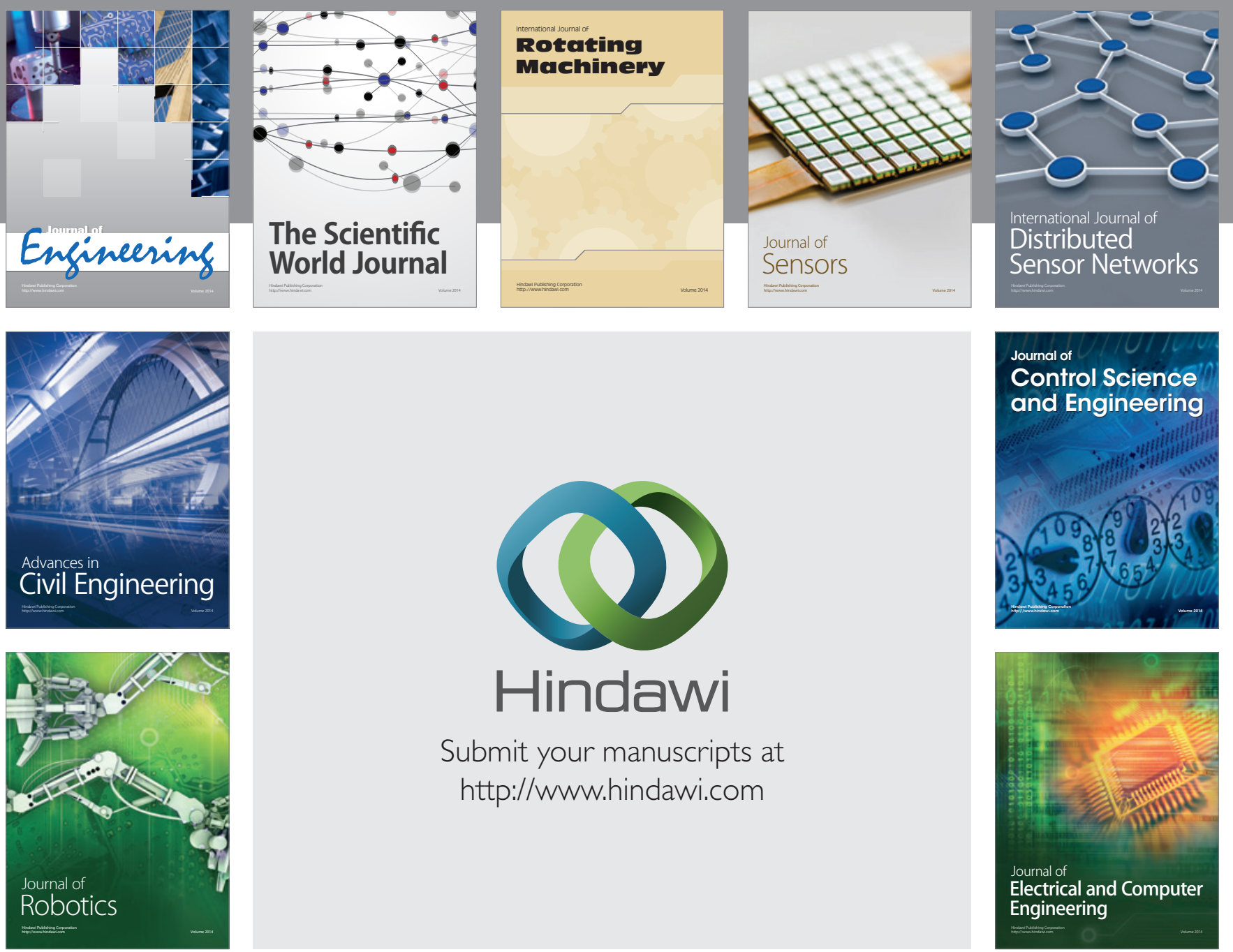

Submit your manuscripts at

http://www.hindawi.com
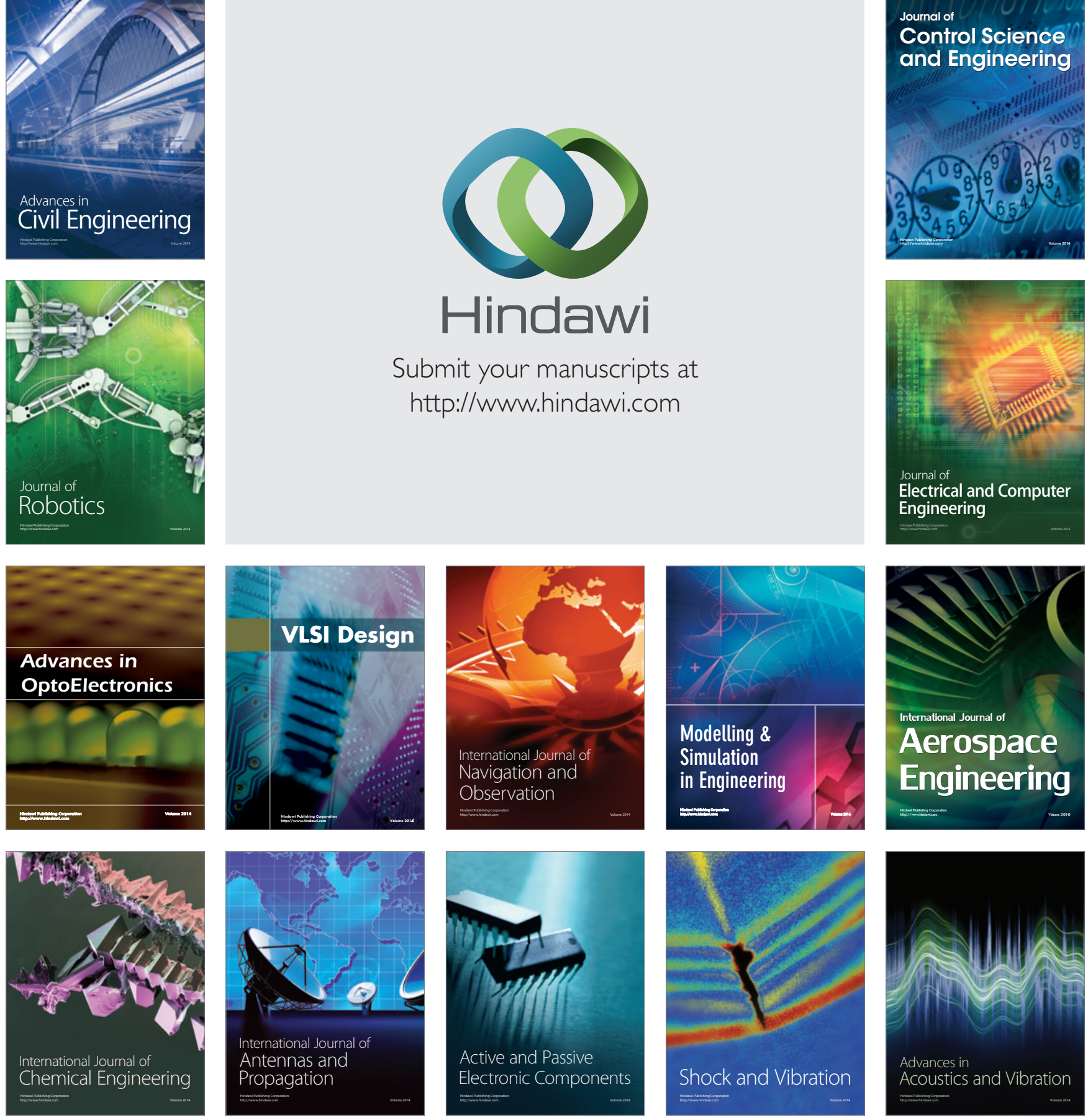